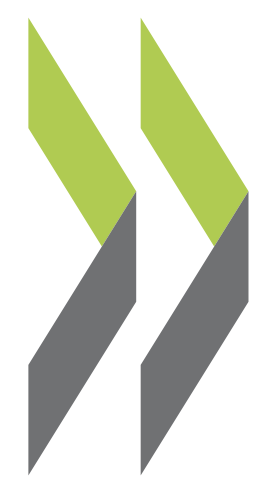

OECD Economics Department Working Papers No. 649

What Drives the NAIRU?

Evidence from a Panel of OECD Countries

\section{Christian Gianella,} Isabell Koske, Elena Rusticelli, Olivier Chatal 
Organisation de Coopération et de Développement Économiques

Organisation for Economic Co-operation and Development

04-Dec-2008

ECONOMICS DEPARTMENT

English text only

Cancels \& replaces the same document of 10 November 2008

WHAT DRIVES THE NAIRU? EVIDENCE FROM A PANEL OF OECD COUNTRIES

ECONOMICS DEPARTMENT WORKING PAPER No. 649

By

Christian Gianella, Isabell Koske, Elena Rusticelli and Olivier Chatal

All Economics Department Working Papers are available through OECD's internet web site at www.oecd.org/eco/Working_Papers 


\section{ABSTRACT/RÉSUMÉ \\ What Drives the NAIRU? Evidence from a Panel of OECD Countries}

This paper analyses the determinants of structural unemployment rates in a two-stage approach. First, time-varying NAIRUs are estimated for a panel of OECD economies on the basis of Phillips curve equations using Kalman filter techniques. In a second stage, the estimated NAIRUs are regressed on selected policy and institutional variables. As predicted by theoretical wage-setting/price-setting models, the level of the tax wedge and the user cost of capital are found to be important drivers of structural unemployment. Consistent with earlier studies, the level of product market regulation, union density and the unemployment benefit replacement rate also play an important role in explaining changes in the NAIRU although there is considerable variation in estimates across countries. Nonetheless, the set of structural variables provides a reasonable explanation of NAIRU dynamics over the period 1978-2003, even though recent decreases are better explained than the earlier surge.

JEL Classification: C13; C22; E24; E31; J38; J58; J68

Key words: Unemployment; NAIRU; Phillips curve; institutions; user cost of capital; policy reforms

*******************************

\section{Quels déterminants du NAIRU ? Évidence empirique à partir d'un panel de pays de l'OCDE}

Cette étude analyse les déterminants du taux de chômage structurel par une approche en deux étapes. Premièrement, des taux de chômage non inflationnistes (NAIRU) variables au cours du temps sont estimés sur la base de courbes de Phillips en utilisant les techniques de type filtre de Kalman. Dans une seconde étape, les NAIRUs estimés sont régressés sur une sélection de variables institutionnelles et de politique économique. Conformément aux prédictions théoriques de modèles de type WS PS «wage-setting/pricesetting », le niveau du coin fiscal et le coût d'usage du capital et apparaissent comme des déterminants-clés du chômage structurel. Conformément aux études précédentes, le niveau de réglementation sur le marché de biens, l'implantation syndicale et le taux de remplacement des allocations chômage jouent également un rôle important dans l'explication des variations du NAIRU bien qu'il y ait des différences considérables d'un pays á l'autre dans les résultats. Néanmoins, cet ensemble de variables structurelles s'avèrent avoir une capacité prédictive de la dynamique du NAIRU relativement élevée sur la période 1978-2003, même si la phase récente de reflux est mieux expliquée que la hausse préalable.

Classification JEL : C13 ; C22 ; E24 ; E31 ; J38 ; J58 ; J68

Mots clés : Chômage ; NAIRU ; courbe de Phillips ; institutions ; coût d'usage du capital ; réformes de politique économique

\section{Copyright OECD 2008}

Application for permission to reproduce or translate all, or part of, this material should be made to : Head of Publications Service, OECD, 2 rue André Pascal, 75775 Paris Cedex 16, France. 


\section{TABLE OF CONTENTS}

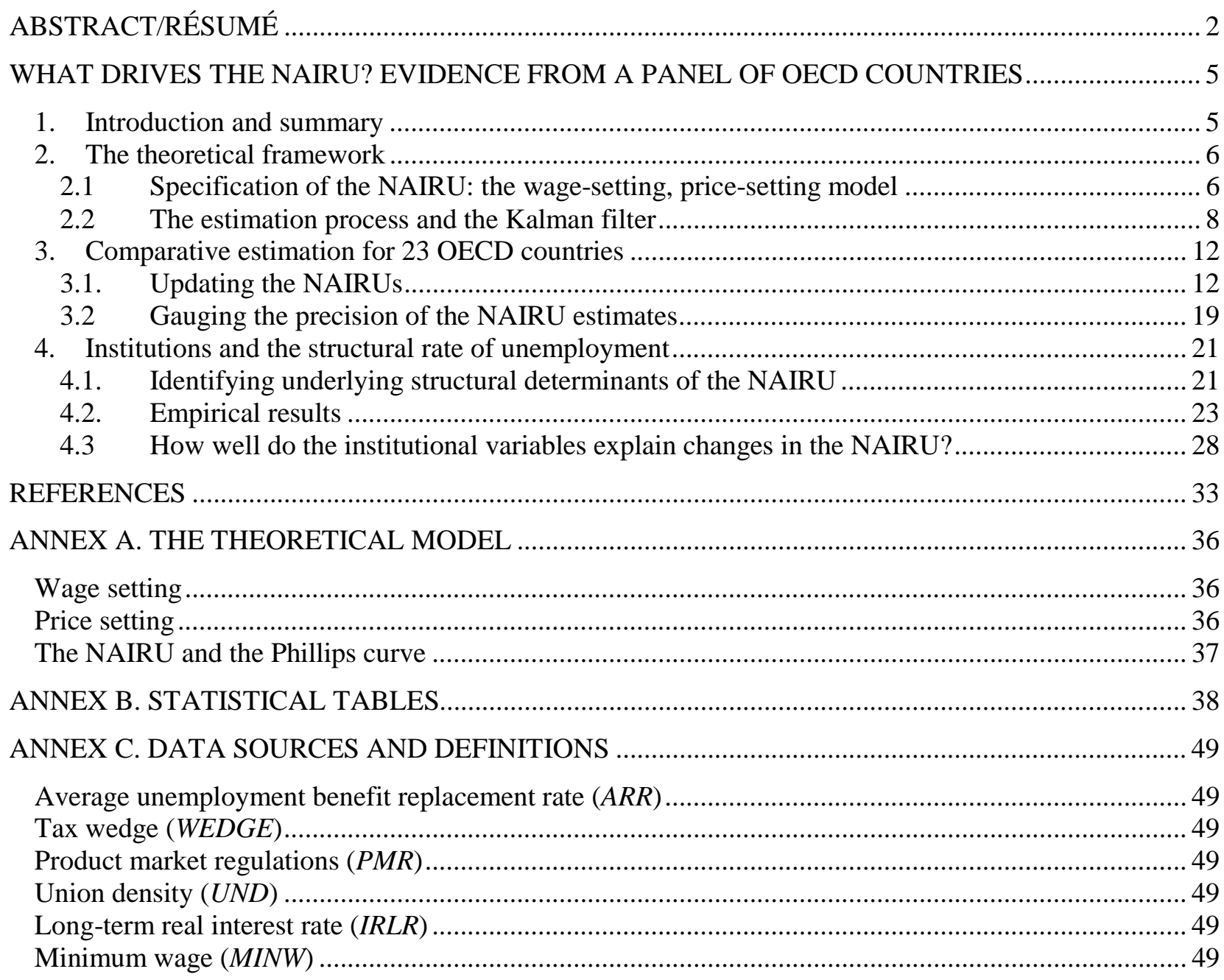

\section{Boxes}

Box 1. Estimating time-varying NAIRUs by means of the Kalman filter .............................................. 9

Box 2. Hamilton simulation method for standard errors estimation .................................................... 20

\section{Tables}

1. Pooled regression results, 1976-2003

2. The role of minimum wages

3. Panel regression results, 1976-2003, with cross-country heterogeneity 
4a. Impact of institutions on NAIRUs during periods of increasing NAIRUs

4b. Impact of institutions on NAIRUs during periods of decreasing NAIRUs

B1. Estimated Phillips Curves and diagnostics tests using the Kalman filter

B2. Estimated NAIRUs for 23 OECD countries

B3. Pooled regression results, 1976-2003, with time dummies

B4. Pooled regression results, 1976-2003, instrument variables

\section{Figures}

1. Unemployment rate, NAIRU and the $90 \%$ error band

B1. NAIRUs and fitted NAIRUs 
ECO/WKP(2008)57

\title{
WHAT DRIVES THE NAIRU? EVIDENCE FROM A PANEL OF OECD COUNTRIES
}

\author{
by \\ Christian Gianella, Isabell Koske, Elena Rusticelli and Olivier Chatal ${ }^{1}$
}

\section{Introduction and summary}

1. A considerable body of empirical research has studied the large and persistent movements in the unemployment rates of OECD countries over the past three decades. In particular, much attention has been devoted to the heterogeneity of individual countries' experience that cannot be ascribed to differences in cyclical positions and/or idiosyncratic short-term macroeconomic shocks. While a number of policy and institutional settings have been identified as determinants of the structural rate of unemployment, this heterogeneity remains to be fully understood. Moreover, as the structural rate of unemployment is unobservable by nature, analysing its determinants is fraught with potentially important measurement problems.

2. The present study updates existing OECD estimates of the NAIRU on a consistent basis across countries and then goes on to investigate their relationship with labour and product market institutions. This approach differs from others which seek to analyse such effects with respect to actually observed unemployment rates. This involves a two-stage approach. First, the NAIRU is identified using a standard semi-structural method, with a uniform specification for 23 OECD countries. The estimation of timevarying NAIRUs is based on the Phillips curve framework and makes use of filtering techniques that do not require specific information about their determinants. Special attention is given to the modelling of the statistical properties of the NAIRU, along the lines of Laubach (2001) and Mourougane et al. (2005). In a second stage, the obtained NAIRUs are regressed on a set of likely explanatory variables using panel estimation techniques.

3. For most OECD countries, the new estimates support the view that the structural unemployment rate has declined in recent years, except in Austria, Belgium, Sweden and Switzerland where it has more or less stabilised and Luxembourg and Portugal where it has increased. Furthermore, for most OECD economies, the NAIRU dynamics display an inverted U-shape, with an increase during the 1970s and 1980s that is followed by a decline that starts in the early to mid-1990s. With regard to the underlying structural factors influencing the NAIRU, the overall results are broadly in line with earlier studies based on actual unemployment rates, although they need to be treated with caution given the uncertain nature of the NAIRU estimates. Even so, for many countries, the timing of changes and overall dynamics of the

1. At the time of writing, the authors were members of the Macroeconomic Analysis and Systems Management Division and Country Studies V Division of the Economics Department. They are grateful to Pete Richardson, Vincent Koen, Christophe André, Hervé Boulhol, Romain Duval, Rafal Kierzenkowski, Orsetta Causa, Dave Turner and Luke Willard for helpful comments and suggestions on an earlier version of the paper, and to Diane Scott for assistance in preparing the document. 
NAIRU over the past 20 years are found to be reasonably well explained by the pattern of structural reforms. More precisely, the following conclusions emerge:

- The study confirms that -- among the standard indicators of labour and product market rigidities -- the level of the tax wedge, the average unemployment benefit replacement rate, union density and the level of product market regulation (PMR) strongly influence the structural unemployment rate. These results hold for pooled panel regressions, as well as for panel regressions that allow for cross-country heterogeneity in the coefficients, though in the latter case, the size of the impact may vary considerably across countries.

- When controlling for unobserved macroeconomic shocks and trying to correct for the potential endogeneity of institutions, it appears that the level of the tax wedge and, to a lesser extent, union density remain robust determinants of structural unemployment -- their estimated impact being even higher.

- Overall, the elasticities of the main policy variables considered here are of a similar order of magnitude compared to those obtained by Bassanini and Duval (2006).

- In a wage-setting/price-setting framework, the user cost of capital can be theoretically identified as a determinant of the structural unemployment rate. The present analysis shows that the longterm real interest rate -- used as a proxy for the cost of capital -- has a significant impact on the NAIRU in all countries but Japan and Portugal. This result is robust when controlling for unobserved macroeconomic shocks and for the potential endogeneity of institutions.

- The change in the level of the minimum wage was not found to have a direct impact on the NAIRU. There is also only limited support for the view that a large tax wedge has a greater effect when the minimum wage is high and there is no evidence that interactions between institutions play an important role in explaining NAIRU.

- Even though the selected structural variables considered in this study make it possible to match the evolution of the NAIRU with a relatively good fit over the period 1980-2003, there is still a high degree of asymmetry in their predictive capacity: the recent decrease in the NAIRUs is in general better explained than the earlier surge.

4. The rest of this paper is organised as follows. Section 2 briefly presents the theoretical framework and discusses the empirical procedure used to estimate time-varying NAIRUs. Section 3 then presents the obtained NAIRU estimates. The impact of institutions on NAIRUs is investigated in section 4 . The main paper is complemented by three annexes that lay out the wage-setting/price-setting model in more detail (Annex A), provide additional tables and figures on the results (Annex B), and summarise data sources and definitions (Annex C).

\section{The theoretical framework}

\subsection{Specification of the NAIRU: the wage-setting, price-setting model}

5. Numerous empirical approaches have been put forward in the literature to estimate a timevarying NAIRU. These approaches can for the most part be classified into three broad categories. ${ }^{2}$ The socalled "structural" approaches model the NAIRU as a function of labour and product market variables and

2. A comprehensive overview on the different estimation strategies is provided by Richardson et al. (2000). 
involve estimating a system of equations explaining wage and price-setting behaviour (see, for example, Weiner, 1993 and Staiger et al., 1996). Though theoretically appealing, in practice these methods suffer from the difficulty of quantifying the many relevant structural variables which theory suggests should be important. The second category of purely "statistical" approaches relies solely on information about the unemployment rate to derive the NAIRU. The NAIRU is modelled as a deterministic function of time and its time path is derived by splitting the unemployment rate into cyclical and trend components using univariate filter techniques (see, for example, King, Stock and Watson, 1995). The third category of "semistructural" approaches is a combination of the other two in that the NAIRU is estimated on the basis of a Phillips-curve-type equation, relating inflation to the gap between the NAIRU and the unemployment rate and, similarly to the statistical approaches, identifying constraints are imposed on the path of the NAIRU and/or the unemployment gap. In this framework, the time-varying NAIRU is estimated by means of a Kalman filter. ${ }^{3}$

6. Among the various approaches, the latter has proven the most popular and promising in recent years, given its relative simplicity and transparency on the one hand and its direct link with the definition of the NAIRU as the rate of unemployment that is consistent with stable inflation on the other. More fundamentally, this concept of a time-varying NAIRU can also be derived as a reduced-form system of a structural wage-price setting model. In such a theoretical framework, formalised by Layard, Nickell and Jackman (1991), it is relatively straightforward, firstly, to incorporate the NAIRU concept into the microeconomic foundations of the augmented Phillips curve and, secondly, to derive an explicit expression of the NAIRU as a function of structural variables affecting labour and product markets in the long run. ${ }^{4}$

7. As shown in Annex A, the system of two equations which gives both the short-term inflation dynamics and the determinants of the NAIRU, can be expressed as follows:

$$
\left\{\begin{array}{l}
\pi_{t}=\varphi(L) \pi_{t-1}-\beta\left(U_{t}-U_{t}^{*}\right)+\eta_{W} \cdot Z_{t}^{W, S R}+\eta_{P} \cdot Z_{t}^{P, S R} \\
\text { with } U_{t}^{*}=\mu+\gamma \cdot c_{K}+\rho t_{w}+\theta_{W} \cdot Z_{t}^{W, L R}+\theta_{P} \cdot Z_{t}^{P, L R}
\end{array}\right.
$$

where $\pi_{t}$ is inflation, $U_{t}$ is the observed unemployment rate, $U_{t}^{*}$ is the NAIRU, $\varphi(L)$ is a polynomial function of the lag operator, $c_{K}$ is the real user cost of capital, $t_{w}$ is the tax wedge, $Z_{t}^{W, S R}$ and $Z_{t}^{P, S R}$ are vectors of short-run supply-shocks affecting wage and price inflation and $Z_{t}^{W, L R}$ and $Z_{t}^{P, L R}$ are vectors of long-lasting supply-shocks affecting the wage-setting and price-setting mechanisms.

8. In this framework, the NAIRU is the unemployment rate prevailing in the absence of any temporary supply shocks and at a constant rate of inflation, i.e. after the dynamic adjustment of inflation has taken place. Typical temporary supply shocks are those reflecting changes in real import prices or changes in real oil prices, which are expected to revert to zero over a relatively short time horizon, around one to two years. Such temporary shocks may alter the rate of inflation, but the NAIRU will be unchanged once they have passed, provided they are not aggravated by policy mistakes or long-lasting modifications of expectations. By contrast, changes in the institutional settings of labour or product markets will have a permanent effect on the NAIRU: in that case, inflation will rise or fall until the unemployment rate has adjusted towards the new NAIRU. The list of potential long-lasting supply shocks includes factors intervening in the wage setting mechanism such as the tax wedge, the average unemployment benefit replacement rate, the bargaining power of unions and factors affecting the cost and pricing behaviour of

3. See, for example, Richardson et al., (2000), Franz, (2005) or Batini and Greenslade, (2005).

4. In fact, the Phillips curve can be interpreted as a reduced form relationship of the interaction between the wage setting and price setting mechanisms. 
firms, such as the level of long-term real interest rates or the degree of monopoly in specific industries (see Annex A for details).

9. Such a reduced-form approach has been adopted by the OECD for the estimation of time-varying NAIRUs for the member countries since $2000 .^{5}$ This paper makes two contributions to the literature. The first relates to the methodology used: a uniform specification is adopted for all countries and particular attention is devoted to the modelling of the statistical properties of the NAIRU, along the lines of Laubach (2001). ${ }^{6}$ More importantly, the paper analyses in a second stage the link between the estimated NAIRU and a range of structural variables commonly used at the OECD to assess the level of rigidities of labour and product markets. Although past work has systematically controlled for short-run supply shocks in the Phillips curve equation, less attention has been given to the identification of long-run supply shocks in the framework described by the second equation of system (1).

10. The system of equations (1) is thus estimated in a two-stage approach. There are several reasons why such a two-step procedure is preferred over a one-stage procedure that would involve including the variables that represent long-term shocks directly in system (1). First, the estimation of the Phillips curve is based on quarterly data, while data on the structural variables which potentially affect the NAIRU are only available at annual frequency. Second, the structural variables like the tax wedge or the indicator of product market regulations are available only over a limited time period, which would severely constrain a country-by-country econometric analysis. Finally, it is important to run panel data regressions to check first if the candidate variables identified in the theoretical model can be robustly used as explanatory variables for the long-run structural unemployment rate. Panel data analysis also allows testing whether the influence of these structural variables can be considered as similar or heterogeneous across different OECD economies.

\subsection{The estimation process and the Kalman filter}

11. State-space models with Kalman filter techniques have been widely used in the recent literature to estimate the NAIRU. In this framework, the estimated NAIRU is time varying and treated as an unobserved stochastic variable: it is derived from its ability to explain inflationary developments, subject to various constraints on its evolution over time. Such a NAIRU estimate is hence obtained without requiring all factors affecting it to be specified explicitly: its time-path is extracted from the information contained in the Phillips-curve equation by means of the Kalman filter (the so-called signal equation of the filter, see Box 1).

5. Such a methodology is also frequently used by the European Central Bank and the European Commission (see e.g. Fabiani and Mestre, 2000).

6. This extension was already introduced by Mourougane et al. (2005), but not generalised for all countries in a uniform framework. 


\section{Box 1. Estimating time-varying NAIRUs by means of the Kalman filter}

The Kalman filter is a frequently used tool for estimating equation systems with time-varying parameters. ${ }^{1}$ To apply the Kalman filter, the system of equations must be written in state space form with a signal equation [equation (1); for example, a Phillips curve relation] and a transition equation [equation (2)] specifying the time-series properties of the time-varying parameter (the NAIRU):

$$
\begin{aligned}
& y_{t}=A^{\prime} x_{t}+H^{\prime} \xi_{t}+w_{t} \\
& \xi_{t}=F \xi_{t-1}+v_{t}
\end{aligned}
$$

where $y_{t}$ is an observed endogenous variable (e.g. inflation), $x_{t}$ is a vector of observed exogenous variables (e.g. lagged inflation, unemployment rate), $A, H$ and $F$ are matrices of (time-invariant) parameters, $A^{\prime}$ is the transpose of matrix $A, \xi_{t}$ is an unobserved (time-varying) parameter known as the state vector (the NAIRU) and $w_{t}$ and $v_{t}$ are white noise error terms with the variance-covariance matrices $R$ and $Q$.

The Kalman filter makes it possible to estimate both the parameter matrices $A^{\prime}, H^{\prime}$ and $F$ and the state vector $\xi_{\text {t. }}$ Assuming for the moment that the numerical values of the parameter matrices were known with certainty, the Kalman filter can be thought of as an algorithm for calculating linear least squares forecasts of the state vector $\xi_{t}$ based on data observed through date $t$,

where

$$
\begin{gathered}
\hat{\xi}_{t+1 \mid t} \equiv \hat{E}\left(\xi_{t+1} \mid \mathcal{Y}_{t}\right) \\
\mathcal{Y}_{t}=\left(y_{t}, y_{t-1}, \ldots, y_{1}, x_{t}, x_{t-1}, \ldots, x_{1}\right)^{\prime}
\end{gathered}
$$

Together with these linear projections, the Kalman filter calculates a mean squared error (MSE) matrix:

$$
P_{t+1 \mid t} \equiv E\left[\left(\xi_{t+1}-\hat{\xi}_{t+1 \mid t}\right)\left(\xi_{t+1}-\hat{\xi}_{t+1 \mid t}\right)^{\prime}\right]
$$

The recursion is initiated by setting starting values for the state vector and its MSE matrix, $\hat{\xi}_{1 \mid 0}$ and $P_{1 \mid 0}$. Given these starting values analogous magnitudes are calculated for the following date, $\hat{\xi}_{2 \mid 1}$ and $P_{2 \mid 1}$, continuing this way until the end of the sample. Using the state space model introduced above as an example, the calculations have the following general form:

$$
\begin{aligned}
& \hat{\xi}_{t+1 \mid t} \equiv \hat{E}\left(\xi_{t+1} \mid \mathcal{Y}_{t}\right)=F \hat{\xi}_{t \mid t-1}+K_{t}\left(y_{t}-A^{\prime} x_{t}-H^{\prime} \hat{\xi}_{t \mid t-1}\right) \\
& P_{t+1 \mid t} \equiv E\left[\left(\xi_{t+1}-\hat{\xi}_{t+1 \mid t}\right)\left(\xi_{t+1}-\hat{\xi}_{t+1 \mid t}\right)^{\prime}\right]=\left(F-K_{t} H^{\prime}\right) P_{t \mid t-1}\left(F^{\prime}-H K_{t}{ }^{\prime}\right)+K_{t} R K_{t}{ }^{\prime} Q
\end{aligned}
$$

where the coefficient matrix $K_{t}=F P_{t \mid t-1} H\left(H^{\prime} P_{t \mid t-1} H+R\right)^{-1}$ is known as the gain matrix.

If the initial state and the innovations $v_{t}$ and $w_{t}$ are multivariate Gaussian, then the generated forecasts are optimal for any numerical values of the parameter matrices. They can thus be inserted into the log likelihood function:

$$
\log f_{y_{t} \mid x_{t}, y_{t-1}}\left(y_{t} \mid x_{t}, y_{t-1}\right)=-\frac{1}{2} \log 2 \pi+\frac{1}{2} \log \left|Z_{t}^{-1}\right|-\frac{1}{2}\left(y_{t}-A^{\prime} x_{t}-H^{\prime} \hat{\xi}_{t \mid t-1}\right)^{\prime} Z_{t}^{-1}\left(y_{t}-A^{\prime} x_{t}-H^{\prime} \hat{\xi}_{t \mid t-1}\right)
$$

where $Z_{t}=H^{\prime} P_{t \mid t-1} H+R$. Expression (B1.7) can be maximised numerically with respect to the unknown parameters in the matrices $A, H, F, Q$, and $\mathrm{R}$.

So far, inference about the value of the state vector $\xi_{t}$ was based on observations through date $t$. In applications where the state vector is of interest itself it might be preferential to use information on the full data set. Such an estimate is called the smoothed estimate of $\xi_{t}$. It is obtained through a backward recursion starting with the estimate $\xi_{T / T}$ and iterating backwards to calculate $\xi_{T-1 / T}, \xi_{T-2 / T}, \ldots, \xi_{1 / T}$ together with the associated MSE matrices:

$$
\begin{aligned}
& \hat{\xi}_{t \mid T}=\hat{E}\left(\xi_{t} \mid \mathcal{Y}_{T}\right)=\hat{\xi}_{t \mid t-1}+P_{t \mid t-1} H Z_{t}^{-1}\left(y_{t}-A^{\prime} x_{t}-H^{\prime} \hat{\xi}_{t \mid t-1}\right)+P_{t \mid t} F^{\prime} P_{t+1 \mid t}^{-1}\left(\hat{\xi}_{t+1 \mid T}-\hat{\xi}_{t+1 \mid t}\right) \\
& P_{t \mid T}=E\left[\left(\xi_{t}-\hat{\xi}_{t}\right)\left(\xi_{t}-\hat{\xi}_{t}\right)^{\prime}\right]=P_{t \mid t-1}-P_{t \mid t-1} H Z_{t}^{-1} H^{\prime} P_{t \mid t-1}+P_{t \mid t} F^{\prime} P_{t+1 \mid t}^{-1}\left(P_{t+1 \mid T}-P_{t+1 \mid t}\right)\left(P_{t \mid t} F^{\prime} P_{t+1 \mid t}^{-1}\right)^{\prime}
\end{aligned}
$$

1. For further details on the technique see Harvey (1993) or Hamilton (1994). 
12. The specification of the Phillips curve equation is similar to that employed in Richardson et al. (2000). It includes two types of short-term supply shocks: oil price shocks, via the introduction of real oil price inflation, weighted by the oil intensity of production, and the impact of trade and globalisation, via the inclusion of real import price inflation weighted by import penetration. ${ }^{7}$ Domestic inflation is measured by the change in the core consumer price index where sufficiently long time spans of data are available and by the change in the consumer price index otherwise. ${ }^{8}$ It is assumed that there is no feedback from inflation to unemployment as in Gordon (1997), meaning that there is no simultaneity bias issue when allowing the contemporaneous unemployment rate to enter the Phillips curve. Assuming dynamic homogeneity to hold, the relationship takes the following form: ${ }^{9}$

$$
\begin{aligned}
\Delta \pi_{t}= & \sum_{j=1}^{m} \chi_{j}(L) \Delta \pi_{t-j}-\beta\left(U_{t}-U_{t}^{*}\right)+\sum_{j=0}^{n} \eta_{j} M G S_{t-j}^{S H}\left(\pi_{t-j}^{M G S}-\pi_{t-j}\right) \\
& +\sum_{j=0}^{l} \kappa_{j} O I L_{t-j}^{S H}\left(\pi_{t-j}^{O I L}-\pi_{t-j}\right)+v_{t}
\end{aligned}
$$

where $\pi$ is domestic inflation, $M G S^{S H}$ is the import content of consumption, ${ }^{10} \pi^{M G S}$ is import price inflation (goods and services), $O I L^{S H}$ is the oil intensity of production (calculated as the ratio between oil supply and domestic output), $\pi^{\text {OIL }}$ is oil price inflation and $v_{t}$ is the residual. The appropriate number of lags ( $m, n$ and $l$ ) for the three right-hand-side inflation variables is determined by starting with four lags each and then dropping statistically insignificant lags. All data are taken from the OECD Economic Outlook database.

13. There is no unique way of using the Kalman filter to estimate the NAIRU and a variety of assumptions may be adopted to describe the stochastic process it follows. In this paper, the NAIRU is inferred from two transition equations specifying the time-series properties of respectively the NAIRU and the unemployment gap. ${ }^{11}$ In the empirical literature the NAIRU is commonly modelled as a simple random walk process. A look at the unemployment rate series (see Figure 1) suggests that this assumption is appropriate for all countries in the sample. ${ }^{12}$ The transition equation for the NAIRU thus takes the following form:

$$
U_{t}^{*}=U_{t-1}^{*}+\varepsilon_{t}
$$

7. Import prices are deflated by consumer price inflation. Using producer price inflation would probably better match the structure of trade, but the choice has been made to keep a uniform definition of inflation.

8. To check the robustness of the results, the model is also estimated measuring domestic inflation by the change in the private consumption deflator. The obtained NAIRU series are very similar to the ones reported in this paper suggesting that the choice of the domestic inflation variable does not matter much for the results.

9. $\pi_{\mathrm{t}}=\varphi(L) \pi_{t-1}$ is equivalent to $\Delta \pi_{\mathrm{t}}=\chi(L) \Delta \pi_{t-1}$ after imposing dynamic homogeneity on the lagged inflation terms $(\varphi(1)=1)$.

10. Calculated as $M G S_{t}^{S H}=M_{t} /\left(Y_{t}+M_{t}-X_{t}\right)$ where $M, X$ and $Y$ denote total imports, total exports and domestic output.

11. In addition to the Phillips curve relation linking inflation to the unemployment gap.

12. Laubach (2001) who estimates time-varying NAIRUs for seven OECD economies allows for a stochastic trend in the NAIRU specification. This strategy is not adopted in this paper given that a stochastic trend of the NAIRU would imply that the unemployment rate is integrated of order two -- a presumption that is not supported by the data. Both augmented Dickey-Fuller and Dickey-Fuller GLS unit root tests clearly indicate that the unemployment rate is integrated of order one in all countries considered. 
where the error term $\varepsilon_{t}$ is assumed to be normally distributed with mean zero and variance $\sigma_{\varepsilon}^{2}$ and uncorrelated with the error term of the Phillips-curve equation $v_{t}$.

14. In addition, a law of motion is imposed on the gap between the NAIRU and the unemployment rate, in order to ensure that the unemployment rate converges to the structural rate in the absence of shocks. This assumption is consistent with the work by Friedman (1968) on the natural rate hypothesis which implies that the unemployment rate cannot deviate permanently from its natural rate. Following Laubach (2001), the unemployment gap is assumed to follow an autoregressive process. This additional restriction means that the level of the NAIRU can be inferred not only on the basis of the information on inflationary pressures in the economy, but also on the basis of the unemployment rate dynamics themselves.

15. The transition equation for the unemployment gap can be written as:

$$
U_{t}-U_{t}^{*}=\psi(L)\left(U_{t-1}-U_{t-1}^{*}\right)+\zeta_{t}
$$

where the error term $\xi_{t}$ is normally distributed with mean zero and variance $\sigma_{\zeta}^{2}$ and uncorrelated with $\varepsilon_{t}$. An AR(2) model for the unemployment gap is in general found to provide a good description of the data as suggested by Jaeger and Parkinson (1994). As shown by Laubach (2001), the stability and robustness of the results -- notably to changes in the sample period or the initial parameters --- is largely improved when using transition equation (4) in addition to transition equation (3) in the estimation. Although not necessary for the solution of the model, constraints are imposed on the sum of the autoregressive parameters to ensure sensible time-series properties of the unemployment gap. ${ }^{13}$

16. Applying the Kalman filter to the model outlined above requires assumptions about several of the parameters of the model. Firstly, the values and variances of the two state variables (the NAIRU and the unemployment gap) in the initial period have to be pre-specified. The most common approach to setting the initial value of a non-stationary state variable such as the NAIRU is to obtain it directly from the maximum likelihood procedure by specifying a reasonable prior for the initial value together with a large variance term (Laubach, 2001). This strategy is also adopted in this paper with the initial value of the NAIRU being set equal to the average unemployment rate around the first year of the sample period and the initial value of the unemployment gap being set equal to the difference between the unemployment rate in the initial period and the prior for the NAIRU.

17. Secondly, assumptions are made about the relative variances of the residuals of the three equations. The variance of the error term in the transition equation of the NAIRU relative to the one of the error term in the Phillips-curve equation $\left(\sigma_{\varepsilon}^{2} / \sigma_{v}^{2}\right)$ determines the smoothness of the NAIRU series. The smaller this so-called 'signal-to-noise ratio', the less volatile will be the resulting NAIRU. In the extreme case of $\sigma_{\varepsilon}^{2} / \sigma_{v}^{2}=0$ the NAIRU will be constant, whereas it will soak up all the residual variation in the Phillips-curve equation if $\sigma_{\varepsilon}^{2} / \sigma_{v}^{2}$ approaches infinity. ${ }^{14}$ Similarly, the smaller the relative variance of the transition equation of the unemployment gap the more volatile will be the NAIRU series. While in principle the Kalman filter allows estimating the three variances $\sigma_{v}^{2}, \sigma_{\varepsilon}^{2}$ and $\sigma_{\zeta}^{2}$ together with the other parameters of the model, this often leads to disappointing results as the resulting NAIRU series are too smooth (Richardson et al., 2000). As a consequence, the variances are typically fixed in empirical

13. The value chosen for the sum of the autoregressive parameters varies across countries, between 0.75 and 0.9 across countries).

14. For a given value of $\sigma_{\zeta}^{2}$. 
applications (see, for example, Laubach, 2001, and Llaudes, 2005). ${ }^{15}$ This is the strategy adopted in this paper.

\section{Comparative estimation for 23 OECD countries}

\subsection{Updating the NAIRUs}

18. The OECD has revised its NAIRU estimates previously, but as mentioned above, the present study represents a comprehensive overhaul of the system. The reduced form approach described in the previous section is used to estimate NAIRUs for 23 OECD countries. ${ }^{16}$ The sample period varies by country depending on the availability of all relevant data. The longest sample is available for Belgium, covering the period 1961Q1 to 2007Q4; Portugal and New Zealand have the shortest sample period, running from 1980Q1 to 2007Q4. ${ }^{17}$ The results of the estimation procedure are summarized in Table B1 with the profiles of the estimated NAIRUs shown in Figure 1 and Table B2.

19. The unemployment gap is found to have a significant impact on the change in domestic inflation in all but one of the 23 countries considered, supporting the underlying theoretical framework. The only country where the gap is not found to be significant at conventional significance levels is Japan with a $p$ value $0.16{ }^{18}$ This result is in line with previous research demonstrating that for Japan a significant relationship between inflation and activity is difficult to establish (e.g. Nishizaki, 1997). For most countries, the magnitudes of the estimated coefficients imply sacrifice ratios that are close to those obtained by Richardson et al. (2000). The dispersion in the sacrifice ratio across countries appears quite high with the point estimates ranging from $1 / 2$ for Austria and Korea to $2 \frac{1}{4}$ for Finland and the United States. Nonetheless the dispersion is somewhat lower than in earlier exercises of this type, and most of the values obtained lie between 1 and 2 .

20. Whilst real import price inflation is also found to have a significant impact on changes in domestic inflation in most countries, real oil price inflation is significant only in a few number of countries. Overall, NAIRU and Phillips curve estimates are found to be relatively insensitive to the choice of the inflation indicator. The overall goodness-of-fit varies considerably across countries, with over $80 \%$ of the variation in inflation explained by the model for Greece and Switzerland compared with only $28 \%$ for Germany, France and Italy.

15. Gordon (1997) suggests choosing a signal-to-noise ratio that allows the NAIRU to move around freely but rules out sharp quarter-to-quarter zigzags.

16. These are the G7 economies, Australia, Austria, Belgium, Denmark, Finland, Greece, Ireland, Korea, Luxembourg, the Netherlands, New Zealand, Portugal, Sweden, Switzerland and Norway. For the Czech Republic, Hungary, Iceland, Mexico, Poland, the Slovak Republic and Turkey the NAIRU is derived by applying an HP filter to the unemployment rate as the relevant data are not available for a sufficiently long time period to allow estimating the NAIRU as an unobservable component in a Phillips-curve equation. For Spain, the methodology used in this paper was not giving satisfactory results. The NAIRU estimate is in fact obtained with a different specification, where a drift is included into the NAIRU dynamics (see Mourougane et al., 2005). For a recent estimation of the Polish NAIRU by means of a Kalman filter see Kierzenkowski et al. (2008).

17. For Germany, the NAIRU is estimated over the whole period 1970-2007 using retropolated data before reunification.

18. The significance of the unemployment gap in the Japanese model turned out to be very sensitive to the choice of the signal-to-noise ratio. 
Figure 1. Unemployment rate, NAIRU and the $90 \%$ error band
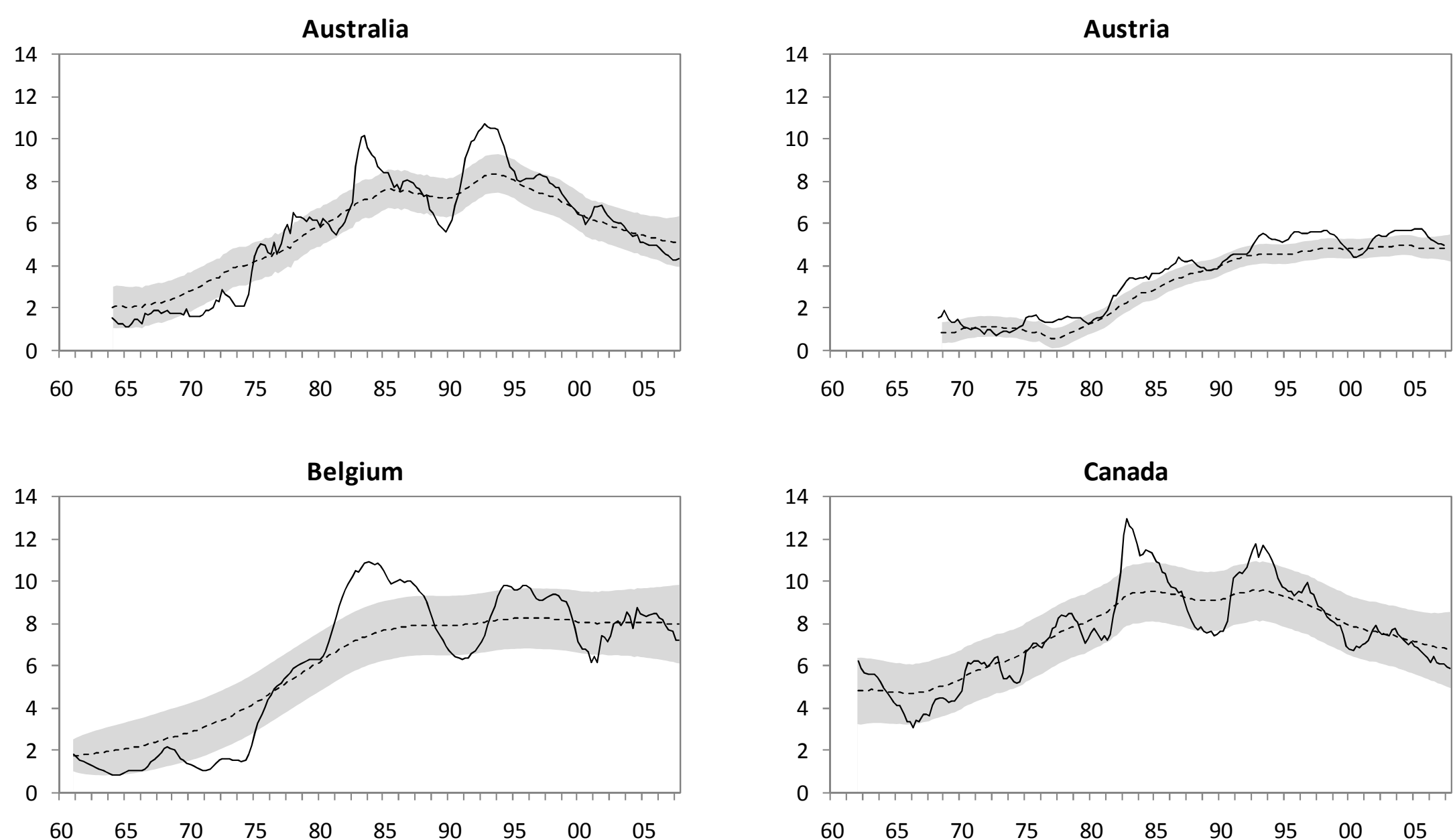
Figure 1. Unemployment rate, NAIRU and the $90 \%$ error band (cont'd)
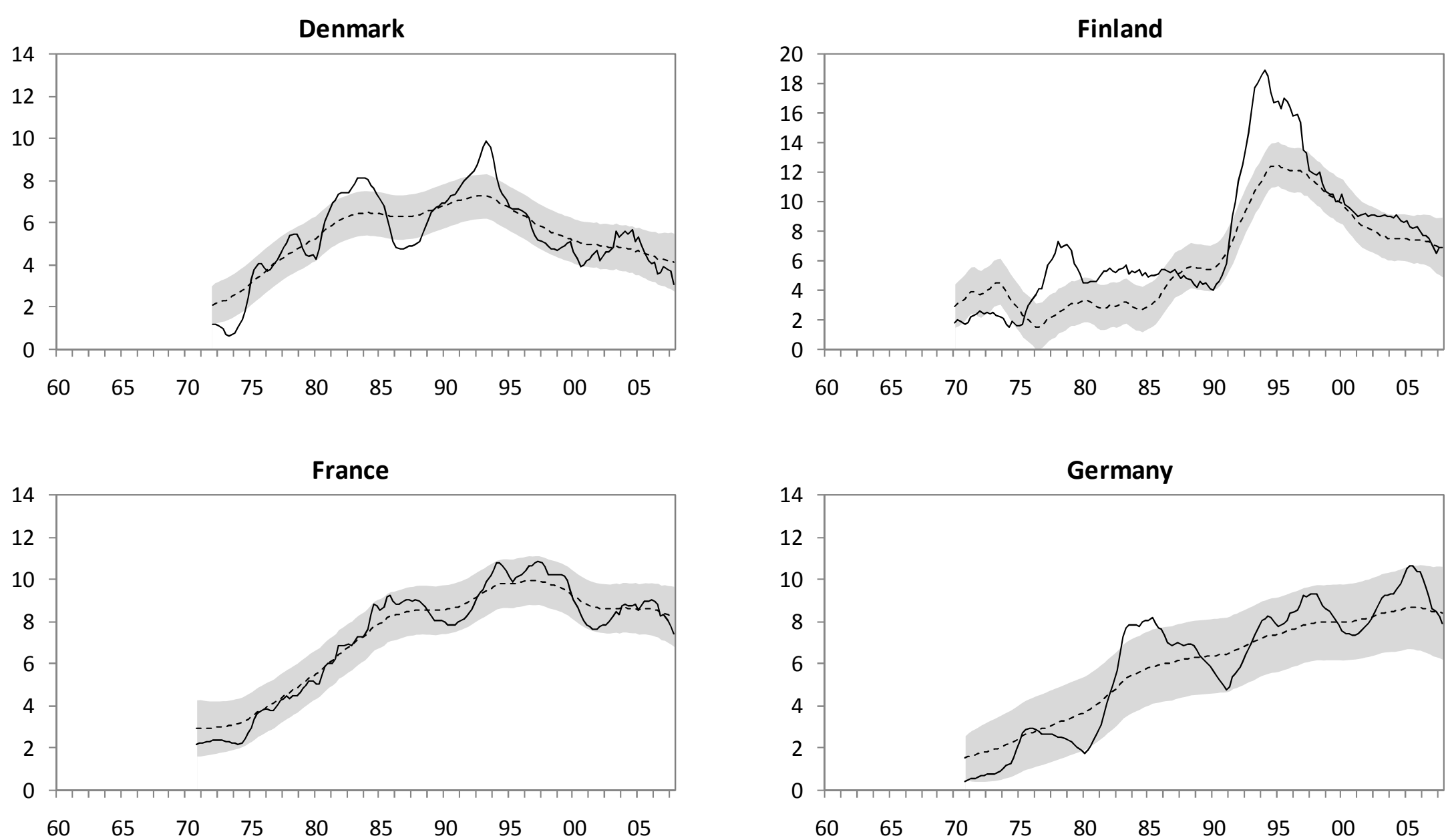
Figure 1. Unemployment rate, NAIRU and the $90 \%$ error band (cont'd)
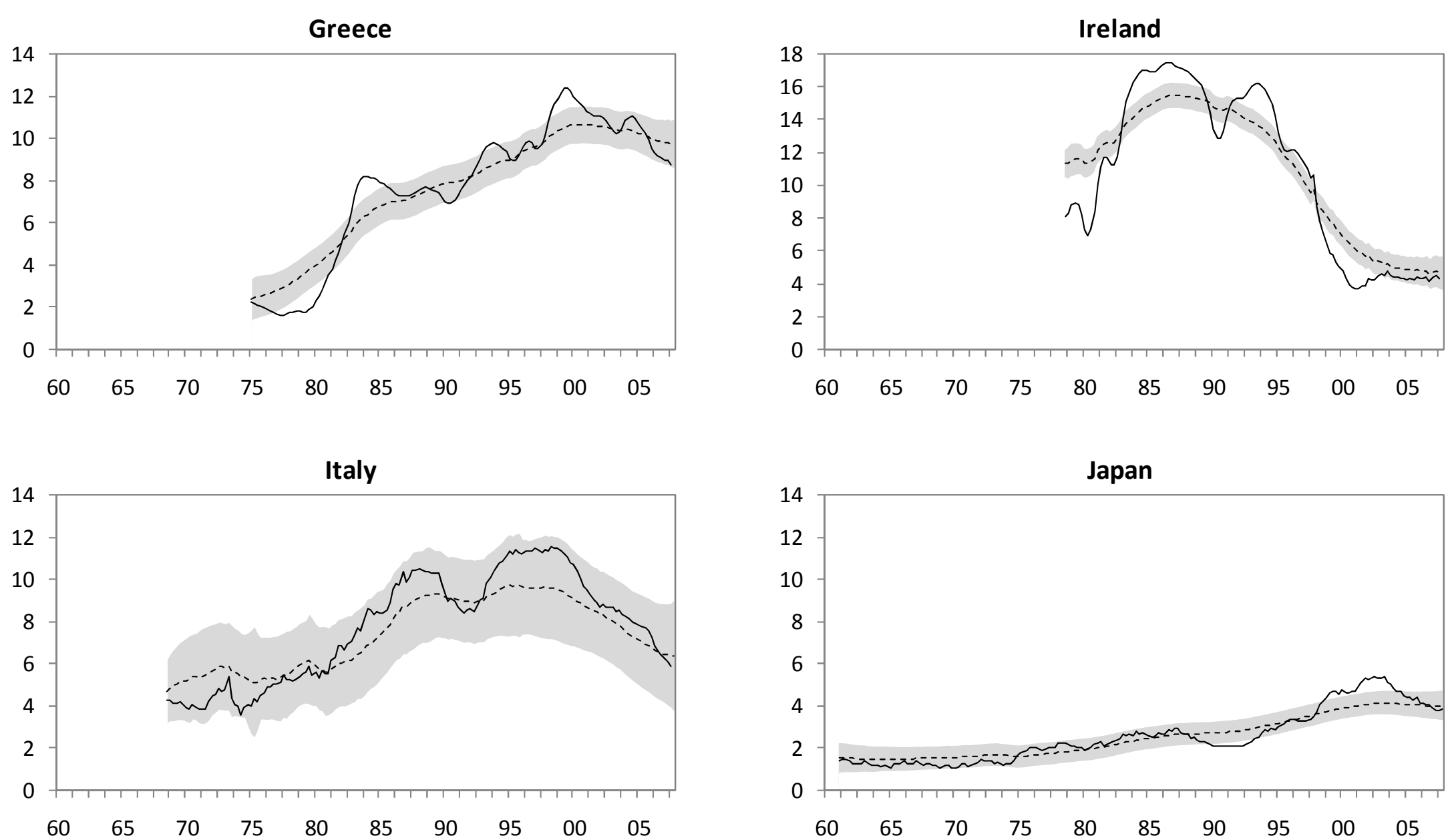
Figure 1. Unemployment rate, NAIRU and the $90 \%$ error band (cont'd)
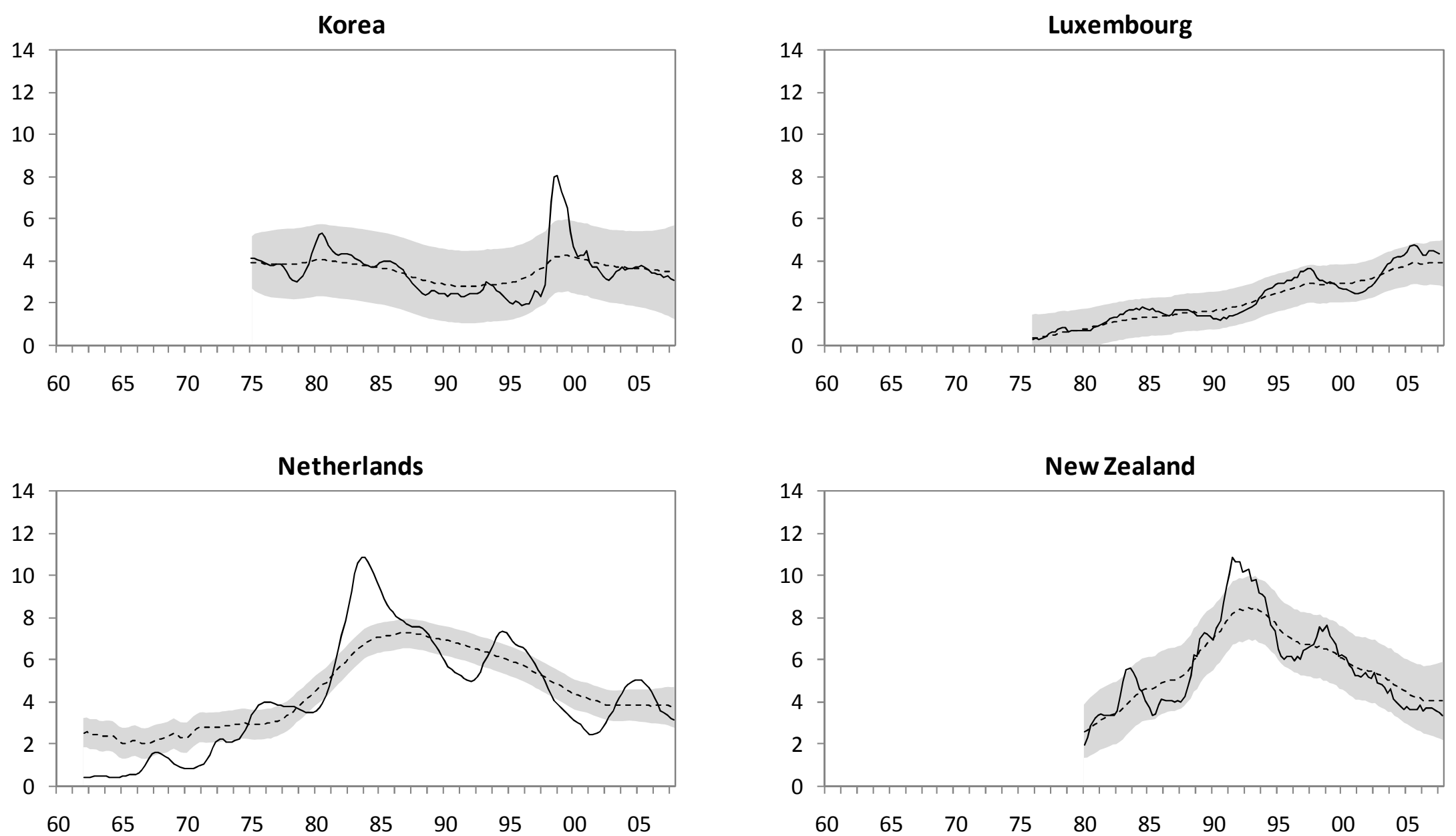
Figure 1. Unemployment rate, NAIRU and the $90 \%$ error band (cont'd)
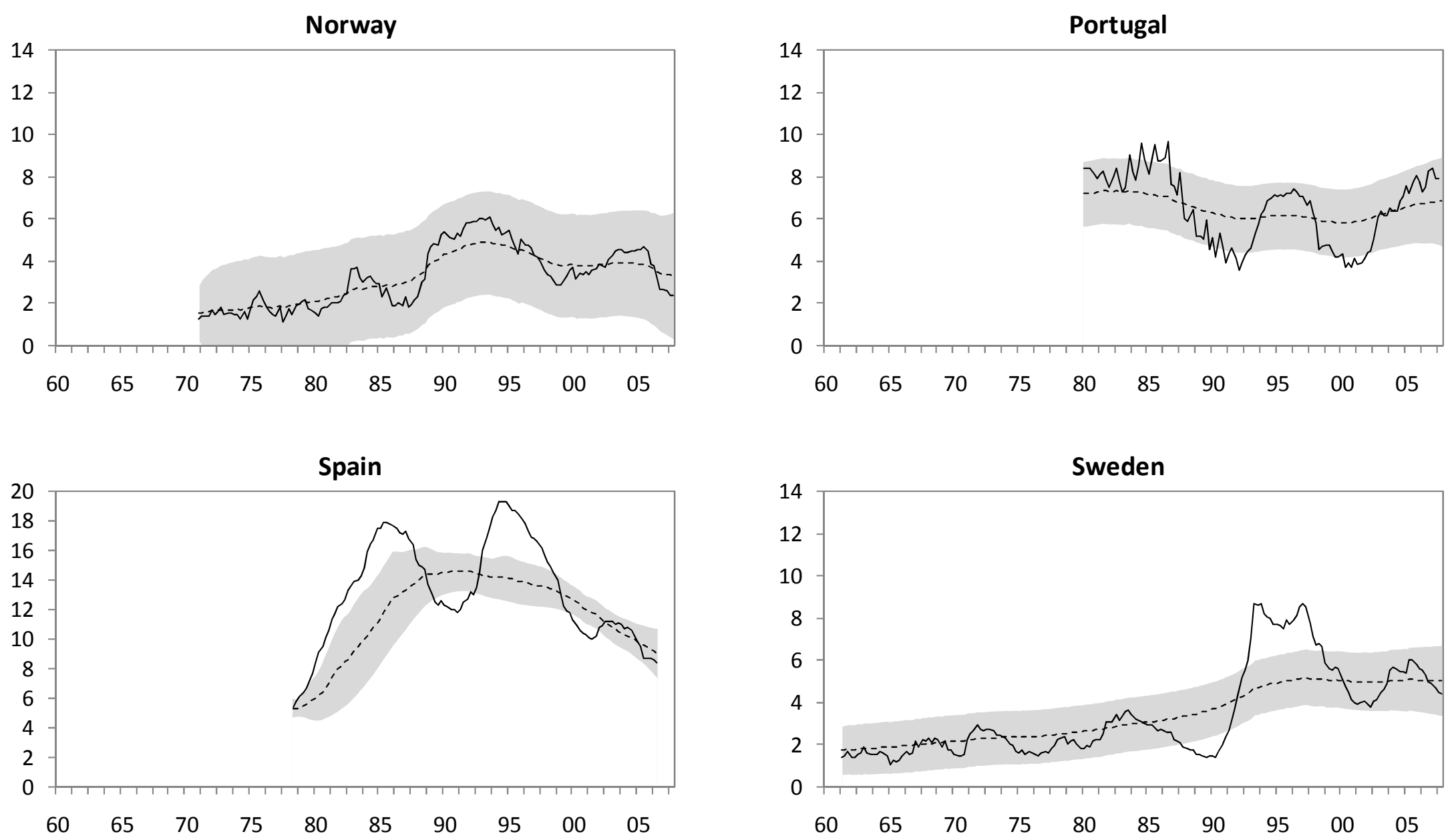
ECO/WKP(2008)57

Figure 1. Unemployment rate, NAIRU and the 90\% error band (cont'd)
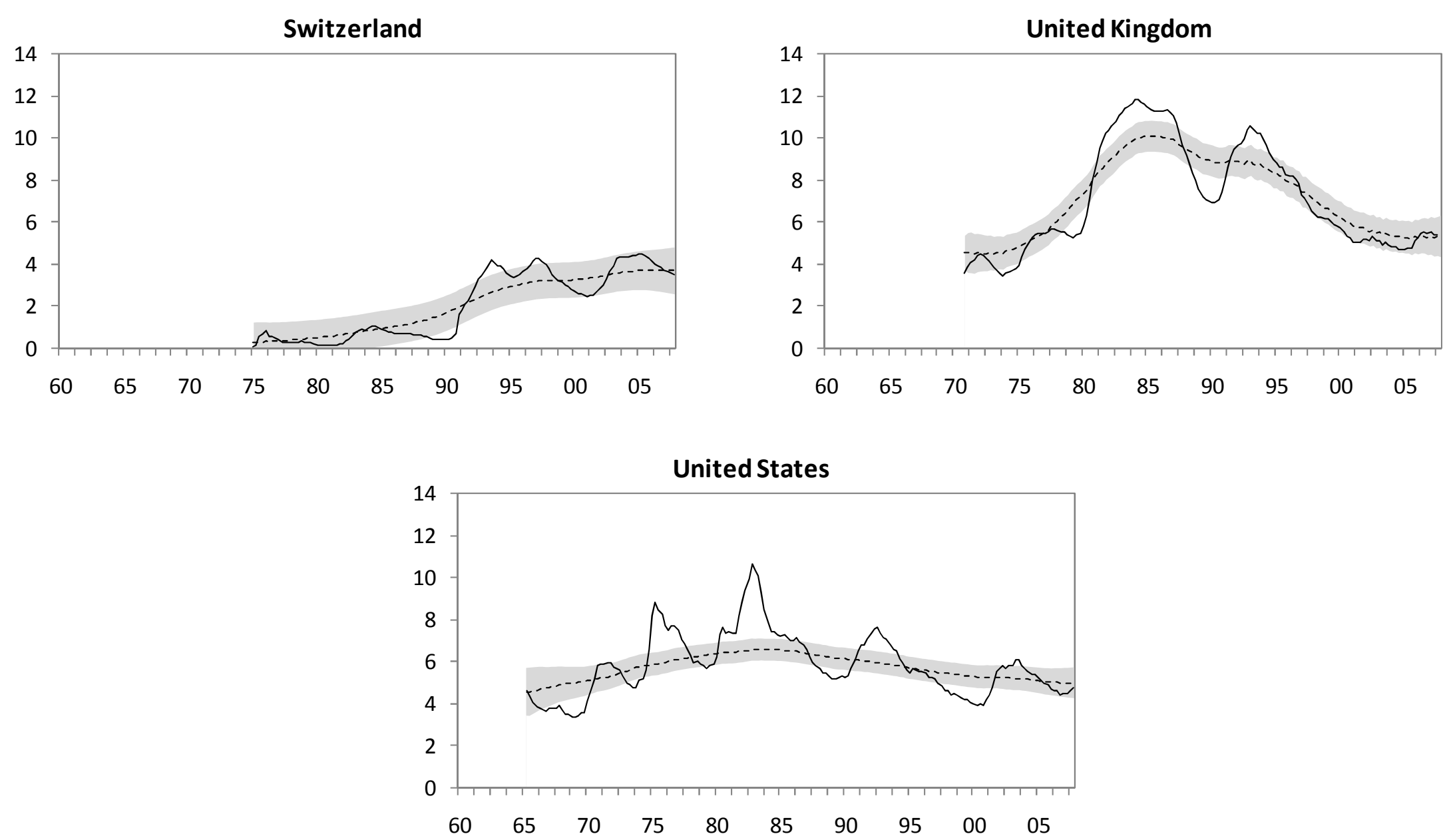
21. The profiles of the updated NAIRU series are very similar to the existing estimates for most countries with correlation coefficients of around 0.9. Nonetheless, sizable level shifts have occurred for a number of countries, reflecting either major revisions to the underlying unemployment data (Germany and Switzerland) or improvements in the sense that the updated NAIRU series are more easily reconcilable with the historic profile of inflationary pressures in the respective countries (Australia, Belgium, Portugal and the United Kingdom). For those countries where there are sizeable changes in the NAIRU estimates, the unemployment gaps implied by the updated estimates are generally in line with other measures of the cyclical positions used by the OECD. ${ }^{19}$

\subsection{Gauging the precision of the NAIRU estimates}

22. Within the Kalman-filter framework, the computation of the uncertainty surrounding the NAIRU estimates requires specific econometric treatment. The total uncertainty associated with the Kalman filter estimates can be decomposed into two sources: filter uncertainty associated with the estimation technique and represented by the estimated variance of the maximum likelihood estimates of the NAIRU and parameter uncertainty associated with errors made in fixing the set $\theta$ of initial parameters of the model (such as the value and variance of the NAIRU in the initial period). Although uncertainty around the initial value of the NAIRU generally only matters during the first years of the sample period, ignoring it would lead to an underestimation of the mean square error of the NAIRU. Standard estimation techniques enable to quantify the first source of uncertainty by providing the estimated prediction error variance for the state at any time $t$. On the contrary, quantifying the second source of uncertainty requires the application of specific simulation methods such as Monte Carlo simulations (Hamilton, 1986; Schumacher, 2008), parametric and nonparametric bootstrapping (Pfeffermann and Tiller, 2005) or the delta method (Staiger et al., 1996).

23. The parameter uncertainty was quantified by means of Monte Carlo simulations (details on the procedure are provided in Box 2), by which 1000 replications were carried out under the same initial conditions. In particular, the initial state was randomly drawn from a Normal distribution with mean and variance equal to the estimated smoothed state variables (i.e. the NAIRU and the gap, see Box 1). The other parameters of the model, i.e. the variances of the residuals, were fixed identical to those chosen in the estimation process since they provide the best fit for the unobserved NAIRU and gap in the Phillips curve. ${ }^{20}$ By contrast, all coefficients of the state space model are re-estimated at each Monte Carlo replication.

24. The $90 \%$ confidence interval and the average standard errors obtained for the NAIRU estimates using Monte-Carlo simulations are reported in Tables B1 and B2. The average standard errors lie between 0.3 for the United States and Austria to 1.5 for Norway, with most values being less than one. The uncertainty is found to be relatively high for Germany, Italy, Korea and Finland. The filter uncertainty appears to be much larger than the parameter uncertainty surrounding the value of the initial NAIRU: for the vast majority of countries parameter uncertainty accounts for less than $1 \%$ of the total variance of the NAIRU over the whole sample period but for around one-third at the beginning of the sample period. Italy, Finland and Ireland are exceptions: for these countries, the variance of the NAIRU linked to fluctuations in the initial parameters explains more than $10 \%$ of the total variance of the NAIRU.

19. These are the TFP gap, the capital gap, the participation gap and the hours worked gap that together with the unemployment gap enter into the construction of the OECD's estimate of the output gap (see Beffy et al., 2006). The result implies that the information given by the revised unemployment gap and the output gap are more consistent with each other.

20. Similarly to Schumacher (2008), the variances $\sigma_{v}^{2}, \sigma_{\varepsilon}^{2}$ and $\sigma_{\zeta}^{2}$ are fixed. 


\section{Box 2. Hamilton simulation method for standard errors estimation}

Using the same notations and variables as in Box 1 , let $\sigma_{v}^{2}$ denote the set of estimated parameters in the state space model and $\hat{\xi}_{t \mid T}(\hat{\theta})$ the estimated state vector obtained by the Kalman filter application. Considering $\hat{\xi}_{t \mid T}(\hat{\theta})$ as the best guess for the unknown true state vector, Hamilton (1986) shows that the corresponding mean squared error (MSE) matrix, at any time $t$, equals:

$$
P_{t \mid T}(\hat{\theta}) \equiv E\left[\left(\xi_{t}-\hat{\xi}_{t \mid T}(\hat{\theta})\right)\left(\xi_{t}-\hat{\xi}_{t \mid T}(\hat{\theta})\right)^{\prime}\right]
$$

Ashley and Kohn (1986) demonstrate that the estimated MSE matrix can be decomposed into the sum of two terms

$$
\hat{P}_{t \mid T}(\hat{\theta})=E\left[\left(\xi_{t}-\hat{\xi}_{t \mid T}(\hat{\theta})\right)\left(\xi_{t}-\hat{\xi}_{t \mid T}(\hat{\theta})\right)^{\prime}\right]+E\left[\left(\hat{\xi}_{t \mid T}(\theta)-\hat{\xi}_{t \mid T}(\hat{\theta})\right)\left(\hat{\xi}_{t \mid T}(\theta)-\hat{\xi}_{t \mid T}(\hat{\theta})\right)^{\prime}\right]
$$

which represent respectively the filter and the parameter uncertainty around the estimated vector $\hat{\xi}_{t \mid T}(\hat{\theta})$. In particular, the filter uncertainty reflects the error in estimating the state by applying the Kalman filter on known parameters $\theta$, whereas the parameter uncertainty provides a measure of the error made in the specification of $\sigma_{v}^{2}$.

In order to estimate the matrix $\hat{P}_{t \mid T}(\hat{\theta})$, Monte Carlo simulations are performed to obtain $J$ replications of the initial parameter vector $\theta_{j}$ together with $J$ estimates of the state vector $\hat{\xi}_{t \mid T}\left(\hat{\theta}_{j}\right)$, with $j=1, \ldots, J$. Precisely, $J$ draws of the state value at the initial time $t=1$ are made from a Normal distribution $N\left(\hat{\xi}_{1 \mid T}(\hat{\theta}), \hat{P}_{1 \mid T}(\hat{\theta})\right)$ with mean and variance given by the maximum likelihood estimate of $\hat{\xi}_{t \mid T}(\hat{\theta})$ at time $t=1$. After the repeated estimation of the state space model, the new set of $J$ state estimates $\hat{\xi}_{t \mid T}\left(\hat{\theta}_{j}\right)$, together with their relative covariance matrices $\hat{P}_{t \mid T}\left(\hat{\theta}_{j}\right)$ is used to approximate both filter and parameter uncertainty by means of Monte Carlo replications. In particular:

$$
\hat{P}_{t \mid T}(\hat{\theta})=J^{-1} \sum_{j=1}^{J} \hat{P}_{t \mid T}\left(\hat{\theta}_{j}\right)+J^{-1} \sum_{j=1}^{J}\left(\hat{\xi}_{t \mid T}\left(\hat{\theta}_{j}\right)-\hat{\xi}_{t \mid T}(\hat{\theta})\right)\left(\hat{\xi}_{t \mid T}\left(\hat{\theta}_{j}\right)-\hat{\xi}_{t \mid T}(\hat{\theta})\right)^{\prime}
$$

Here, the first term on the right-hand side represents the filter uncertainty and is obtained by averaging the estimated variances of the simulated smoothed states across $J$ replications, whereas the second term represents the uncertainty due to the choice of the initial parameter vector $\hat{\theta}$ and is calculated as the MSE around the $J$ replications of the estimated state vectors.

The estimated MSE matrix $\hat{P}_{t \mid T}(\hat{\theta})$ can be further used to calculate the $\alpha \%$-confidence interval around the estimated state vector $\hat{\xi}_{t \mid T}(\hat{\theta})$ at each time point in time $t$ :

$$
\hat{\xi}_{t \mid T}(\hat{\theta}) \pm z_{\alpha / 2} \sqrt{\hat{P}_{t \mid T}(\hat{\theta})}
$$

Under the assumption of Gaussian errors, Gaussian confidence intervals have exact coverage rates and values from the standard Normal distribution can be used to set the significance level $\alpha$ and its relative $z$ value. 


\section{Institutions and the structural rate of unemployment}

\subsection{Identifying underlying structural determinants of the NAIRU}

25. A large body of empirical research has studied the impact of structural factors on aggregate unemployment, stressing the key role of institutional policies and the need for fundamental labour and product market reforms to deal with high and persistent unemployment (IMF, 2003; Bassanini and Duval, 2006; Nickel et al. 2005). One of the difficulties most of these studies face is that of controlling for the effects of both cyclical demand pressures and short-term supply shocks on unemployment. Cyclical pressures are usually taken into account by adding a measure of the output gap (Bassanini and Duval, 2006) or, simply, the change in inflation (Belot and Van Ours, 2001 or Baker et al., 2004). A few studies, however, try to directly study the impact of structural reforms on the natural rate of unemployment itself, which is more consistent with the underlying theoretical models. Blanchard and Wolfers (2000) present an attempt to adjust unemployment for deviations from equilibrium unemployment using the Phillips curve framework, but this is simply done by calibrating the value of the sacrifice ratio and considering the implied impact of inflationary pressures on the unemployment gap. The contribution of the present study is to investigate the impact of changes in institutions directly on NAIRUs rather than unemployment rates, using the empirical estimates derived above. This makes it possible to neutralise both the effect of shortterm supply shocks -- which are explicitly taken into account within the Phillips curve framework -- and the cyclical component of the unemployment rate.

26. There is relatively little controversy about which variables should be considered as potential determinants of the NAIRU in a wage-setting/price-setting framework (see Annex A). The list of recurrent candidates identified in the literature, albeit not always easy to measure properly, includes the unemployment benefit replacement rate, the tax wedge, union density, the level of the minimum wage, product market regulations, employment protection legislation, measures of skill mismatch, and the efficiency of active labour market policies and of the job matching process. Amongst this large set of determinants, the analysis conducted for the OECD Jobs Strategy (OECD, 2006) identified a high level of unemployment benefits, a high the tax wedge and stringent product market regulation as being most robustly associated with higher unemployment rates (and also with lower participation). High union density and an inefficient wage bargaining process are also found to raise unemployment in some studies (Nicoletti and Scarpetta, 2005, Boone and Van Ours, 2004). ${ }^{21}$

27. The role of macroeconomic shocks such as changes in real interest rates or changes in TFP growth has been more controversial in theoretical discussions. Empirically, higher real interest rates appear to be unambiguously associated with higher unemployment (Bertola et al., 2002; IMF, 2003; Blanchard and Wolfers, 2000). This is consistent with the intuition that higher costs of capital translate into higher production costs and higher pressures to shed labour (Phelps and Zoega, 1998, Carruth et al. 1998, Cotis et al. 1998). As real long-term interest rates are an imperfect proxy for the user cost of capital, employing them in the empirical analysis raises the issue of the monetary policy impact. In theory, however, there should be no effect of monetary policy on long-term real rates, which are essentially driven by the investment-saving balance. Empirical evidence suggests, moreover, that long-term real rates are determined by global factors such as oil prices and world stock returns (Barro and Sala-i-Martin, 1990) and domestic factors such as the government fiscal position, the current account and risk premia (Orr et al., 1995). Of course, movements in short-term real rates will mechanically affect the kinds of long-term real

21. It is worth mentioning that the robustness of these findings is challenged by a few other empirical analyses using panel data (see, for example, Baker et al., 2004). 


\section{ECO/WKP(2008)57}

rates considered here, but the magnitude of the impact seems likely to be small and as such as the impact of short-term real rates on the NAIRU should also be small. ${ }^{22}$

28. The institutions and shocks considered in this study were selected by drawing on this body of empirical findings. As suggested by the theoretical model developed in Annex A, the real interest rate is systematically included in the estimated equations to capture changes in the user cost of capital. The institutional variables considered in the baseline estimates are essentially those variables for which data are available over a sufficiently long time period. These are the tax wedge, the average unemployment benefit replacement rate, union density and an indicator of regulatory impediments to product market competition. $^{23,24}$ The impact of the minimum wage legislation -- for which data are only available over a limited period -- is tested for a subset of countries at a later stage.

29. The system of equations that links the estimated NAIRU $\hat{U}^{*}$ to current and lagged values of the institutional variables $\Omega$ is written in first differences to control for unobserved country specific fixed effects. ${ }^{25}$ Moreover, taking first differences makes it possible to transform the variables of interest into stationary processes, provided structural reforms are $\mathrm{I}(1)$ or $\mathrm{I}(0)$ (and such an assumption is indeed accepted by the data). ${ }^{26}$ Hence the preferred empirical specification derived from equation (3) can be written as:

$$
\Delta \hat{U}_{i t}^{*}=\sum_{j} \sum_{k} \alpha_{i j k} \Delta \Omega_{i j t-k}+w_{i t}
$$

where $i$ is the country index, $t$ the time index, and $j$ an institution index so that $\Omega_{i j t}$ is the value of institution $j$ in country $i$ at time $t$. The number of lags $k$ may depend on the institution or the country considered. It is worth mentioning at this stage that interaction terms between institutions are also added in equation (5), in particular the interaction between union density and product market regulation, although such terms are not found to be significant.

30. The fact that the dependent variable is itself a statistical estimate adds a further source of uncertainty and the econometric procedure used to estimate equation (5) needs to take this into account (Lewis and Linzer, 2005). In particular, if the sampling errors of the variances of the estimated NAIRUs are not constant across countries, the error term $\left(w_{i t}\right)$ will be heteroscedastic. In this case, OLS estimates will not be efficient and the usual standard error estimates are potentially inconsistent. White (1980)

22. Some studies find that short-term and long-term real rates might have a somewhat higher correlation, but without establishing a causal relation (see e.g. Upper and Worms, 2003).

23. See Annex $\mathrm{C}$ for the data sources and the definitions of the variables.

24. For Japan a constant is included in the specification as it is highly significant. This constant is likely to capture the impact of the prolonged banking crisis on the labour market. In the case of Japan, none of the other explanatory variables considered is actually contributing to explain the observed upward trend in the Japanese NAIRU.

25. As a robustness check and in order to compare the results with similar studies that measure the impact of reforms on the unemployment rate the relationship is also estimated in levels.

26. A panel unit root test suggests that the PMR index and union density are $\mathrm{I}(1)$, while other variables are $\mathrm{I}(0)$. 
heteroscedastic standard errors are therefore used to correct for this. ${ }^{27}$ It appears, however, that such estimates are very close to those of the OLS regression.

31. Another concern relates to the potential endogeneity of institutions with respect to unemployment -- and therefore the NAIRU. For instance, the observed relationship between the tax wedge (or unemployment benefits) and unemployment may reflect policy actions taken to raise (cut) taxes when unemployment is high (low). To overcome the possible existence of such an endogeneity bias equation (5) was also estimated using instrumental variable (IV) techniques. Following Arellano and Bond (1991) and Blundell and Bond (1998), GMM estimates were obtained using respectively lagged levels of the explanatory variables as instruments in the equation in first differences and lagged first differences as instruments in the equation in levels. ${ }^{28}$ The validity of the associated moment conditions, that is, the absence of correlation between these instruments and the independent variable, is also tested systematically.

\subsection{Empirical results}

\section{Pooled regression results}

32. The system of equations described by equation (5) was estimated for a sample of 19 OECD economies over the period 1978 to $2002 .{ }^{29}$ The data set is unbalanced in the sense that not all years can be covered for all countries. ${ }^{30}$ In a first step, the system of equations was estimated as a standard pooled regression model with all coefficients constrained to be equal across countries. The results are reported in Table 1. The number of lags of all explanatory variables varies between one and three where insignificant lags have been dropped from the specification. ${ }^{31}$ Specification 3, which includes three lags of the explanatory variables, provides the best fit of the data and is therefore the preferred specification.

33. The tax wedge (WEDGE), the PMR indicator (PMR) and the real interest rate (IRLR) are found to have a significant influence on the NAIRU, with a rise in any of the variables being associated with a rise in the NAIRU. It is worth noting that the speed of adjustment to changes in the level of interest rates appears to be relatively long. The average unemployment benefit replacement rate $(A R R)$ and union density $(U N D)$ are also found to be significant, respectively with a lag of two/three years and for the current period. This result differs from Bassanini and Duval (2006) who have difficulties in establishing a significant relationship between union density and the unemployment rate, while obtaining a more robust impact of the replacement rate.

27. To check robustness of the estimates, seemingly unrelated regression (SUR) procedures proposed by Zellner (1962) correcting for both cross-section heterogeneity and contemporaneous correlation are also used.

28. The instruments are valid if the correlations between regressors and the independent variables are constant over time (see Arellano and Bover, 1995).

29. The countries considered are those for which updated NAIRU estimates were produced with the exceptions of Greece, Korea, Luxembourg, and New Zealand as for these countries no sufficiently long time spans of data on institutions are available.

30. For Portugal, data on tax wedge are for instance only available after 1995.

31. The maximum number of lags found to be significant is three. 
Table 1. Pooled regression results, 1976-2003

\begin{tabular}{|c|c|c|c|c|}
\hline Specification & $\Delta(1)$ & $\Delta(2)$ & $\Delta(3)$ & Level (4) \\
\hline$W E D G E_{t}$ & $\begin{array}{l}0.068^{\star \star \star} \\
(0.017)\end{array}$ & $\begin{array}{l}0.039^{\star * *} \\
(0.014)\end{array}$ & $\begin{array}{l}0.030^{\star *} \\
(0.014)\end{array}$ & $\begin{array}{l}0.212^{\star \star \star} \\
(0.031)\end{array}$ \\
\hline$W E D G E_{t-1}$ & $\begin{array}{l}0.076^{* * *} \\
(0.017)\end{array}$ & $\begin{array}{l}0.065^{\star * *} \\
(0.016)\end{array}$ & $\begin{array}{l}0.053^{* * *} \\
(0.015)\end{array}$ & \\
\hline$W E D G E_{t-2}$ & & $\begin{array}{l}0.056^{* * *} \\
(0.010)\end{array}$ & $\begin{array}{l}0.056^{* * *} \\
(0.013)\end{array}$ & \\
\hline$W E D G E_{t-3}$ & & & $\begin{array}{l}0.041^{* * *} \\
(0.014)\end{array}$ & \\
\hline$A R R_{t}$ & & & & $\begin{array}{l}0.034^{\star * *} \\
(0.011)\end{array}$ \\
\hline$A R R_{t-2}$ & & $\begin{array}{l}0.018^{* *} \\
(0.009)\end{array}$ & & \\
\hline$A R R_{t-3}$ & & & $\begin{array}{l}0.014^{*} \\
(0.008)\end{array}$ & \\
\hline$U N D_{t}$ & $\begin{array}{l}0.034^{\star *} \\
(0.016)\end{array}$ & $\begin{array}{l}0.028^{*} \\
(0.016)\end{array}$ & $\begin{array}{l}0.032^{*} \\
(0.017)\end{array}$ & $\begin{array}{l}0.051^{* * *} \\
(0.017)\end{array}$ \\
\hline$P M R_{t-1}$ & $\begin{array}{l}0.187^{\star * *} \\
(0.063)\end{array}$ & $\begin{array}{l}0.140^{*} \\
(0.080)\end{array}$ & & \\
\hline$P M R_{t-2}$ & & $\begin{array}{l}0.177^{\star *} \\
(0.080)\end{array}$ & $\begin{array}{l}0.194^{\star *} \\
(0.086)\end{array}$ & \\
\hline$P M R_{t-3}$ & & & $\begin{array}{l}0.139^{*} \\
(0.078)\end{array}$ & \\
\hline$I R L R_{t}$ & $\begin{array}{l}0.040^{* * *} \\
(0.011)\end{array}$ & $\begin{array}{l}0.037^{\star \star *} \\
(0.012)\end{array}$ & $\begin{array}{l}0.030^{\star *} \\
(0.014)\end{array}$ & $\begin{array}{l}0.266^{\star * \star} \\
(0.028)\end{array}$ \\
\hline$I R L R_{t-1}$ & $\begin{array}{l}0.051^{* * *} \\
(0.011)\end{array}$ & $\begin{array}{l}0.039^{\star * *} \\
(0.011)\end{array}$ & $\begin{array}{l}0.040^{\star * *} \\
(0.012)\end{array}$ & \\
\hline$I R L R_{t-2}$ & & $\begin{array}{l}0.054^{\star * *} \\
(0.010)\end{array}$ & $\begin{array}{l}0.049^{\star * *} \\
(0.011)\end{array}$ & \\
\hline$I R L R_{t-3}$ & & & $\begin{array}{l}0.047^{* * *} \\
(0.010)\end{array}$ & \\
\hline Country Fixed Effects & No & No & No & Yes \\
\hline & \multicolumn{4}{|c|}{ Implied total Impact } \\
\hline WEDGE & 0.144 & 0.160 & 0.179 & 0.212 \\
\hline$A R R$ & - & 0.018 & 0.014 & 0.034 \\
\hline UND & 0.034 & 0.028 & 0.032 & 0.051 \\
\hline$P M R$ & 0.187 & 0.316 & 0.334 & - \\
\hline$I R L R$ & 0.091 & 0.130 & 0.167 & 0.266 \\
\hline Observations & 474 & 452 & 432 & 434 \\
\hline Adj. R-squared & 0.18 & 0.27 & 0.32 & 0.89 \\
\hline
\end{tabular}

Notes: $\quad \Delta$ denotes the first difference operator. The equations are respectively estimated in differences (specifications (1) to (3) where the dependent variable is $\Delta \hat{U}_{t}^{*}$ ) and in levels (specification (4) where the dependent variable is $\hat{U}_{t}^{*}$ ). Country fixed effects are included in the level specification. Germany, Sweden and Finland are withdrawn from the sample for the level specification as there is a break in the level series. In the upper part of the table, the numbers in parentheses are the standard errors of the coefficients obtained using the White (1980) correction. *, ${ }^{* *}$ and ${ }^{* * *}$ denote significance at the $10 \%$, $5 \%$ and $1 \%$ levels, respectively. The total impact of a given variable is calculated as the sum of the coefficients on all lags (significant at least at the $10 \%$ level) of this variable. 


\section{Checking the robustness of the results to alternative model specifications}

34. To check the robustness of the results to alternative model specifications, several variants of equation (5) are estimated. Firstly, the equation was estimated with time dummies to capture the impact of common shocks; secondly, it was estimated with instrumental variables to account for the possible endogeneity of institutions and policies; and thirdly, it was estimated including the ratio of gross statutory minimum wages to median wages as an additional explanatory variable to check whether this the minimum wage was an important omitted variable in the original model.

35. When estimating equation (5) with time dummies, the results are broadly similar to those discussed above (Table B3 in Annex B), with the tax wedge, the average unemployment benefit replacement rate, union density and the real interest rate positively affecting the NAIRU. The PMR indicator, however, becomes statistically insignificant. Overall, the magnitudes of the estimated impacts are somewhat lower than in the specifications without time dummies, in particular for real interest rates. This latter result is not surprising, given that most countries under study faced similar interest rate shocks over the sample period. Similarly, the implementation of product market reforms proceeded similarly across most of the countries in the 1990s which could explain the insignificance of the PMR indicator when time dummies are included. Finally, it is interesting to note that time dummies are mostly positive in the 1980s and negative in the 1990s (and respectively significant from 1982 to 1985 and 1995 to 2000).

36. As mentioned above, the endogeneity of institutions and policies is a potentially important factor to take into account. This applies in particular to the level of the tax wedge, the average replacement rate and the user cost of capital. It is, on the other hand, unlikely that union density and product market regulations are driven by the evolution of structural unemployment rates, so that the risk of reverse causality for these variables appears to be limited. Although finding good instruments is a difficult task, GMM estimates were produced for two different specifications: first, lagged levels of dependent variables were used as instruments for estimating equation (5) in differences (see Arellano and Bond, 1991) and second, lagged differences of explanatory variables were used as instruments for estimating the equation in levels (following Arellano and Bover, 1995). The specifications in first differences are preferred as the moment conditions are more likely to be valid in that case. Looking at the data shows that lagged levels of the explanatory variables are indeed not correlated with the changes in the NAIRUs. The corresponding results are reported in Table B4 in Annex B, assuming initially that only changes in real interest rates, the level of the tax wedge and the replacement rates are endogenous. A notable result is that the coefficients on real interest rates remain highly significant in both the specifications in first differences and the specification in levels. Moreover, the elasticities obtained for real interest rates in specifications 1 to 4 are similar to those presented in Table 1. This suggests that the endogeneity bias is limited for this variable. The tax wedge and union density also come out as significant, although here the results are somewhat less robust as they depend on the inclusion of country fixed effects.

37. The possibility that omitted variables could also play a substantial role in driving the NAIRU in one direction or the other is not to be excluded. In particular, the role of the minimum wage needs to be investigated more carefully for some countries. This is done by augmenting the system of equations by the change in the ratio of gross statutory minimum wages to median wages $(M I N W)$. As not all countries have a statuary minimum wage, only the equations of those countries that had one during the whole sample period are modified. ${ }^{32}$ To allow for a time lag of the impact of changes in the minimum wage on the NAIRU the maximum number of lags is set equal to two. Consistent with previous work (Elmeskov et al.,

32. These are Australia, Belgium, Canada, France, Japan, the Netherlands, Portugal, Spain and the United States. Although Ireland and the United Kingdom introduced a national minimum wage in 1999 the equations of the two countries are not augmented by the minimum wage rate as the corresponding time series are too short. 
1998; Bassanini and Duval, 2006) no significant direct impact of the minimum wage on the NAIRU is found. The hypothesis that the coefficients on all lags are equal to zero cannot be rejected at conventional significance levels for any of the nine countries considered (see Table 2).

Table 2. The role of minimum wages

\begin{tabular}{l|cc}
\hline \hline & $\Delta M I N W$ & $\Delta($ WEDGE $\cdot$ MINW $)$ \\
\hline Australia & 0.30 & 0.09 \\
Belgium & 0.87 & 0.96 \\
Canada & 0.90 & 0.99 \\
Spain & 0.46 & 0.11 \\
France & 0.87 & 0.36 \\
Portugal & 0.99 & 0.91 \\
Japan & 0.92 & 0.99 \\
Netherlands & 0.83 & 0.24 \\
United States & 0.99 & 0.76 \\
\hline ALL & 0.99 & 0.65 \\
\hline \hline
\end{tabular}

Notes: $\quad$ The first (second) column shows the $p$-values of Wald tests that the coefficients on the changes in the minimum wage (the product of the minimum wage and the tax wedge) are equal to zero for all lags. The underlying equation systems are $\Delta \hat{U}_{i t}^{*}=\sum_{j} \sum_{k} \alpha_{i j k} \Delta \Omega_{i j t-k}+\sum_{k=0}^{2} \beta_{i k} \Delta M I N W_{i t-k}+w_{i t}$ and $\Delta \hat{U}_{i t}^{*}=\sum_{j} \sum_{k} \alpha_{i j k} \Delta \Omega_{i j t-k}$ $+\sum_{k=0}^{2} \beta_{i k} \Delta M I N W_{i t-k}+\sum_{k=0}^{2} \gamma_{i k} \Delta\left(W E D G E_{i t-k} \cdot M I N W_{i t-k}\right)+w_{i t}$.

38. As high tax wedges are often argued to have more adverse effects on unemployment when the minimum wage is high, the system of equations is augmented further by including an interaction term between the tax wedge and the statutory minimum wage. The hypothesis that the coefficients on all lags of the interaction term are equal to zero cannot be rejected for any country (see Table 2) thus not lending strong support to the hypothesis that minimum wages raise the elasticity of the unemployment rate to the tax wedge.

\section{Allowing for cross-country heterogeneity}

39. The results reported in Table 1 identify the level of the tax wedge, real interest rates and union density as key drivers of the NAIRU. In addition, the results indicate that the NAIRU is influenced by other policy variables such as the level of product market regulations. These estimates assume, however, that the size of the impact of all institutional variables is identical across countries, with the same lag structure. Wald tests indicate that such an assumption is not supported by the data. To allow for crosscountry heterogeneity, equation (5) was also estimated as a system of 19 equations, one for each country, with cross-country restrictions imposed on the coefficients where accepted by the data. The system of equation was estimated in first differences using SUR methodology. This leads to the final specification reported in Table 3. 
Table 3. Panel regression results, 1976-2003, with cross-country heterogeneity

ECO/WKP(2008)57

\begin{tabular}{|c|c|c|c|c|c|c|c|c|c|c|c|c|c|c|c|}
\hline & $\Delta W E D G E_{t}$ & $\Delta W E D G E_{t-1}$ & $\Delta W E D G E_{t-2}$ & $\Delta A R R_{t}$ & $\Delta A R R_{t-1}$ & $\Delta A R R_{t-2}$ & $\Delta U N D_{t}$ & $\Delta U N D_{t-1}$ & $\Delta U N D_{t-2}$ & $\Delta P M R_{t}$ & $\Delta P M R_{t-1}$ & $\Delta P M R_{t-2}$ & $\Delta I R L R_{t}$ & $\Delta I R L R_{t-1}$ & $\Delta I R L R_{t-2}$ \\
\hline$\overline{\text { AUS }}$ & & & & $\begin{array}{c}0.036 \\
(0.000)\end{array}$ & $\begin{array}{c}0.022 \\
(0.004)\end{array}$ & $\begin{array}{l}0.058 \\
(0.000)\end{array}$ & & $\begin{array}{c}0.036 \\
(0.000)\end{array}$ & & & & $\begin{array}{l}0.455 \\
(0.000)\end{array}$ & & $\begin{array}{c}0.024 \\
(0.000)\end{array}$ & $\begin{array}{c}0.063 \\
(0.000)\end{array}$ \\
\hline AUT & $\begin{array}{c}0.092 \\
(0.000)\end{array}$ & $\begin{array}{l}0.046 \\
(0.000)\end{array}$ & $\begin{array}{c}0.051 \\
(0.000)\end{array}$ & & & & & & & & & & & $\begin{array}{l}0.024 \\
(0.000)\end{array}$ & $\begin{array}{l}0.063 \\
(0.000)\end{array}$ \\
\hline BEL & $\begin{array}{c}0.092 \\
(0.000)\end{array}$ & $\begin{array}{c}0.097 \\
(0.000)\end{array}$ & $\begin{array}{c}0.051 \\
(0.000)\end{array}$ & & & & & $\begin{array}{c}0.036 \\
(0.000)\end{array}$ & $\begin{array}{c}0.041 \\
(0.000)\end{array}$ & & & & $\begin{array}{c}0.042 \\
(0.000)\end{array}$ & $\begin{array}{c}0.024 \\
(0.000)\end{array}$ & $\begin{array}{c}0.063 \\
(0.000)\end{array}$ \\
\hline CAN & & $\begin{array}{l}0.046 \\
(0.000)\end{array}$ & $\begin{array}{c}0.127 \\
(0.000)\end{array}$ & $\begin{array}{c}0.036 \\
(0.000)\end{array}$ & & & & $\begin{array}{l}0.036 \\
(0.000)\end{array}$ & $\begin{array}{l}0.041 \\
(0.000)\end{array}$ & $\begin{array}{l}0.207 \\
(0.010)\end{array}$ & $\begin{array}{c}0.394 \\
(0.000)\end{array}$ & & $\begin{array}{l}0.042 \\
(0.000)\end{array}$ & $\begin{array}{c}0.024 \\
(0.000)\end{array}$ & $\begin{array}{l}0.063 \\
(0.000)\end{array}$ \\
\hline DEU & $\begin{array}{c}0.092 \\
(0.000)\end{array}$ & & $\begin{array}{c}0.051 \\
(0.000)\end{array}$ & & & $\begin{array}{l}0.058 \\
(0.000)\end{array}$ & & & & & & & $\begin{array}{c}0.042 \\
(0.000)\end{array}$ & $\begin{array}{c}0.066 \\
(0.000)\end{array}$ & $\begin{array}{c}0.117 \\
(0.000)\end{array}$ \\
\hline DNK & & & & & & & $\begin{array}{l}0.041 \\
(0.001)\end{array}$ & $\begin{array}{c}0.036 \\
(0.000)\end{array}$ & & $\begin{array}{l}0.207 \\
(0.010)\end{array}$ & $\begin{array}{c}0.394 \\
(0.000)\end{array}$ & & & $\begin{array}{c}0.024 \\
(0.000)\end{array}$ & $\begin{array}{c}0.021 \\
(0.011)\end{array}$ \\
\hline ESP & $\begin{array}{c}0.092 \\
(0.000)\end{array}$ & $\begin{array}{c}0.173 \\
(0.000)\end{array}$ & $\begin{array}{c}0.127 \\
(0.000)\end{array}$ & $\begin{array}{c}0.036 \\
(0.000)\end{array}$ & $\begin{array}{c}0.022 \\
(0.004)\end{array}$ & $\begin{array}{c}0.058 \\
(0.000)\end{array}$ & $\begin{array}{c}0.041 \\
(0.001)\end{array}$ & $\begin{array}{l}0.036 \\
(0.000)\end{array}$ & & $\begin{array}{c}0.207 \\
(0.010)\end{array}$ & $\begin{array}{c}0.394 \\
(0.000)\end{array}$ & $\begin{array}{c}0.455 \\
(0.000)\end{array}$ & & $\begin{array}{c}0.024 \\
(0.000)\end{array}$ & $\begin{array}{c}0.021 \\
(0.011)\end{array}$ \\
\hline FIN & & $\begin{array}{c}0.046 \\
(0.000)\end{array}$ & $\begin{array}{l}0.127 \\
(0.000)\end{array}$ & & $\begin{array}{l}0.022 \\
(0.004)\end{array}$ & $\begin{array}{l}0.058 \\
(0.000)\end{array}$ & $\begin{array}{c}0.181 \\
(0.000)\end{array}$ & $\begin{array}{c}0.036 \\
(0.000)\end{array}$ & $\begin{array}{c}0.041 \\
(0.000)\end{array}$ & $\begin{array}{l}0.207 \\
(0.010)\end{array}$ & $\begin{array}{c}0.394 \\
(0.000)\end{array}$ & $\begin{array}{l}0.455 \\
(0.000)\end{array}$ & & & $\begin{array}{c}0.021 \\
(0.011)\end{array}$ \\
\hline FRA & $\begin{array}{c}0.170 \\
(0.005)\end{array}$ & $\begin{array}{c}0.097 \\
(0.000)\end{array}$ & $\begin{array}{l}0.127 \\
(0.000)\end{array}$ & & $\begin{array}{c}0.022 \\
(0.004)\end{array}$ & $\begin{array}{c}0.058 \\
(0.000)\end{array}$ & & & & & & $\begin{array}{l}0.455 \\
(0.000)\end{array}$ & & $\begin{array}{c}0.024 \\
(0.000)\end{array}$ & $\begin{array}{l}0.021 \\
(0.011)\end{array}$ \\
\hline IRL & & $\begin{array}{c}0.173 \\
(0.000)\end{array}$ & $\begin{array}{c}0.051 \\
(0.000)\end{array}$ & $\begin{array}{c}0.036 \\
(0.000)\end{array}$ & & & $\begin{array}{c}0.181 \\
(0.000)\end{array}$ & $\begin{array}{l}0.036 \\
(0.000)\end{array}$ & $\begin{array}{c}0.041 \\
(0.000)\end{array}$ & & & $\begin{array}{l}0.455 \\
(0.000)\end{array}$ & $\begin{array}{l}0.096 \\
(0.000)\end{array}$ & $\begin{array}{l}0.066 \\
(0.000)\end{array}$ & $\begin{array}{l}0.063 \\
(0.000)\end{array}$ \\
\hline ITA & & $\begin{array}{c}0.046 \\
(0.000)\end{array}$ & $\begin{array}{c}0.051 \\
(0.000)\end{array}$ & & $\begin{array}{c}0.022 \\
(0.004)\end{array}$ & & & & & $\begin{array}{l}0.207 \\
(0.010)\end{array}$ & $\begin{array}{c}0.394 \\
(0.000)\end{array}$ & & & $\begin{array}{c}0.024 \\
(0.000)\end{array}$ & $\begin{array}{c}0.021 \\
(0.011)\end{array}$ \\
\hline PRT & & & & & & & & $\begin{array}{l}0.036 \\
(0.000)\end{array}$ & & & & & & & \\
\hline JPN & & & & & $\begin{array}{c}0.022 \\
(0.004)\end{array}$ & & $\begin{array}{l}0.041 \\
(0.001)\end{array}$ & $\begin{array}{c}0.036 \\
(0.000)\end{array}$ & $\begin{array}{c}0.041 \\
(0.000)\end{array}$ & & $\begin{array}{c}0.394 \\
(0.000)\end{array}$ & $\begin{array}{c}0.455 \\
(0.000)\end{array}$ & & & \\
\hline NLD & $\begin{array}{c}0.092 \\
(0.000)\end{array}$ & $\begin{array}{c}0.097 \\
(0.000)\end{array}$ & $\begin{array}{c}0.051 \\
(0.000)\end{array}$ & $\begin{array}{c}0.036 \\
(0.000)\end{array}$ & & & & & & $\begin{array}{l}0.207 \\
(0.010)\end{array}$ & & & $\begin{array}{c}0.042 \\
(0.000)\end{array}$ & $\begin{array}{c}0.024 \\
(0.000)\end{array}$ & $\begin{array}{c}0.063 \\
(0.000)\end{array}$ \\
\hline NOR & & & $\begin{array}{l}0.051 \\
(0.000)\end{array}$ & & & & $\begin{array}{c}0.041 \\
(0.001)\end{array}$ & $\begin{array}{c}0.036 \\
(0.000)\end{array}$ & $\begin{array}{c}0.041 \\
(0.000)\end{array}$ & & & & & & $\begin{array}{c}0.021 \\
(0.011)\end{array}$ \\
\hline $\mathrm{CHE}$ & & & & $\begin{array}{c}0.036 \\
(0.000)\end{array}$ & & & & & & & & & & & $\begin{array}{c}0.021 \\
(0.011)\end{array}$ \\
\hline SWE & & $\begin{array}{c}0.046 \\
(0.000)\end{array}$ & $\begin{array}{c}0.051 \\
(0.000)\end{array}$ & $\begin{array}{c}0.036 \\
(0.000)\end{array}$ & $\begin{array}{l}0.022 \\
(0.004)\end{array}$ & & & & & $\begin{array}{c}0.207 \\
(0.010)\end{array}$ & & & & & $\begin{array}{c}0.021 \\
(0.011)\end{array}$ \\
\hline GBR & $\begin{array}{c}0.092 \\
(0.000)\end{array}$ & $\begin{array}{c}0.097 \\
(0.000)\end{array}$ & & $\begin{array}{c}0.036 \\
(0.000)\end{array}$ & $\begin{array}{c}0.022 \\
(0.004)\end{array}$ & $\begin{array}{l}0.058 \\
(0.000)\end{array}$ & & & & & $\begin{array}{c}0.394 \\
(0.000)\end{array}$ & $\begin{array}{c}0.455 \\
(0.000)\end{array}$ & $\begin{array}{l}0.096 \\
(0.000)\end{array}$ & $\begin{array}{c}0.066 \\
(0.000)\end{array}$ & $\begin{array}{c}0.021 \\
(0.011)\end{array}$ \\
\hline USA & & & $\begin{array}{l}0.051 \\
(0.000)\end{array}$ & & $\begin{array}{c}0.022 \\
(0.004)\end{array}$ & & & & $\begin{array}{c}0.041 \\
(0.000)\end{array}$ & & $\begin{array}{c}0.394 \\
(0.000)\end{array}$ & & $\begin{array}{l}0.042 \\
(0.000)\end{array}$ & $\begin{array}{c}0.024 \\
(0.000)\end{array}$ & $\begin{array}{c}0.021 \\
(0.011)\end{array}$ \\
\hline
\end{tabular}

Notes: The dependent variable is $\Delta \hat{U}_{t}^{*}$. The numbers in parentheses are the $\mathrm{p}$-values of exclusion restrictions on the coefficients. 
40. For this less restricted specification, the tax wedge, the average unemployment benefit replacement rate and the PMR indicator are found to have a significant impact on the NAIRU in 14 out of 19 countries, whilst union density comes out as significant in only 11 countries. The long-term real interest rate which is supposed to capture the cost of capital is found to have a significant impact on the NAIRU in all countries but Japan and Portugal. In general, it is worth noting that when cross-country heterogeneity is allowed in the estimation, the elasticities of the NAIRU with respect to structural variables vary quite substantially across certain groups of countries (see Table 3 ).

41. For several countries (Germany, Norway, Denmark, Japan, and Portugal) the relation between the NAIRU and the selected institutional variables is difficult to establish. In the case of Germany, the estimated equation is likely to be affected by the quality of the data and the break in the series in the early 1990s whilst in the case of Portugal the results might be affected by the absence of the tax wedge variable and the relatively small sample period. For Japan and the Norway, the absence of robust results might be due to the omission of financial variables that would capture the effects of higher risk premia and the severe banking crisis that hit these countries. In the case of Japan, the fact that Phillips curve estimates generally give poor results might also play a role.

42. Notwithstanding the above country differences, the magnitudes of the long-run coefficients are broadly of the same order of magnitude as those obtained by Bassanini and Duval (2006) and Blanchard and Wolfers (2000) for the reaction of the unemployment rate to changes in institutional variables. For example, the point estimates obtained with the preferred specification in Table 3 imply that responses to a 1 percentage point cut in the tax wedge is associated with a decline in the NAIRU in the range 0.05 to 0.39 percentage points. A 1 percentage point reduction in unemployment benefits would lead to reduction in the NAIRU in the range 0.02 to 0.12 percentage points, slightly weaker on average than the effect obtained by Bassanini and Duval (2006). ${ }^{33}$ Product market reforms have also the potential to improve substantially the functioning of the labour market: a drop in the PMR indicator by two standard deviations $\mathrm{s}^{34}$ is found to be associated with a reduction in the structural unemployment rate in the range 0.6 to $1.4 \%$. Finally, a 1 percentage point decline in the cost of capital is associated with a decrease in the NAIRU in the range by around $0.02-0.18$.

\subsection{How well do the institutional variables explain changes in the NAIRU?}

43. To assess the usefulness of the set of structural variables for explaining the NAIRU the actual changes in the NAIRUs are compared to the fitted values obtained from three selected specification: specification (3) in Table 1 (pooled regression without time dummies), specification (4) in Table B3 (pooled regression with time dummies) and the system estimates in Table 3.

44. A first visual inspection suggests that the dynamics of the NAIRUs are relatively well explained by the set of structural variables (Figure B1). Notable exceptions are Germany, Denmark and to a lesser extent Norway, which is not very surprising given the weak explanatory power of institutional variables obtained in equation(5), as already mentioned above: Denmark and Norway have, for example, experienced respectively large increases in the tax wedge and the replacement rate in the 1980s, but these

33. For comparison, Bassanini and Duval found the following elasticities: on average, a 1 percentage point reduction in the tax wedge, a 1 percentage point reduction of unemployment benefits and/or a decline in product market regulation by two standard deviations would be associated with a drop in the unemployment rate by about $0.28,0.12$ and 0.7 percentage points, respectively.

34. The PMR indicator covers regulations and market conditions in seven non-manufacturing industries (see Annex A) and ranges from 0 to 6 with a higher value indicating more severe restrictions (see Conway et al., 2006, for details). Its average value across countries was equal to 2.4 in 2002 and its standard deviation was equal to 0.7 . 
variables are, rather counter-intuitively, not found to play a significant role in driving the NAIRU. In the case of Japan, the increase in the NAIRU is essentially captured by the constant and only marginally explained by changes in the policy variables considered. The estimated equations tend to provide a better fit of the data during phases where the NAIRU is declining rather than rising. This good fit during phases of rising NAIRUs is particularly striking for Denmark and Norway, but also applies to countries where the structural unemployment rate was increasing monotonically such as Austria, Belgium and Switzerland.

45. This asymmetry ${ }^{35}$ in predictive capacity is investigated further by looking systematically at the predictive capacity of equation (5) for two sub-periods: periods of increasing NAIRUs and periods of decreasing NAIRUs (see Tables $4 \mathrm{a}$ and $4 \mathrm{~b}$ ). Both the elasticities of the pooled regression reported in Table 1 [specification (3)] and those obtained when allowing for cross-country heterogeneity (Table 3) are used for the comparison, with the latter specification being the preferred one. First, it is worth noting that the direction of change in the NAIRU is well predicted for all periods considered. Exceptions are Japan and Denmark when using country-varying coefficients and Germany when using the coefficients of the pooled regression. When these problematic countries are excluded, it appears that on average equation (5) explains more than half of the upward movements in NAIRUs and approximately three quarters of the downward movements (which essentially occurred over the most recent period).

46. Tables $4 \mathrm{a}$ and $4 \mathrm{~b}$ also report the individual contributions of each institutional/policy variable on the change in the NAIRU. ${ }^{36}$ Although the impact of the tax wedge is found to vary considerably across countries, reflecting divergent developments in this variable over time, this variable appears to account for a large part of the observed increase in NAIRUs. This applies in particular to Austria, Canada, Spain, Finland, France, Ireland, Italy, the Netherlands and Sweden. Symmetrically, a drop in the tax wedge over the most recent period contributed to a significant decline in the NAIRU of Finland, France, Ireland, the Netherlands and the United Kingdom.

47. The contribution of unemployment benefits is also found to vary markedly across countries, again reflecting divergent labour market policies. It is estimated to have pushed up the level of the NAIRU substantially in the 1980s and early 1990s in Spain, Finland, France, Switzerland, France, and, to a lesser extent, in Australia, Italy and the Netherlands. For Ireland, Italy, France and Spain unemployment benefits became also more generous over the period 1993 to 2003, whereas substantial cuts in the average replacement rate over the period 1993 to 2003 are estimated to have brought down the level of the NAIRU in Australia, Canada, Finland, Sweden and the United Kingdom. Although benefits were also reduced in several other countries, most notably Denmark, no significant impact on the NAIRU was found in these cases.

35. This relative difficulty to identify the roots behind the rises in NAIRU is well documented in the literature (and discussed e.g. in Blanchard and Wolfers, 2000).

36. As the calculations account for time lags in the impact of institutional variables on the NAIRU, changes in the NAIRU that occurred for example over the period 1995 to 2003 are driven by changes in the institutional variables over the period 1993 to 2003. 
Table 4a. Impact of institutions on NAIRUs during periods of increasing NAIRUs

In per cent

\begin{tabular}{|c|c|c|c|c|c|c|c|c|c|c|}
\hline & \multicolumn{8}{|c|}{ Implied impact on the NAIRU } & \multirow{4}{*}{$\begin{array}{l}\text { Actual } \\
\text { change in } \\
\text { the NAIRU }\end{array}$} & \multirow{4}{*}{ Period } \\
\hline & \multirow{2}{*}{\multicolumn{6}{|c|}{ Panel regression with cross-country heterogeneity }} & \multicolumn{2}{|c|}{ Pooled regression } & & \\
\hline & & & & & & & \multirow{2}{*}{$\begin{array}{c}\begin{array}{c}\text { Without time } \\
\text { dummies }^{1}\end{array} \\
\text { TOTAL }\end{array}$} & \multirow{2}{*}{$\begin{array}{c}\begin{array}{c}\text { With time } \\
\text { dummies }^{2}\end{array} \\
\text { TOTAL }\end{array}$} & & \\
\hline & WEDGE & ARR & PMR & UND & IRLR & TOTAL & & & & \\
\hline AUS & 0.00 & 0.34 & -0.15 & -0.35 & 0.89 & 0.73 & 1.26 & 0.65 & 3.06 & 1978-1993 \\
\hline AUT & 1.46 & 0.00 & 0.00 & 0.00 & 0.17 & 1.62 & 0.40 & 0.68 & 4.13 & $1978-2003$ \\
\hline BEL & 0.35 & 0.00 & 0.00 & 0.13 & 0.68 & 1.15 & 1.04 & 0.78 & 2.62 & 1978-1994 \\
\hline CAN & 0.78 & 0.01 & -1.05 & -0.14 & 0.51 & 0.12 & 0.97 & 0.95 & 1.77 & 1978-1993 \\
\hline $\mathrm{DEU}^{3}$ & 0.02 & -0.09 & 0.00 & 0.00 & 0.55 & 0.48 & 0.36 & 0.21 & 3.10 & $1978-1990$ \\
\hline $\mathrm{DEU}^{3}$ & -0.10 & -0.01 & 0.00 & 0.00 & 0.11 & 0.00 & -0.91 & -0.20 & 0.96 & $1995-2003$ \\
\hline DNK & 0.00 & 0.00 & -0.53 & -0.02 & 0.06 & -0.49 & 1.03 & 1.01 & 2.52 & 1978-1992 \\
\hline ESP & 3.66 & 1.32 & -0.33 & 0.43 & 0.70 & 5.79 & 4.29 & 3.13 & 8.21 & 1980-1991 \\
\hline $\mathrm{FIN}^{3}$ & 1.02 & 0.58 & -0.74 & 1.40 & 0.25 & 2.50 & 2.66 & 2.02 & 3.03 & $1978-1990$ \\
\hline FRA & 2.34 & 1.00 & -0.52 & 0.00 & 0.28 & 3.10 & 1.60 & 1.24 & 5.00 & 1978-1995 \\
\hline $\mathrm{IRL}$ & 2.08 & 0.08 & 0.00 & -1.62 & 1.92 & 2.46 & 2.82 & 1.87 & 4.10 & 1978-1987 \\
\hline ITA & 1.17 & 0.36 & -0.42 & 0.00 & 0.47 & 1.58 & 3.60 & 2.36 & 3.93 & 1978-1995 \\
\hline $\mathrm{PRT}^{4}$ & - & 0.00 & 0.00 & 0.00 & 0.00 & 0.00 & -0.34 & 0.16 & 0.44 & 1999-2003 \\
\hline JPN & 0.00 & 0.00 & -2.32 & -1.52 & 0.00 & -3.84 & 0.81 & 0.97 & 2.31 & 1978-2003 \\
\hline NLD & 0.80 & 0.29 & 0.00 & 0.00 & 0.76 & 1.84 & 1.28 & 0.70 & 3.47 & $1978-1988$ \\
\hline NOR & 0.04 & 0.00 & 0.00 & 0.54 & 0.18 & 0.75 & 1.52 & 1.59 & 2.97 & 1978-1993 \\
\hline $\mathrm{CHE}$ & 0.00 & 0.83 & 0.00 & 0.00 & 0.07 & 0.90 & 0.81 & 0.94 & 3.13 & 1978-2003 \\
\hline$S W E^{3}$ & 0.69 & 0.28 & -0.04 & 0.00 & 0.16 & 1.10 & 2.69 & 1.96 & 1.26 & $1978-1990$ \\
\hline GBR & 0.28 & -0.33 & -0.30 & 0.00 & 1.70 & 1.36 & 1.28 & 0.80 & 3.77 & 1978-1985 \\
\hline USA & 0.15 & -0.04 & -0.39 & -0.06 & 0.45 & 0.13 & 0.79 & 0.69 & 0.31 & 1978-1984 \\
\hline
\end{tabular}

1. Specification (3) in Table 1.

2. Specification (4) in Table B3.

3. There are breaks in the series for Germany, Finland and Sweden.

4. For Portugal, the tax wedge is excluded from the estimation as it is available only since 1995. 
Table 4b. Impact of institutions on NAIRUs during periods of decreasing NAIRUs

In per cent

\begin{tabular}{|c|c|c|c|c|c|c|c|c|c|c|}
\hline & \multicolumn{8}{|c|}{ Implied impact on the NAIRU } & \multirow{4}{*}{$\begin{array}{c}\text { Actual } \\
\text { change in } \\
\text { the NAIRU }\end{array}$} & \multirow{4}{*}{ Period } \\
\hline & \multirow{2}{*}{\multicolumn{6}{|c|}{ Panel regression with cross-country heterogeneity }} & \multicolumn{2}{|c|}{ Pooled regression } & & \\
\hline & & & & & & & \multirow{2}{*}{$\begin{array}{c}\begin{array}{c}\text { Without time } \\
\text { dummies }^{1}\end{array} \\
\text { TOTAL }\end{array}$} & \multirow{2}{*}{$\begin{array}{c}\begin{array}{c}\text { With time } \\
\text { dummies }^{2}\end{array} \\
\text { TOTAL }\end{array}$} & & \\
\hline & WEDGE & ARR & PMR & UND & IRLR & TOTAL & & & & \\
\hline $\begin{array}{l}\text { AUS } \\
\text { AUT }\end{array}$ & 0.00 & -0.38 & -0.88 & -0.53 & -0.28 & -2.08 & -0.97 & -0.32 & -2.51 & 1994-2003 \\
\hline BEL & -0.02 & 0.00 & 0.00 & 0.07 & -0.15 & -0.09 & -0.95 & -0.21 & -0.19 & $1995-2003$ \\
\hline $\begin{array}{l}\text { CAN } \\
\mathrm{DEU}^{3}\end{array}$ & 0.06 & -0.15 & -0.43 & -0.37 & -0.37 & -1.26 & -0.84 & -0.50 & -1.98 & 1994-2003 \\
\hline DNK & 0.00 & 0.00 & -1.46 & -0.18 & -0.16 & -1.80 & -0.58 & 0.24 & -2.37 & $1993-2003$ \\
\hline ESP & 0.31 & 0.27 & -2.53 & -0.14 & -0.24 & -2.34 & -1.53 & -0.50 & -3.81 & $1992-2003$ \\
\hline $\mathrm{FIN}^{3}$ & -0.05 & -0.25 & -1.35 & -0.33 & -0.09 & -2.07 & -1.46 & -0.55 & -4.70 & $1995-2003$ \\
\hline FRA & -0.57 & 0.43 & -0.51 & 0.00 & -0.11 & -0.75 & -0.84 & -0.29 & -1.28 & 1996-2003 \\
\hline $\mathrm{IRL}$ & -0.58 & 0.35 & -0.88 & -3.69 & -1.29 & -6.09 & -2.32 & -1.18 & -10.15 & $1988-2003$ \\
\hline ITA & 0.15 & 0.32 & -1.38 & 0.00 & -0.21 & -1.13 & -0.92 & 0.01 & -1.74 & 1996-2003 \\
\hline $\begin{array}{l}\mathrm{PRT}^{4} \\
\mathrm{JPN}\end{array}$ & - & 0.00 & 0.00 & -1.30 & 0.00 & -1.30 & -0.03 & -0.06 & -1.29 & $1980-2001$ \\
\hline NLD & -2.01 & -0.11 & -0.82 & 0.00 & -0.69 & -3.63 & -3.54 & -1.65 & -3.14 & $1989-2003$ \\
\hline $\begin{array}{l}\text { NOR } \\
\text { CHE }\end{array}$ & 0.15 & 0.00 & 0.00 & -0.46 & -0.20 & -0.51 & -1.08 & -0.36 & -0.86 & $1994-2003$ \\
\hline $\operatorname{SWE}^{3}$ & 0.03 & -0.15 & -0.12 & 0.00 & -0.08 & -0.33 & -0.77 & -0.32 & -0.15 & 1997-2003 \\
\hline \multirow{2}{*}{$\begin{array}{l}\text { GBR } \\
\text { USA }\end{array}$} & -0.36 & -0.48 & -2.72 & 0.00 & -0.60 & -4.17 & -2.20 & -0.98 & -4.58 & 1986-2003 \\
\hline & 0.15 & -0.01 & -0.46 & -0.27 & -0.37 & -0.96 & -0.74 & -0.21 & -1.32 & $1985-2003$ \\
\hline
\end{tabular}

1. Specification (3) in Table 1.

2. Specification (4) in Table B3.

3. There are breaks in the series for Germany, Finland and Sweden.

4. For Portugal, the tax wedge is excluded from the estimation as it is available only since 1995. 
48. Product market regulations were continuously eased in all countries between 1978 and 2003, thereby contributing to a decline in the NAIRU in each sub-period considered. The impact was found to be the highest in the United Kingdom, Spain, Japan, Finland and Denmark, reflecting a combination of both high elasticities and large falls in the PMR indices in all five countries. A sizeable effect of product market reform is also found for Australia, France, Italy and Canada. Union density also declined in all countries, but Belgium and -- only in the 1980s -- Norway. Despite the relatively low elasticity the impact on the NAIRU is found to have been quite sizeable in many countries (generally between $1 / 4$ and $1 / 2$ percentage point) due to the sharp drop in union density. The effect is estimated to be particularly strong for Ireland where a fall in union density of more than 15 percentage points between 1988 and 2003 was associated with a decline in the NAIRU of around 4 percentage points over that period.

49. Finally, the user cost of capital is found to perform quite well in explaining the observed changes in the NAIRU. The estimated model suggests indeed that higher real interest rates were a key driver of the surge in structural unemployment rate in the 1980s (until the early 1990s for some countries). The effect is found to be close to or above 1 percentage point for the United Kingdom, Ireland, Austria, Belgium, Spain, Ireland, the Netherlands and Italy. Symmetrically, the steady decline in real interest rates over the most recent period is found have contributed significantly to the decline in the estimated NAIRUs for most of the countries in the sample. Notable exceptions are Japan and Norway -- two countries hit by a banking crisis and for which interest rate elasticities are either not significant or relatively low, but where credit constraints and changes in risk premia are likely to have been substantial.

50. Overall, although the set of structural variables performs quite well in explaining changes in the NAIRU, the asymmetry in predictive ability suggests that potentially important contributors might have been omitted. In particular, this work could be possibly extended by trying to introduce demographic variables, the taxation of capital and, above all, variables capturing financial sector and risk premia developments, which are likely to help explaining, for instance, the sharp increase of the NAIRUs of Japan and the Nordic countries during the 1990s. 


\section{REFERENCES}

Anshley, C. and R. Kohn (1986), "Prediction Mean Squared Error for State Space Models with Estimated Parameters", Biometrika, Vol. 73, pp. 467-473.

Arellano, M. and S. Bond (1991), "Some Tests of Specification for Panel Data: Monte Carlo Evidence and an Application to Employment Equation", Review of Economic Studies No. 58, pp. 227-297.

Arellano, M. and O. Bover (1995), "Another Look at the Instrumental-Variable Estimation of ErrorComponents Models", Journal of Econometrics, Vol. 68, pp. 29-51.

Baker, D., A. Glyn, D. Howell and J. Schmitt (2004), "Labour Market Institutions and Unemployment: A Critical Assessment of the Cross-Country Evidence", in D. Howell (ed.), Fighting Unemployment: The Limits of Free Market Orthodoxy, Oxford, Oxford University Press.

Bassanini, A. and R. Duval (2006), "Employment Patterns in OECD Countries: Reassessing the Role of Policies and Institutions", OECD Economics Department Working Paper No. 486.

Barro, R.J. and X. Sala-i-Martin (1990), "World Real Interest Rates", NBER Working Paper No. 3317.

Batini, N. and J.V. Greenslade (2005), "Measuring the UK Short-Run NAIRU", Oxford Economic Papers, Vol. 58, pp. 28-49.

Beffy, P.O., P. Ollivaud, P. Richardson and F. Sedillot (2006), "New OECD Methods for Supply-Side and Medium Term Assessments: A Capital Services Approach", OECD Economics Department Working Paper No. 482.

Belot, M. and J. Van Ours (2004), "Does the Recent Success of Some OECD Countries in Lowering their Unemployment Rates Lie in the Clever Design of their Labour Market Reform?", Oxford Economic Papers, Vol. 56, pp. 621-642.

Bertola, G., F. Blau and L. Kahn (2002a), "Comparative Analysis of Labor Market Outcomes: Lessons for the US from International Long-Run Evidence", in A.B. Krueger and R. Solow, The Roaring Nineties: Can Full Employment Be Sustained?, New York, Russell Sage Foundation.

Blanchard, O. and J. Wolfers (2000), "The Role of Shocks and Institutions in the Rise of European Unemployment: The Aggregate Evidence", Economic Journal, Vol. 110, pp. C1-C33.

Blundell, R. and S. Bond (1998), "Initial Conditions and Moment Restrictions in Dynamic Panel Data Models", Journal of Econometrics, Vol. 87, pp. 115-143.

Boone, J., and J. Van Ours (2004) "Effective Active Labor Market Policies", IZA Discussion Paper No. 1335.

Cahuc, P. and A. Zylberberg (2001), Le marché du travail, De Boeck University.

Carruth, A., M. Hooker and A. Oswald (1998), "Unemployment Equilibria and Input Prices: Theory and Evidence from the United States", Review of Economics and Statistics, Vol. 80, pp. 621-628.

Conway, P., D. De Rosa, G. Nicoletti and F. Steiner (2006): "Regulation, Competition, and Productivity Convergence", OECD Economics Department Working Paper No. 509.

Cotis, J.P., R. Méary and N. Sobczak (1998), "Le chômage d'équilibre en France: une évaluation”, Revue économique, Vol. 49, pp. 921-935 
Crépon, B. and C. Gianella (2001), "Fiscalité et coût d'usage du capital : incidences sur l'investissement, l'activité et l'emploi", Economie et Statistique, Vol. 341-342, pp. 107-127.

Elmeskov, J., J. Martin and S. Scarpetta (1998), "Key Lessons for Labour Market Reforms: Evidence from OECD Countries. Experiences", Swedish Economic Policy Review, Vol. 5, pp. 205-252.

Fabiani, S and R. Mestre (2000), "Alternative Measures of the NAIRU in the Euro Area: Estimates and Assessment”, ECB Working Paper No. 17.

Franz, W. (2005), "Will the German NAIRU Please Stand Up", German Economic Review, Vol. 6, pp. 131-153.

Friedman, M. (1968), “The Role of Monetary Policy”, American Economic Review, Vol. 58, pp. 1-17.

Gordon, R.J. (1997), "The Time-Varying NAIRU and its Implications for Economic Policy", Journal of Economic Perspectives, Vol. 11, pp. 11-32.

Hamilton, J.D. (1986), “A Standard Error for the Estimated State Vector of a State-Space Model”, Journal of Econometrics, Vol. 33, pp. 387-397.

Hamilton, J.D. (1994), Time Series Analysis, Princeton University Press, Princeton.

Harvey, A.C. (1993), Time Series Models (second ed.), Harvester Wheatsheaf, London.

IMF (2003), "Unemployment and Labour Market Institutions: Why Reforms Pay Off", Chapter IV, World Economic Outlook.

Jaeger, A. and M. Parkinson (1994), "Some Evidence in Hysteresis in Unemployment Rates", European Economic Review, Vol. 38, pp. 329-342.

Kierzenkowski, R., P. Ollivaud, F. Sedillot and P. Briard (2008), "Estimating a Supply Block for Poland", OECD Economics Department Working Paper No. 601.

King, R., J.H. Stock, and M.W. Watson (1995): "Temporal Instability of the Unemployment-Inflation Relationship", Economic Perspectives of the Federal Reserve Bank of Chicago, Vol. 19, pp. 2-12.

Layard, D.R., S. Nickell and R. Jackman (1991), "Unemployment: Macroeconomic Performance and the Labour Market", Oxford University Press, Oxford.

Nishizaki, F. (1997), "The NAIRU in Japan: Measurement and its Implications", OECD Economics Department Working Paper No. 173.

Laubach, T. (2001), "Measuring the NAIRU: Evidence from Seven Economies", The Review of Economics and Statistics, Vol. 38, pp. 218-231.

Lewis, J.B. and D.A. Linzer (2005), "Estimating Regression Models in Which the Dependent Variable is Based on Estimates", Political Analysis, Vol. 13, pp. 345-364.

Llaudes, R. (2005), "The Phillips Curve and Long-term Unemployment”, ECB Working Paper No. 441.

Mourougane, A., N. Pain and D. Taglioni (2005), "Updated NAIRU Estimates for 24 OECD Economies", mimeo.

Nickel, S., L. Nunziata and W. Ochel (2005), "Unemployment in the OECD since the 1960s. What do we know?", The Economic Journal, Vol. 115, pp.1-27.

Nicoletti, G. and S. Scarpetta (2005), "Product Market Reforms and Employment in OECD Countries", OECD Economics Department Working Paper No. 472.

OECD (2006), "Boosting Jobs and Incomes", Special Issue, OECD Employment Outlook, Paris.

Orr, A., M. Edey and M. Kennedy (1995), "The Determinants of Real Long-Term Rates: 17 Country Pooled Time Series Evidence”, OECD Economics Department Working Paper No. 155. 
Pfefferman, D. and R. Tiller (2005), "Bootstrap Approximation to Prediction MSE for State-Space Modelswith Estimated Parameters", Journal of Time Series Analysis, Vol. 26, pp. 893-916.

Phelps, E. and G. Zoega (1998), "Natural Rate Theory and OECD Unemployment", Economic Journal, Vol. 108, pp.782-801.

Richardson, P., L. Boone, C. Giorno, M. Meacci, D. Rae and D. Turner (2000), "The Concept, Policy Use and measurement of Structural Unemployment: Estimating a Time Varying NAIRU across 21 OECD Countries", OECD Economics Department Working Paper No. 250.

Schumacher, C. (2008), "Measuring Uncertainty of the Euro Area NAIRU: Monte Carlo and Empirical Evidence for Alternative Confidence Intervals in a State Space Framework", Empirical Economicsm Vol. 34, pp. 357-379.

Staiger, D., J.H. Stock and M.W. Watson (1996), "How Precise are Estimates of the Natural Rate of Unemployment?", NBER Working Paper Series No. 5477.

Weiner, S. (1993), "New Estimates of the Natural Rate of Unemployment", Economic review of the Federal reserve Bank of Kansas City, Vol. 78, pp. 53-69.

White, H. (1980), "A Heteroscedasticity-Consistent Covariance Matrix Estimator and a Direct Test for the Heteroscedasticity", Econometrica, Vol. 48, pp. 817-838.

Zellner, A. (1962), "An Efficient Method of Estimating Seemingly Unrelated Regressions and Tests for Aggregation Bias", Journal of the American Statistical Association, Vol. 57, pp. 348-368.

Upper, C. and A. Worms (2003), "Real Long-Term Interest Rates and Monetary Policy: a Cross-Country Perspective"; in: BIS (ed.): Monetary Policy in a Changing Environment, BIS Paper No. 19, pp. 234-257. 


\section{ANNEX A. THE THEORETICAL MODEL}

Using the framework formalised by Layard et al. (1991), this appendix reviews the theoretical underpinnings of the NAIRU concepts, showing the Phillips curve to be generally consistent with this theoretical model; one that can be interpreted as a reduced form relationship derived from the interaction of wage and price setting.

\section{Wage setting}

The wage equation can be derived from standard microeconomic models of wage bargaining, efficiency wage or implicit contract (see e.g. Cahuc and Zylberberg, 2001). In the wage bargaining framework, negotiated net real wages at the firm level $\left(\underline{w}-p^{e}\right)$ are shown to be a decreasing function of the unemployment rate $U$ and an increasing function of wage push factors. The latter may have either longlasting effects -- this is typically the case for the unemployment benefit replacement rate and the degree of unionisation of employees -- or short-run effects. The employees negotiate their wage on the basis of anticipated price (and inflation) and trend labour efficiency gains eff. Finally, the employer might pass on to employees' part of the change in the tax wedge $t_{w}$. The negotiated wage can therefore be expressed the following way:

$$
\underline{w}-p^{e}=a_{W}^{0}+e f f-b \cdot U-\lambda t_{w}+a_{W}^{1} \cdot Z^{W, S R}+a_{W}^{2} \cdot Z^{W, L R}
$$

where $w$ is the logarithm of the net nominal wage negotiated at the firm level, $p^{e}$ the logarithm of anticipated price level, $Z^{W, L R}$ and $Z^{W, S R}$ denote long-run and short-run wage push factors.

At the aggregate level, equation (1a) gives the following expression of the real wage curve:

$$
w-p=a_{W}^{0}+e f f-b \cdot U-\left(p-p^{e}\right)+a_{W}^{1} \cdot Z^{W, S R}+a_{W}^{2} \cdot Z^{W, L R}
$$

with $\left(p-p^{e}\right)$ denoting the price surprise (or equivalently the inflation surprise).

\section{Price setting}

Prices are fixed at the firm level as a margin over total costs, which are a weighted average of total labour cost and the cost of capital (Cotis et al., 1998). Similarly to the wage equation, temporary and permanent shocks can influence the price formation. Typical short-term shocks are oil price or import price changes $Z^{P, S R}$, while long-lasting factors of influence $Z^{P, L R}$ are essentially those affecting the competition conditions (captured empirically with the OECD product market regulation indicator):

$$
\underline{p}=a_{P}^{0}+\alpha\left(t_{w}+\underline{w}-e f f\right)+(1-\alpha)\left(c_{K}+p^{e}\right)+a_{P}^{1} \cdot Z^{P, S R}+a_{P}^{2} \cdot Z^{P, L R}
$$

Where $\underline{p}$ the price set at the firm level, $c_{K}$ is the real user cost of capital nominal, $p^{e}$ the aggregated anticipated price level and $\alpha$ the labour share.

Aggregating equation (2a) gives the following expression of the (PS) curve: 


$$
p-w=t_{w}-e f f+\frac{1}{\alpha}\left[a_{P}^{0}+(1-\alpha) c_{K}-(1-\alpha)\left(p-p^{e}\right)+a_{P}^{1} \cdot Z^{P, S R}+a_{P}^{2} \cdot Z^{P, L R}\right]
$$

\section{The NAIRU and the Phillips curve}

The expression of the unemployment rate can be inferred from equation (1b) and (2b), as dependent from institutional variables, shocks and error in inflation expectations $\left(\Delta p-(\Delta p)^{e}\right)$. Similarly, the structural unemployment rate or NAIRU is obtained as the solution to equations (1b) and (2b), when price $\Delta p-(\Delta p)^{e}$ $=0$ are met and in the absence of temporary supply shocks, meaning that $Z^{W, S R}=0$ and $Z^{W, L R}=0$. This makes it possible to obtain simultaneously the derivation of the Phillips curve and the long term value of the NAIRU:

$$
\left\{\begin{array}{l}
\Delta p-(\Delta p)^{e}=-\beta\left(U_{t}-U_{t}^{*}\right)+\eta_{W} \cdot Z_{t}^{W, S R}+\eta_{P} Z_{t}^{P, S R} \\
U_{t}^{*}=\mu+\gamma \cdot c_{K}+\rho t_{w}+\theta_{W} \cdot Z_{t}^{W, L R}+\theta_{P} \cdot Z_{t}^{P, L R}
\end{array}\right.
$$

With $\beta=\alpha \cdot b$ and where $\gamma, \rho$ are also functions of the parameters $\alpha, b$ and $\lambda$.

Assuming the inflation expectations are adaptive, $\pi^{e}=\varphi(L) \pi_{-1}$, the previous system of equations becomes equation (1) of the core text:

$$
\left\{\begin{array}{l}
\pi_{t}=\varphi(L) \pi_{-1}-\beta\left(U-U^{*}\right)+\eta_{W} \cdot Z^{W, S R}+\eta_{P} Z^{P, S R} \\
U_{t}^{*}=\mu+\gamma \cdot c_{K}+\rho t_{w}+\theta_{W} \cdot Z^{W, L R}+\theta_{P} \cdot Z^{P, L R}
\end{array}\right.
$$

$N B$ : In a general framework, the user cost of capital can be expressed as the sum of the depreciation rate of the capital stock and a weighted average of the interest rates on bank loans (r) and the cost of equity financing -- which depends in turn on the corporate tax rate $t_{K}$, the real rate of return imposed by shareholders $\tau$ and a risk premium. ${ }^{37}$ In this study, the user cost of capital is simply proxied by real interest rates, ignoring therefore the impact of capital taxation (and assuming implicitly a constant risk premium and depreciation rate).

37. More specifically, the real user cost of capital could be expressed the following way (see e.g. Crépon and Gianella, 2001):

$c_{K}=(1-s) \cdot r+s \frac{\tau}{1-t_{K}}+\xi+\delta$

where $s$ is the share of equity financing, $\xi$ the risk premium and $\delta$ the depreciation rate of the capital stock. 
ANNEX B. STATISTICAL TABLES

Table B1. Estimated Phillips Curves and diagnostics tests using the Kalman filter

\begin{tabular}{|c|c|c|c|c|c|c|c|c|c|c|c|c|c|c|}
\hline \multirow[t]{2}{*}{ Dependent variable $\Delta \pi$} & \multicolumn{2}{|c|}{$\begin{array}{c}\text { USA } \\
\text { 1965Q2-2007Q3 }\end{array}$} & \multicolumn{2}{|c|}{$\begin{array}{c}\text { JPN } \\
\text { 1972Q3-2007Q4 }\end{array}$} & \multicolumn{2}{|c|}{$\begin{array}{c}\text { DEU } \\
\text { 1970Q4-2007Q4 }\end{array}$} & \multicolumn{2}{|c|}{$\begin{array}{c}\text { FRA } \\
\text { 1970Q4-2007Q4 }\end{array}$} & \multicolumn{2}{|c|}{$\begin{array}{c}\text { ITA } \\
\text { 1968Q3-2007Q4 }\end{array}$} & \multicolumn{2}{|c|}{$\begin{array}{c}\text { GBR } \\
\text { 1970Q4-2007Q4 }\end{array}$} & \multicolumn{2}{|c|}{$\begin{array}{c}\text { CAN } \\
\text { 1962Q1-2007Q4 }\end{array}$} \\
\hline & COEF & $T$-STAT & COEF & $T$-STAT & COEF & $T$-STAT & COEF & $T$-STAT & COEF & $T$-STAT & COEF & $T$-STAT & COEF & T-STAT \\
\hline$\Delta \pi(-1)$ & -0.52 & -7.27 & -0.56 & -9.06 & -0.59 & -7.34 & -0.43 & -5.76 & -0.38 & -5.12 & -0.55 & -7.21 & -0.61 & -9.06 \\
\hline$\Delta \pi(-2)$ & -0.31 & -4.02 & -0.30 & -4.95 & -0.34 & -3.69 & -0.43 & -5.68 & -0.50 & -6.80 & -0.44 & -5.39 & -0.53 & -7.44 \\
\hline$\Delta \pi(-3)$ & -0.19 & -2.59 & & & -0.26 & -2.83 & -0.33 & -4.32 & -0.27 & -3.61 & -0.54 & -6.35 & -0.38 & -5.48 \\
\hline$\Delta \pi(-4)$ & -0.18 & -2.58 & & & -0.27 & -3.39 & & & & & 0.17 & 2.32 & & \\
\hline$U-U^{*}$ & -0.06 & -3.97 & -0.13 & -1.15 & -0.08 & -3.41 & -0.15 & -2.91 & -0.10 & -2.13 & -0.22 & -2.89 & -0.11 & -2.93 \\
\hline$\omega^{\mathrm{m}} *\left(\pi^{\mathrm{m}}(-1)-\pi(-1)\right)$ & 0.38 & 4.36 & 0.47 & 4.02 & & & 0.13 & 1.80 & 0.32 & 3.94 & 0.47 & 4.39 & 0.31 & 3.79 \\
\hline \multicolumn{15}{|l|}{$\omega^{\mathrm{m}} *\left(\pi^{\mathrm{m}}(-4)-\pi(-4)\right)$} \\
\hline$\omega^{\mathrm{oil}}(-1) *\left(\pi^{\mathrm{oil}}(-1)-\pi(-1)\right)$ & 0.03 & 2.62 & & & & & 0.02 & 0.94 & & & 0.40 & 3.45 & 0.03 & 1.79 \\
\hline Dum1974Q1 & & & 4.07 & 7.87 & & & & & & & & & & \\
\hline \multirow[t]{2}{*}{ Sacrifice ratio } & \multicolumn{2}{|c|}{2.43} & \multicolumn{2}{|c|}{1.15} & \multicolumn{2}{|c|}{1.99} & \multicolumn{2}{|c|}{0.93} & \multicolumn{2}{|c|}{1.55} & \multicolumn{2}{|c|}{0.68} & \multicolumn{2}{|c|}{1.38} \\
\hline & $\begin{array}{c}\text { Test } \\
\text { Statistic }\end{array}$ & Prob. & $\begin{array}{c}\text { Test } \\
\text { Statistic }\end{array}$ & Prob. & $\begin{array}{c}\text { Test } \\
\text { Statistic }\end{array}$ & Prob. & $\begin{array}{c}\text { Test } \\
\text { Statistic }\end{array}$ & Prob. & $\begin{array}{c}\text { Test } \\
\text { Statistic }\end{array}$ & Prob. & $\begin{array}{c}\text { Test } \\
\text { Statistic }\end{array}$ & Prob. & $\begin{array}{l}\text { Test } \\
\text { Statistic }\end{array}$ & Prob. \\
\hline HETEROSKED. & 1.67 & 0.04 & 1.66 & 0.15 & 2.38 & 0.01 & 1.57 & 0.07 & 5.78 & 0.00 & 4.68 & 0.00 & 3.36 & 0.00 \\
\hline SERIAL COR.(1) & 12.06 & 0.00 & 1.22 & 0.27 & 0.01 & 0.94 & 0.03 & 0.87 & 2.29 & 0.13 & 0.45 & 0.50 & 2.97 & 0.09 \\
\hline SERIAL COR.(4) & 3.29 & 0.01 & 1.88 & 0.12 & 1.70 & 0.15 & 1.30 & 0.27 & 0.83 & 0.51 & 2.70 & 0.03 & 1.70 & 0.15 \\
\hline NORMALITY & 10.64 & 0.00 & 41.19 & 0.00 & 34.85 & 0.00 & 431.29 & 0.00 & 22.93 & 0.00 & 79.74 & 0.00 & 0.09 & 0.96 \\
\hline$\sigma_{\varepsilon}^{2} / \sigma_{v}^{2}$ & \multirow{2}{*}{\multicolumn{2}{|c|}{0.02}} & \multirow{2}{*}{\multicolumn{2}{|c|}{$\begin{array}{l}0.08 \\
0.33\end{array}$}} & \multicolumn{2}{|c|}{2.00} & \multirow{2}{*}{\multicolumn{2}{|c|}{$\begin{array}{l}0.91 \\
071\end{array}$}} & \multirow{2}{*}{\multicolumn{2}{|c|}{$\begin{array}{l}0.15 \\
1.30\end{array}$}} & \multirow{2}{*}{\multicolumn{2}{|c|}{$\begin{array}{l}0.80 \\
0.45\end{array}$}} & \multirow{2}{*}{\multicolumn{2}{|c|}{$\begin{array}{l}2.00 \\
0.86\end{array}$}} \\
\hline Avg. S.E. of NAIRU & & & & & & & & & & & & & & \\
\hline
\end{tabular}


Table B1. Estimated Phillips Curves and diagnostics tests using the Kalman filter (cont'd)

\begin{tabular}{|c|c|c|c|c|c|c|c|c|c|c|c|c|c|c|}
\hline \multirow[t]{2}{*}{ Dependent variable $\Delta \pi$} & \multicolumn{2}{|c|}{$\begin{array}{c}\text { AUS } \\
\text { 1964Q1-2007Q4 }\end{array}$} & \multicolumn{2}{|c|}{$\begin{array}{c}\text { AUT } \\
\text { 1968Q3-2007Q4 }\end{array}$} & \multicolumn{2}{|c|}{\begin{tabular}{|c|} 
BEL \\
1961Q1-2007Q4
\end{tabular}} & \multicolumn{2}{|c|}{$\begin{array}{c}\text { DNK } \\
\text { 1972Q1-2007Q4 }\end{array}$} & \multicolumn{2}{|c|}{$\begin{array}{c}\text { FIN } \\
\text { 1970Q1-2007Q4 }\end{array}$} & \multicolumn{2}{|c|}{$\begin{array}{c}\text { GRC } \\
\text { 1975Q1-2007Q4 }\end{array}$} & \multicolumn{2}{|c|}{$\begin{array}{c}\mathrm{IRL} \\
\text { 1978Q3-2007Q4 }\end{array}$} \\
\hline & COEF & $T$-STAT & COEF & $T$-STAT & COEF & $T-S T A T$ & COEF & $T-S T A T$ & COEF & $T-S T A T$ & COEF & $T-S T A T$ & COEF & T-STAT \\
\hline Constant & & & & & & & & & 0.08 & 1.41 & & & & \\
\hline$\Delta \pi(-1)$ & -0.82 & -11.80 & -0.92 & -15.19 & -0.71 & -10.62 & -0.78 & -10.58 & -0.73 & -9.86 & -0.82 & -10.96 & -0.80 & -8.80 \\
\hline$\Delta \pi(-2)$ & -0.55 & -6.64 & -0.79 & -10.99 & -0.50 & -6.53 & -0.42 & -4.48 & -0.60 & -7.47 & -0.72 & -9.22 & -0.56 & -5.17 \\
\hline$\Delta \pi(-3)$ & -0.27 & -3.84 & -0.67 & -12.32 & -0.26 & -3.92 & -0.45 & -6.13 & -0.48 & -6.43 & -0.69 & -9.30 & -0.17 & -1.92 \\
\hline$\Delta \pi(-4)$ & & & & & & & & & & & 0.15 & 2.24 & & \\
\hline$U-U^{*}$ & -0.20 & -3.54 & -0.43 & -4.28 & -0.06 & -2.33 & -0.14 & -2.32 & -0.08 & -3.29 & -0.23 & -2.17 & -0.09 & -1.99 \\
\hline$\omega^{\mathrm{m}} *\left(\pi^{\mathrm{m}}(-1)-\pi(-1)\right)$ & & & 0.34 & 3.63 & 0.19 & 5.24 & 0.26 & 3.09 & & & 0.19 & 1.51 & 0.29 & 3.62 \\
\hline$\omega^{\mathrm{m}} *\left(\pi^{\mathrm{m}}(-4)-\pi(-4)\right.$ & & & & & & & & & 0.20 & 2.68 & & & & \\
\hline$\omega^{\mathrm{oil}}(-1) *\left(\pi^{\mathrm{oil}}(-1)-\pi(-1)\right)$ & 0.07 & 2.20 & & & & & & & & & & & & \\
\hline$\omega^{\mathrm{oil}}(-2) *\left(\pi^{\mathrm{oil}}(-2)-\pi(-2)\right)$ & & & & & & & & & & & & & & \\
\hline DumQ1 & & & 0.32 & 3.18 & & & & & & & & & & \\
\hline DumQ2 & & & 0.22 & 2.23 & & & & & & & & & & \\
\hline DumQ3 & & & 0.22 & 2.21 & & & & & & & & & & \\
\hline Dum2000Q3 & 2.78 & 3.93 & & & & & & & & & & & & \\
\hline \multirow[t]{2}{*}{ Sacrifice ratio } & \multicolumn{2}{|c|}{0.77} & \multicolumn{2}{|c|}{0.52} & \multicolumn{2}{|c|}{2.01} & \multicolumn{2}{|c|}{1.18} & \multicolumn{2}{|c|}{2.20} & \multicolumn{2}{|c|}{0.84} & \multicolumn{2}{|c|}{1.84} \\
\hline & $\begin{array}{c}\text { Test } \\
\text { Statistic }\end{array}$ & Prob. & $\begin{array}{c}\text { Test } \\
\text { Statistic }\end{array}$ & Prob. & $\begin{array}{c}\text { Test } \\
\text { Statistic }\end{array}$ & Prob. & $\begin{array}{c}\text { Test } \\
\text { Statistic }\end{array}$ & Prob. & $\begin{array}{c}\text { Test } \\
\text { Statistic }\end{array}$ & Prob. & $\begin{array}{c}\text { Test } \\
\text { Statistic }\end{array}$ & Prob. & $\begin{array}{c}\text { Test } \\
\text { Statistic }\end{array}$ & Prob. \\
\hline HETEROSKED. & 2.80 & 0.00 & 2.87 & 0.00 & 2.55 & 0.00 & 3.89 & 0.00 & 1.51 & 0.11 & 1.78 & 0.04 & 4.41 & 0.00 \\
\hline SERIAL COR.(1) & 3.77 & 0.05 & 2.00 & 0.16 & 1.60 & 0.21 & 1.12 & 0.29 & 0.65 & 0.42 & 0.42 & 0.52 & 3.30 & 0.07 \\
\hline SERIAL COR.(4) & 1.35 & 0.25 & 3.51 & 0.01 & 1.51 & 0.20 & 2.88 & 0.03 & 1.35 & 0.25 & 2.92 & 0.02 & 1.39 & 0.24 \\
\hline NORMALITY & 59.64 & 0.00 & 1121.55 & 0.00 & 0.50 & 0.78 & 278.68 & 0.00 & 61.78 & 0.00 & 46.40 & 0.00 & 24.98 & 0.00 \\
\hline$\sigma_{\varepsilon}^{2} / \sigma_{v}^{2}$ & \multicolumn{2}{|c|}{0.25} & \multicolumn{2}{|c|}{0.13} & \multicolumn{2}{|c|}{1.00} & \multicolumn{2}{|c|}{0.70} & \multirow{2}{*}{\multicolumn{2}{|c|}{$\begin{array}{l}0.10 \\
0.93\end{array}$}} & \multirow{2}{*}{\multicolumn{2}{|c|}{$\begin{array}{l}0.63 \\
0.54\end{array}$}} & \multirow{2}{*}{\multicolumn{2}{|c|}{$\begin{array}{l}0.80 \\
0.48\end{array}$}} \\
\hline Avg. S.E. of NAIRU & 0.5 & & 0 & 30 & 0.8 & 87 & 0. & 66 & & & & & & \\
\hline
\end{tabular}


Table B1. Estimated Phillips Curves and diagnostics tests using the Kalman filter (cont'd)

\begin{tabular}{|c|c|c|c|c|c|c|c|c|c|c|c|c|c|c|c|c|}
\hline \multirow[t]{2}{*}{$\begin{array}{l}\text { Dependent } \\
\text { variable } \Delta \pi\end{array}$} & \multicolumn{2}{|c|}{$\begin{array}{c}\text { KOR } \\
\text { 1975Q1- } \\
\text { 2007Q4 }\end{array}$} & \multicolumn{2}{|c|}{$\begin{array}{c}\text { LUX } \\
\text { 1976Q2- } \\
\text { 2007Q4 }\end{array}$} & \multicolumn{2}{|c|}{$\begin{array}{c}\text { NLD } \\
\text { 1962Q1- } \\
\text { 2007Q4 }\end{array}$} & \multicolumn{2}{|c|}{$\begin{array}{c}\text { NZL } \\
\text { 1980Q1- } \\
\text { 2007Q4 }\end{array}$} & \multicolumn{2}{|c|}{$\begin{array}{c}\text { PRT } \\
\text { 1980Q1- } \\
\text { 2007Q4 }\end{array}$} & \multicolumn{2}{|c|}{$\begin{array}{c}\text { SWE } \\
\text { 1961Q2- } \\
\text { 2007Q4 }\end{array}$} & \multicolumn{2}{|c|}{$\begin{array}{c}\text { CHE } \\
\text { 1975Q4- } \\
\text { 2007Q4 }\end{array}$} & \multicolumn{2}{|c|}{$\begin{array}{c}\text { NOR } \\
\text { 1971Q1- } \\
\text { 2007Q4 }\end{array}$} \\
\hline & COEF & T-STAT & COEF & T-STAT & COEF & T-STAT & COEF & T-STAT & COEF & T-STAT & COEF & T-STAT & COEF & T-STAT & COEF & $T$-STAT \\
\hline$\Delta \pi(-1)$ & -0.54 & -6.94 & -0.65 & -8.16 & -0.87 & -16.34 & -0.36 & -4.25 & -0.54 & -6.16 & -0.82 & -11.82 & -0.57 & -9.11 & -0.64 & -7.83 \\
\hline$\Delta \pi(-2)$ & -0.39 & -5.00 & -0.32 & -3.32 & -0.75 & -11.76 & -0.12 & -1.41 & -0.51 & -5.77 & -0.65 & -8.34 & & & -0.23 & -2.80 \\
\hline$\Delta \pi(-3)$ & & & -0.47 & -6.06 & -0.68 & -12.93 & -0.16 & -2.30 & -0.37 & -4.62 & -0.37 & -5.32 & -0.40 & -5.91 & & \\
\hline$\Delta \pi(-4)$ & & & & & & & & & & & & & & & & \\
\hline$U-U^{*}$ & -0.26 & -2.25 & -0.24 & -2.39 & -0.11 & -2.90 & -0.15 & -1.96 & -0.21 & -2.53 & -0.07 & -1.50 & -0.13 & -3.11 & -0.15 & -1.72 \\
\hline$\omega^{\mathrm{m}} *\left(\pi^{\mathrm{m}}(-1)-\pi(-1)\right)$ & & & 0.04 & 2.66 & & & 0.14 & 2.25 & 0.61 & 3.75 & & & 0.13 & 4.06 & & \\
\hline$\omega^{\mathrm{m}} *\left(\pi^{\mathrm{m}}(-2)-\pi(-2)\right)$ & & & & & & & 0.19 & 2.83 & & & & & & & & \\
\hline$\omega^{\mathrm{m}} *\left(\pi^{\mathrm{m}}(-3)-\pi(-3)\right.$ & 0.08 & 1.76 & & & 0.11 & 2.34 & & & & & & & & & & \\
\hline$\omega^{\mathrm{oil}}(-1) * \Delta \pi^{\mathrm{oil}}(-1)$ & 0.14 & 3.62 & & & & & & & & & & & & & & \\
\hline Dum1986Q4 & & & & & & & 4.55 & 6.60 & & & & & & & & \\
\hline Dum1987Q1 & & & & & & & -3.74 & -4.90 & & & & & & & & \\
\hline \multirow[t]{2}{*}{ Sacrifice ratio } & 0.4 & & 0.6 & & $1 . c$ & 92 & 0.7 & 79 & 0.8 & 80 & 2.3 & 37 & 0.9 & 95 & 0.7 & 77 \\
\hline & $\begin{array}{c}\text { Test } \\
\text { Statistic }\end{array}$ & Prob. & $\begin{array}{c}\text { Test } \\
\text { Statistic }\end{array}$ & Prob. & $\begin{array}{c}\text { Test } \\
\text { Statistic }\end{array}$ & Prob. & $\begin{array}{c}\text { Test } \\
\text { Statistic }\end{array}$ & Prob. & $\begin{array}{c}\text { Test } \\
\text { Statistic }\end{array}$ & Prob. & $\begin{array}{c}\text { Test } \\
\text { Statistic }\end{array}$ & Prob. & $\begin{array}{c}\text { Test } \\
\text { Statistic }\end{array}$ & Prob. & $\begin{array}{c}\text { Test } \\
\text { Statistic }\end{array}$ & Prob. \\
\hline HETEROSKED. & 3.56 & 0.00 & 1.60 & 0.08 & 4.02 & 0.00 & 1.05 & 0.41 & 7.59 & 0.00 & 1.35 & 0.19 & 3.88 & 0.00 & 1.24 & 0.27 \\
\hline SERIAL COR.(1) & 0.12 & 0.73 & 0.41 & 0.52 & 0.57 & 0.45 & 0.00 & 1.00 & 1.02 & 0.32 & 0.64 & 0.43 & 1.18 & 0.28 & 1.64 & 0.20 \\
\hline SERIAL COR.(4) & 0.77 & 0.55 & 2.17 & 0.08 & 18.25 & 0.00 & 0.17 & 0.96 & 3.90 & 0.01 & 6.86 & 0.00 & 2.12 & 0.08 & 1.99 & 0.10 \\
\hline NORMALITY & 182.27 & 0.00 & 12.07 & 0.00 & 333.55 & 0.00 & 21.59 & 0.00 & 10.68 & 0.00 & 45.14 & 0.00 & 13.83 & 0.00 & 253.46 & 0.00 \\
\hline$\sigma_{\varepsilon}^{2} / \sigma_{v}^{2}$ & \multicolumn{2}{|c|}{6.67} & \multicolumn{2}{|c|}{0.38} & \multirow{2}{*}{\multicolumn{2}{|c|}{$\begin{array}{l}0.06 \\
0.45\end{array}$}} & \multirow{2}{*}{\multicolumn{2}{|c|}{$\begin{array}{l}0.33 \\
0.91\end{array}$}} & \multirow{2}{*}{\multicolumn{2}{|c|}{$\begin{array}{l}2.00 \\
0.99\end{array}$}} & \multirow{2}{*}{\multicolumn{2}{|c|}{$\begin{array}{l}0.95 \\
0.80\end{array}$}} & \multirow{2}{*}{\multicolumn{2}{|c|}{$\begin{array}{l}0.60 \\
0.52\end{array}$}} & \multirow{2}{*}{\multicolumn{2}{|c|}{$\begin{array}{l}0.80 \\
1.51 \\
\end{array}$}} \\
\hline Avg. S.E. of NAIRU & 1.0 & & 0.5 & & & & & & & & & & & & & \\
\hline
\end{tabular}


Table B2. Estimated NAIRUs for 23 OECD countries

\begin{tabular}{|c|c|c|c|c|c|c|c|c|c|c|c|c|c|c|}
\hline & $\begin{array}{c}\text { Average } \\
19701974\end{array}$ & $\begin{array}{c}\text { Average } \\
1975-19791\end{array}$ & $\begin{array}{c}\text { Average } \\
1980-19841\end{array}$ & $\begin{array}{l}\text { Average } \\
1985-19891\end{array}$ & $\begin{array}{c}\text { Average } \\
1990-1994\end{array}$ & $\begin{array}{c}\text { Average } \\
1 \text { 1995-1999 }\end{array}$ & 2000 & 2001 & 2002 & 2003 & 2004 & 2005 & 2006 & 2007 \\
\hline Australia & 3.5 & 4.9 & 6.7 & 7.4 & 8.0 & 7.4 & 6.4 & 6.1 & 5.9 & 5.7 & 5.6 & 5.4 & 5.3 & 5.2 \\
\hline Austria & 1.1 & 0.9 & 2.1 & 3.5 & 4.4 & 4.8 & 4.8 & 4.9 & 4.9 & 5.0 & 5.0 & 4.9 & 4.9 & 4.9 \\
\hline Belgium & 3.5 & 5.2 & 7.0 & 7.9 & 8.0 & 8.2 & 8.1 & 8.0 & 8.0 & 8.0 & 8.0 & 8.0 & 8.0 & 8.0 \\
\hline Canada & 6.0 & 7.4 & 9.0 & 9.3 & 9.4 & 8.7 & 7.9 & 7.7 & 7.6 & 7.4 & 7.3 & 7.1 & 6.9 & 6.8 \\
\hline Denmark & & 4.3 & 6.1 & 6.4 & 7.1 & 5.9 & 5.1 & 5.0 & 4.9 & 4.9 & 4.7 & 4.6 & 4.4 & 4.2 \\
\hline Finland & 3.8 & 2.4 & 3.1 & 4.8 & 9.1 & 11.5 & 9.6 & 8.6 & 8.1 & 7.7 & 7.6 & 7.5 & 7.4 & 7.0 \\
\hline France & 3.1 & 4.4 & 6.7 & 8.4 & 9.2 & 9.7 & 9.0 & 8.7 & 8.6 & 8.6 & 8.6 & 8.6 & 8.5 & 8.3 \\
\hline Germany & 1.9 & 3.1 & 4.8 & 6.1 & 6.8 & 7.8 & 8.0 & 8.1 & 8.2 & 8.4 & 8.5 & 8.7 & 8.6 & 8.4 \\
\hline Greece & & 3.0 & 5.4 & 7.3 & 8.4 & 9.8 & 10.6 & 10.6 & 10.6 & 10.4 & 10.4 & 10.2 & 9.9 & 9.8 \\
\hline Ireland & & & 13.0 & 15.3 & 14.0 & 9.8 & 6.6 & 5.9 & 5.5 & 5.2 & 5.0 & 4.8 & 4.7 & 4.7 \\
\hline Italy & 5.6 & 5.6 & 6.3 & 8.7 & 9.2 & 9.6 & 8.9 & 8.6 & 8.3 & 7.9 & 7.4 & 7.0 & 6.6 & 6.4 \\
\hline Japan & 1.7 & 1.8 & 2.2 & 2.6 & 2.9 & 3.6 & 4.0 & 4.1 & 4.1 & 4.2 & 4.1 & 4.1 & 4.1 & 4.0 \\
\hline Korea & & 3.9 & 3.9 & 3.3 & 2.9 & 3.7 & 4.1 & 4.0 & 3.8 & 3.8 & 3.7 & 3.6 & 3.6 & 3.5 \\
\hline Luxembourg & & & 1.1 & 1.5 & 2.0 & 2.8 & 4.1 & 4.0 & 3.8 & 3.8 & 3.7 & 3.6 & 3.6 & 3.5 \\
\hline Netherlands & 2.8 & 3.4 & 5.9 & 7.1 & 6.5 & 5.3 & 4.3 & 4.1 & 3.9 & 3.9 & 3.9 & 3.8 & 3.8 & 3.8 \\
\hline New Zealand & & & 3.6 & 5.5 & 8.0 & 6.8 & 5.9 & 5.6 & 5.4 & 5.1 & 4.7 & 4.4 & 4.1 & 4.1 \\
\hline Norway & & 1.9 & 2.5 & 3.3 & 4.7 & 4.2 & 3.8 & 3.8 & 3.9 & 3.9 & 3.9 & 3.9 & 3.6 & 3.4 \\
\hline Portugal & & & 7.3 & 6.8 & 6.1 & 6.0 & 5.8 & 5.9 & 6.1 & 6.3 & 6.5 & 6.7 & 6.8 & 6.9 \\
\hline Spain & & & 8.6 & 13.4 & 14.4 & 13.5 & 5.1 & 5.0 & 5.0 & 5.0 & 5.1 & 5.1 & 5.1 & 5.1 \\
\hline Sweden & 2.3 & 2.5 & 2.9 & 3.3 & 4.4 & 5.1 & 5.1 & 5.0 & 5.0 & 5.0 & 5.1 & 5.1 & 5.1 & 5.1 \\
\hline Switzerland & & 0.4 & 0.7 & 1.2 & 2.3 & 3.2 & 3.3 & 3.4 & 3.5 & 3.6 & 3.7 & 3.7 & 3.7 & 3.7 \\
\hline United Kingdom & 4.6 & 5.9 & 9.0 & 9.7 & 8.8 & 7.3 & 6.1 & 5.8 & 5.6 & 5.4 & 5.3 & 5.3 & 5.3 & 5.3 \\
\hline United States & 5.5 & 6.2 & 6.5 & 6.4 & 6.0 & 5.5 & 5.3 & 5.3 & 5.3 & 5.2 & 5.2 & 5.1 & 5.1 & 5.0 \\
\hline
\end{tabular}


Table B3. Pooled regression results, 1976-2003, with time dummies

\begin{tabular}{|c|c|c|c|c|c|}
\hline Specification & $\Delta(1)$ & $\Delta(2)$ & $\Delta(3)$ & $\Delta(4)$ & Level (5) \\
\hline$W E D G E_{t}$ & $\begin{array}{l}0.033^{* *} \\
(0.014)\end{array}$ & $\begin{array}{l}0.018 \\
(0.013)\end{array}$ & $\begin{array}{l}0.019 \\
(0.013)\end{array}$ & & $\begin{array}{l}0.162^{* * *} \\
(0.029)\end{array}$ \\
\hline$W E D G E_{t-1}$ & $\begin{array}{l}0.054^{\star \star *} \\
(0.016)\end{array}$ & $\begin{array}{l}0.048^{\star \star *} \\
(0.015)\end{array}$ & $\begin{array}{l}0.046^{\star \star *} \\
(0.015)\end{array}$ & $\begin{array}{l}0.045^{\star \star \star} \\
(0.013)\end{array}$ & \\
\hline$W E D G E_{t-2}$ & & $\begin{array}{l}0.042^{* * *} \\
(0.012)\end{array}$ & $\begin{array}{l}0.046^{* * *} \\
(0.013)\end{array}$ & $\begin{array}{l}0.049^{* * *} \\
(0.013)\end{array}$ & \\
\hline$W E D G E_{t-3}$ & & & $\begin{array}{l}0.034^{* *} \\
(0.013)\end{array}$ & $\begin{array}{l}0.033^{* *} \\
(0.013)\end{array}$ & \\
\hline$A R R_{t}$ & & & & & $\begin{array}{l}0.030^{* * *} \\
(0.011)\end{array}$ \\
\hline$A R R_{t-2}$ & & $\begin{array}{l}0.015^{\star} \\
(0.008)\end{array}$ & & & \\
\hline$A R R_{t-3}$ & & & $\begin{array}{l}0.017^{\star *} \\
(0.008)\end{array}$ & $\begin{array}{l}0.018^{* *} \\
(0.008)\end{array}$ & \\
\hline$U N D_{t}$ & $\begin{array}{l}0.042^{\star \star *} \\
(0.015)\end{array}$ & $\begin{array}{l}0.036^{\star *} \\
(0.015)\end{array}$ & $\begin{array}{l}0.035^{\star *} \\
(0.016)\end{array}$ & $\begin{array}{l}0.035^{\star *} \\
(0.014)\end{array}$ & $\begin{array}{l}0.082^{* * *} \\
(0.021)\end{array}$ \\
\hline$P M R_{t-1}$ & $\begin{array}{l}0.041 \\
(0.075)\end{array}$ & $\begin{array}{l}0.019 \\
(0.080)\end{array}$ & & & \\
\hline$P M R_{t-2}$ & & $\begin{array}{l}0.081 \\
(0.077)\end{array}$ & $\begin{array}{l}0.078 \\
(0.080)\end{array}$ & & \\
\hline$P M R_{t-3}$ & & & $\begin{array}{l}0.077 \\
(0.077)\end{array}$ & & \\
\hline$I R L R_{t}$ & $\begin{array}{l}0.023^{*} \\
(0.013)\end{array}$ & $\begin{array}{l}0.024^{*} \\
(0.014)\end{array}$ & $\begin{array}{l}0.023 \\
(0.014)\end{array}$ & $\begin{array}{l}0.022^{*} \\
(0.013)\end{array}$ & $\begin{array}{l}0.193^{\star * *} \\
(0.036)\end{array}$ \\
\hline$I R L R_{t-1}$ & $\begin{array}{l}0.024^{*} \\
(0.013)\end{array}$ & $\begin{array}{l}0.021 \\
(0.013)\end{array}$ & $\begin{array}{l}0.023^{*} \\
(0.014)\end{array}$ & $\begin{array}{l}0.023^{*} \\
(0.012)\end{array}$ & \\
\hline$I R L R_{t-2}$ & & $\begin{array}{l}0.031^{* *} \\
(0.012)\end{array}$ & $\begin{array}{l}0.032^{* *} \\
(0.013)\end{array}$ & $\begin{array}{l}0.032^{* * *} \\
(0.011)\end{array}$ & \\
\hline$I R L R_{t-3}$ & & & $\begin{array}{l}0.026^{\star *} \\
(0.013)\end{array}$ & $\begin{array}{l}0.027^{\star *} \\
(0.011)\end{array}$ & \\
\hline Country Fixed Effects & No & No & No & No & Yes \\
\hline & \multicolumn{5}{|c|}{ Implied total Impact } \\
\hline WEDGE & 0.087 & 0.089 & 0.126 & 0.127 & 0.162 \\
\hline$A R R$ & - & 0.015 & 0.017 & 0.018 & 0.030 \\
\hline UND & 0.042 & 0.036 & 0.035 & 0.35 & 0.082 \\
\hline PMR & - & - & - & - & - \\
\hline$I R L R$ & 0.047 & 0.055 & 0.080 & 0.104 & 0.193 \\
\hline Observations & 474 & 452 & 432 & 432 & 434 \\
\hline Adj. R-squared & 0.37 & 0.41 & 0.42 & 0.42 & 0.90 \\
\hline
\end{tabular}

Notes: $\quad \Delta$ denotes the first difference operator. The equations are respectively estimated in differences (specifications (1) to (4) where the dependent variable is $\Delta \hat{U}_{t}^{*}$ ) and in levels (specification (5) where the dependent variable is $\hat{U}_{t}^{*}$ ). Germany, Sweden and Finland are withdrawn from the sample for the level specification as there is a break in the level series. In the upper part of the table, the numbers in parentheses are the standard errors of the coefficients obtained using the White $(1980)$ correction. ${ }^{*},{ }^{* *}$ and ${ }^{* * *}$ denote significance at the $10 \%, 5 \%$ and $1 \%$ levels, respectively. The total impact of a given variable is calculated as the sum of the coefficients on all lags (significant at least at the $10 \%$ level) of this variable. 
Table B4. Pooled regression results, 1976-2003, instrument variables

\begin{tabular}{|c|c|c|c|c|c|c|}
\hline Specification & $\Delta(1)$ & $\Delta(2)$ & $\Delta(3)$ & $\Delta(4)$ & Level (5) & Level (6) \\
\hline$\overline{W E D G E_{t}}$ & $\begin{array}{l}0.148 \\
(0.104)\end{array}$ & $\begin{array}{l}0.151^{* *} \\
(0.062)\end{array}$ & $\begin{array}{l}0.087 \\
(0.121)\end{array}$ & $\begin{array}{l}0.165^{\star *} \\
(0.071)\end{array}$ & $\begin{array}{l}0.360^{* * *} \\
(0.130)\end{array}$ & $\begin{array}{l}0.345^{\star \star *} \\
(0.124)\end{array}$ \\
\hline$A R R_{t}$ & $\begin{array}{l}0.002 \\
(0.037)\end{array}$ & $\begin{array}{l}-0.028 \\
(0.024)\end{array}$ & $\begin{array}{l}0.014 \\
(0.037)\end{array}$ & $\begin{array}{l}-0.041 \\
(0.026)\end{array}$ & $\begin{array}{l}-0.039 \\
(0.045)\end{array}$ & \\
\hline$U N D_{t}$ & $\begin{array}{l}0.252^{* * *} \\
(0.074)\end{array}$ & $\begin{array}{l}0.0105 \\
(0.084)\end{array}$ & $\begin{array}{l}0.190^{* * *} \\
(0.059)\end{array}$ & $\begin{array}{l}0.131 \\
(0.086)\end{array}$ & $\begin{array}{l}0.305^{\star * *} \\
(0.089)\end{array}$ & $\begin{array}{l}0.274^{* *} \\
(0.107)\end{array}$ \\
\hline$P M R_{t}$ & $\begin{array}{l}0.415 \\
(0.474)\end{array}$ & $\begin{array}{l}0.193 \\
(0.368)\end{array}$ & $\begin{array}{l}0.251 \\
(0.489)\end{array}$ & $\begin{array}{l}0.023 \\
(0.474)\end{array}$ & $\begin{array}{l}-0.103 \\
(0.440)\end{array}$ & \\
\hline$I R L R_{t}$ & $\begin{array}{l}0.140^{* * *} \\
(0.049)\end{array}$ & $\begin{array}{l}0.139^{* * *} \\
(0.034)\end{array}$ & $\begin{array}{l}0.129^{* * *} \\
(0.049)\end{array}$ & $\begin{array}{l}0.135^{\star * *} \\
(0.041)\end{array}$ & $\begin{array}{l}0.317^{* * *} \\
(0.105)\end{array}$ & $\begin{array}{l}0.290^{\star * *} \\
(0.089)\end{array}$ \\
\hline Country Fixed Effects & No & Yes & No & Yes & Yes & Yes \\
\hline Period Fixed E & Yes & Yes & Yes & Yes & Yes & Yes \\
\hline Instruments & 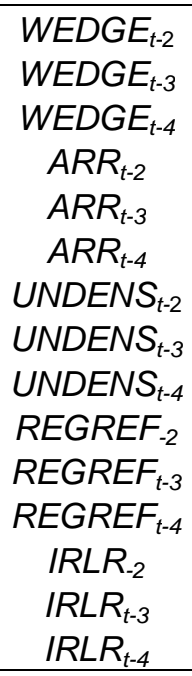 & 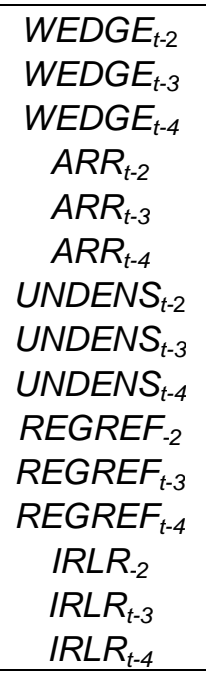 & $\begin{array}{c}\text { WEDGE }_{t-2} \\
\text { WEDGE }_{t-3} \\
\text { ARR } \\
\text { ARR }_{t-3} \\
\text { UNDENS }_{t-2} \\
\text { UNDENS } \\
\text { REGREF }_{t-3} \\
R E G R E F_{t-3} \\
\text { IRLR } \\
\text { IRLR } \\
\text { IRt-3 }\end{array}$ & $\begin{array}{c}\text { WEDGE }_{t-2} \\
\text { WEDGE }_{t-3} \\
\text { ARR }_{t-2} \\
\text { ARR }_{t-3} \\
\text { UNDENS }_{t-2} \\
\text { UNDENS }_{t-3} \\
\text { REGREF }_{t-2} \\
R E G R E F_{t-3} \\
\text { IRLR }_{t-2} \\
\text { IRLR } \\
\text { IR-3 }\end{array}$ & $\begin{array}{c}\Delta \text { WEDGE }_{t-1} \\
\Delta \text { WEDGE }_{t-2} \\
\Delta U N D E N S_{t-1} \\
\Delta U N D E N S_{t-2} \\
\Delta \mathrm{IRLR}_{t-1} \\
\Delta \mathrm{IRLR}_{t-2} \\
\Delta A R R_{t-1} \\
\Delta A R R_{t-2} \\
\Delta R E G R E F_{t-1} \\
\Delta R E G R E F_{t-2}\end{array}$ & $\begin{array}{c}\Delta W E D G E_{t-1} \\
\Delta W E D G E_{t-2} \\
\Delta U N D E N S_{t-1} \\
\Delta U N D E N S_{t-2} \\
\Delta \operatorname{IRLR}_{t-1} \\
\Delta \operatorname{IRLR}_{t-2}\end{array}$ \\
\hline OverID test $^{1}$ ( $p$-value $)$ & 0.730 & 0.405 & 0.130 & 0.494 & 0.991 & 0.906 \\
\hline Observations & 373 & 373 & 388 & 388 & 389 & 389 \\
\hline
\end{tabular}

Notes: $\quad$ The equations are respectively estimated in first differences (specification (1) to (4) where the dependent variable is $\Delta \hat{U}_{t}^{*}$ ) and in levels (specifications (5) and (6) where the dependent variable is $\hat{U}_{t}^{*}$ ). * ${ }^{* *}$ and ${ }^{* *}$ denote significance at the $10 \%, 5 \%$ and $1 \%$ levels, respectively. Germany, Sweden and Finland are withdrawn as there is a break in the level series.

1. Test for the over-identification of instruments under the null hypothesis that all instruments are uncorrelated with the errors from the structural model. If the null hypothesis cannot be rejected, all instruments fulfil the exogeneity condition. 
ECO/WKP(2008)57

Figure B1. NAIRUs and fitted NAIRUs

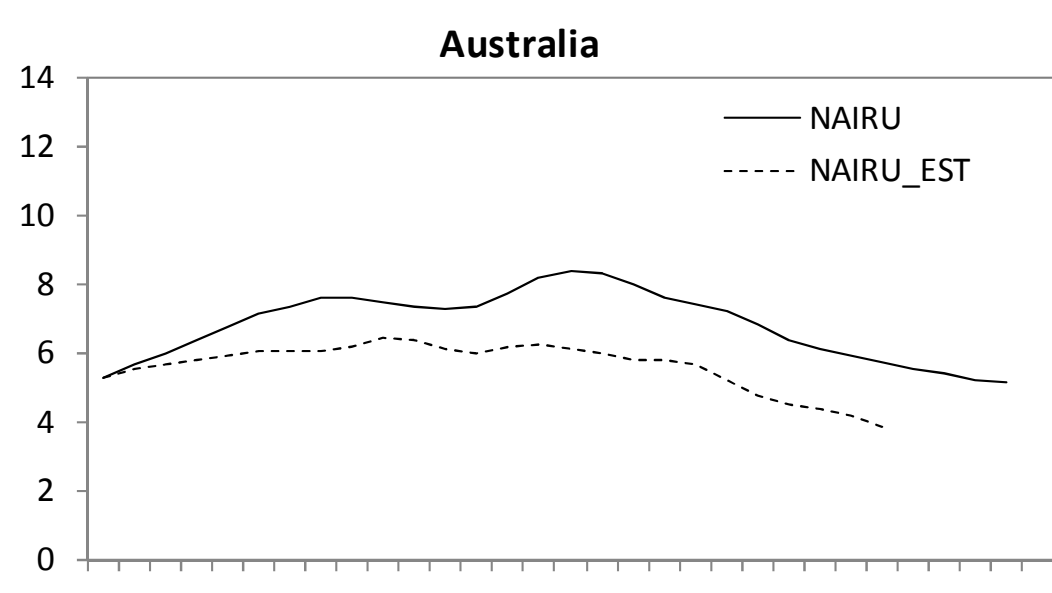

$\begin{array}{lllllllllllllll}78 & 80 & 82 & 84 & 86 & 88 & 90 & 92 & 94 & 96 & 98 & 00 & 02 & 04 & 06\end{array}$

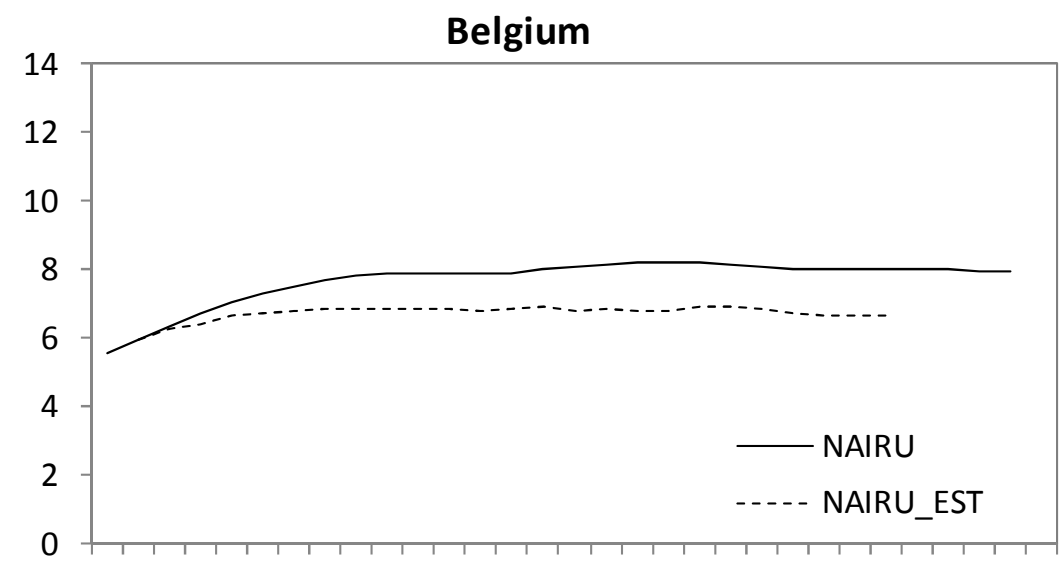

$\begin{array}{lllllllllllllll}78 & 80 & 82 & 84 & 86 & 88 & 90 & 92 & 94 & 96 & 98 & 00 & 02 & 04 & 06\end{array}$

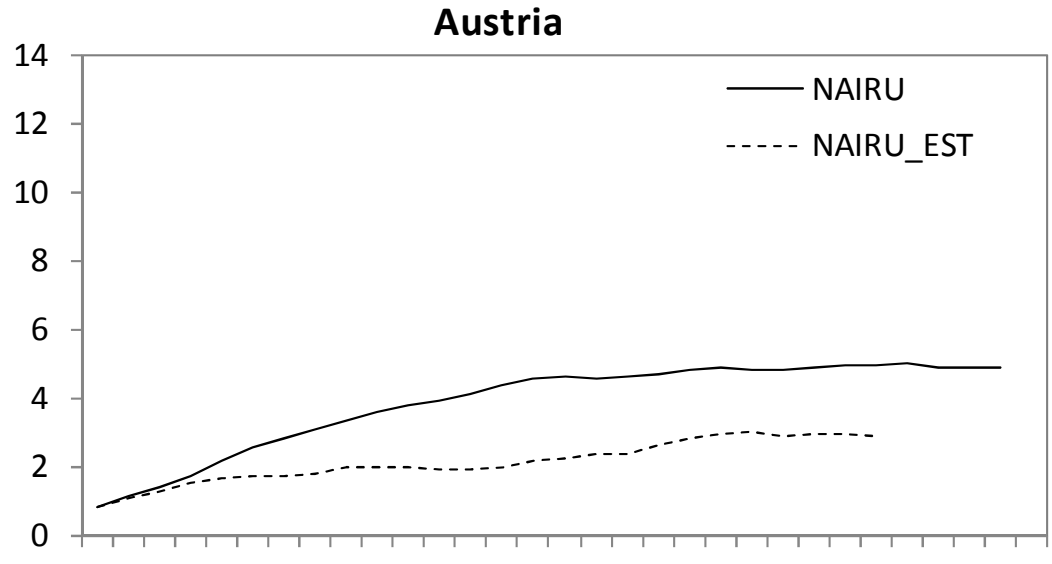

$\begin{array}{lllllllllllllll}78 & 80 & 82 & 84 & 86 & 88 & 90 & 92 & 94 & 96 & 98 & 00 & 02 & 04 & 06\end{array}$

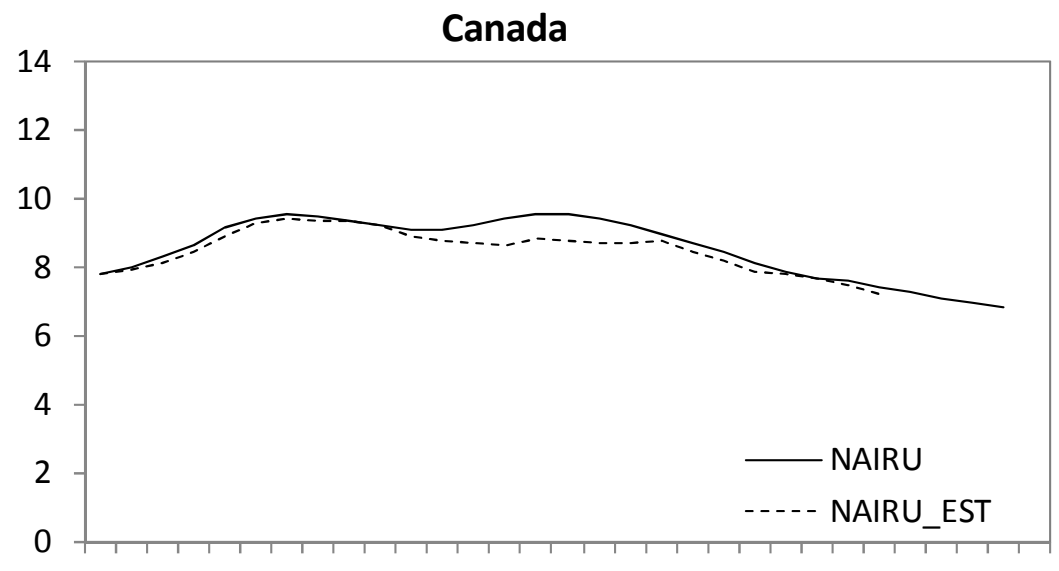

$\begin{array}{lllllllllllllll}78 & 80 & 82 & 84 & 86 & 88 & 90 & 92 & 94 & 96 & 98 & 00 & 02 & 04 & 06\end{array}$ 
Figure B1. NAIRUs and fitted NAIRUs (cont'd)

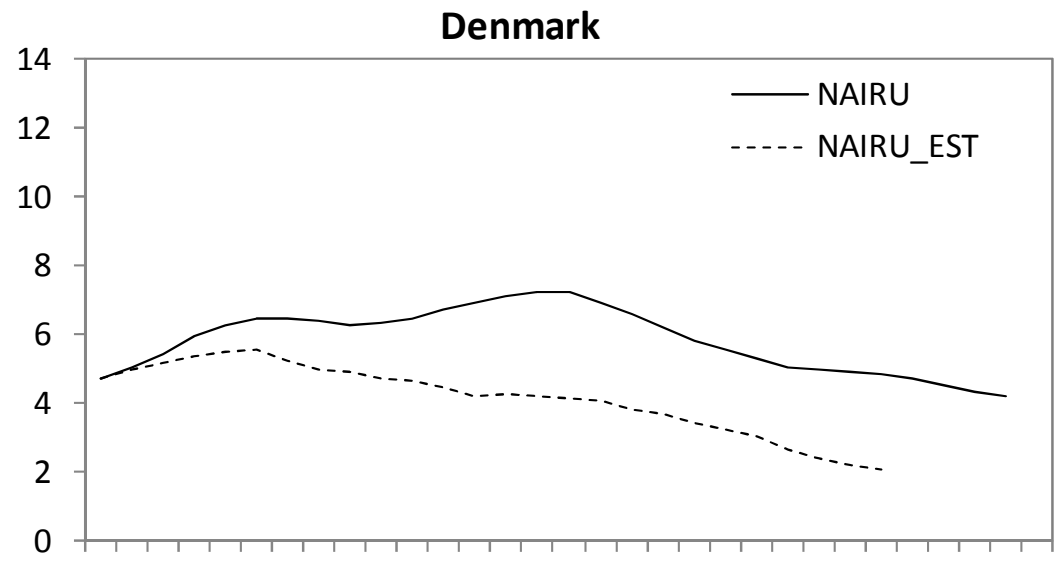

$\begin{array}{lllllllllllllll}78 & 80 & 82 & 84 & 86 & 88 & 90 & 92 & 94 & 96 & 98 & 00 & 02 & 04 & 06\end{array}$

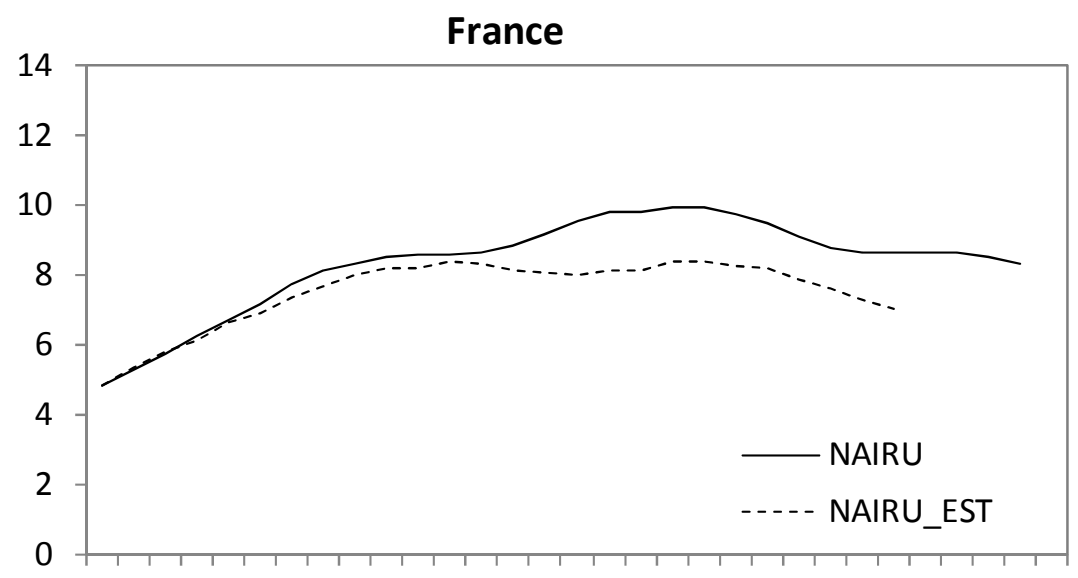

$\begin{array}{lllllllllllllll}78 & 80 & 82 & 84 & 86 & 88 & 90 & 92 & 94 & 96 & 98 & 00 & 02 & 04 & 06\end{array}$

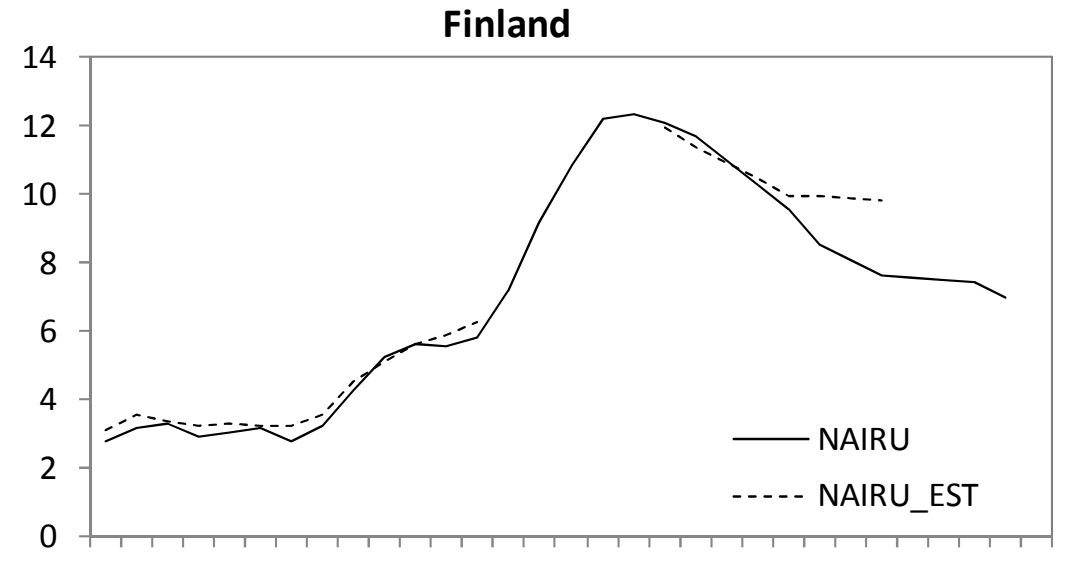

$\begin{array}{lllllllllllllll}78 & 80 & 82 & 84 & 86 & 88 & 90 & 92 & 94 & 96 & 98 & 00 & 02 & 04 & 06\end{array}$

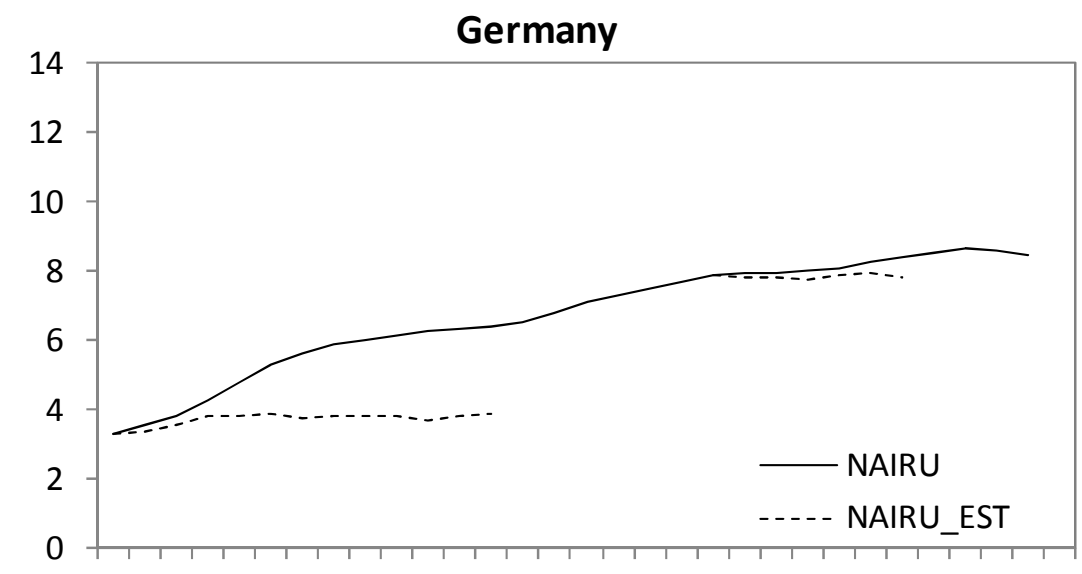

$\begin{array}{lllllllllllllll}78 & 80 & 82 & 84 & 86 & 88 & 90 & 92 & 94 & 96 & 98 & 00 & 02 & 04 & 06\end{array}$ 
Figure B1. NAIRUs and fitted NAIRUs (cont'd)

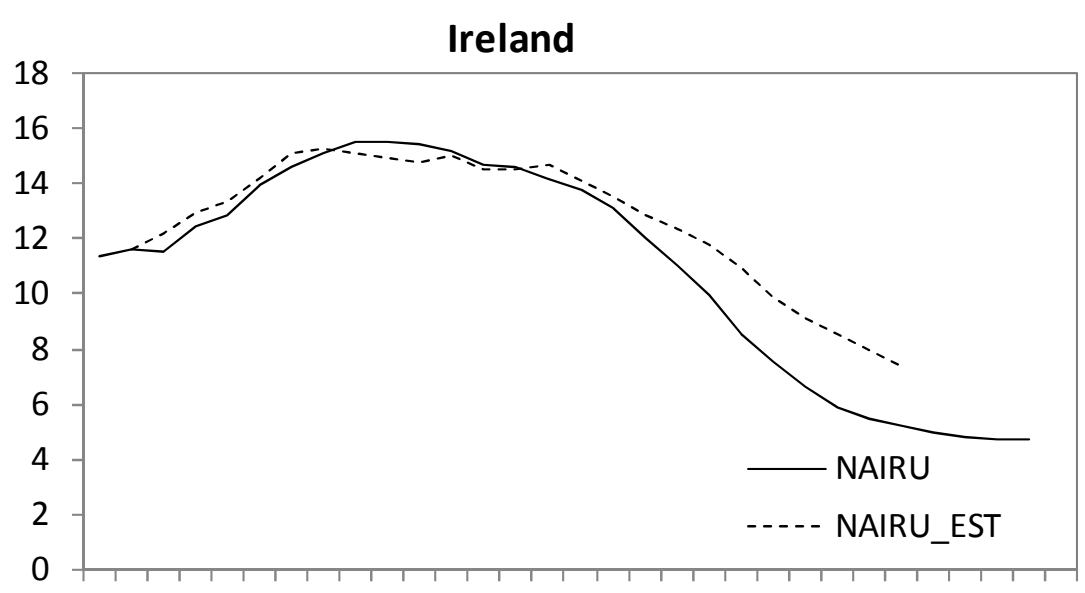

$\begin{array}{lllllllllllllll}78 & 80 & 82 & 84 & 86 & 88 & 90 & 92 & 94 & 96 & 98 & 00 & 02 & 04 & 06\end{array}$

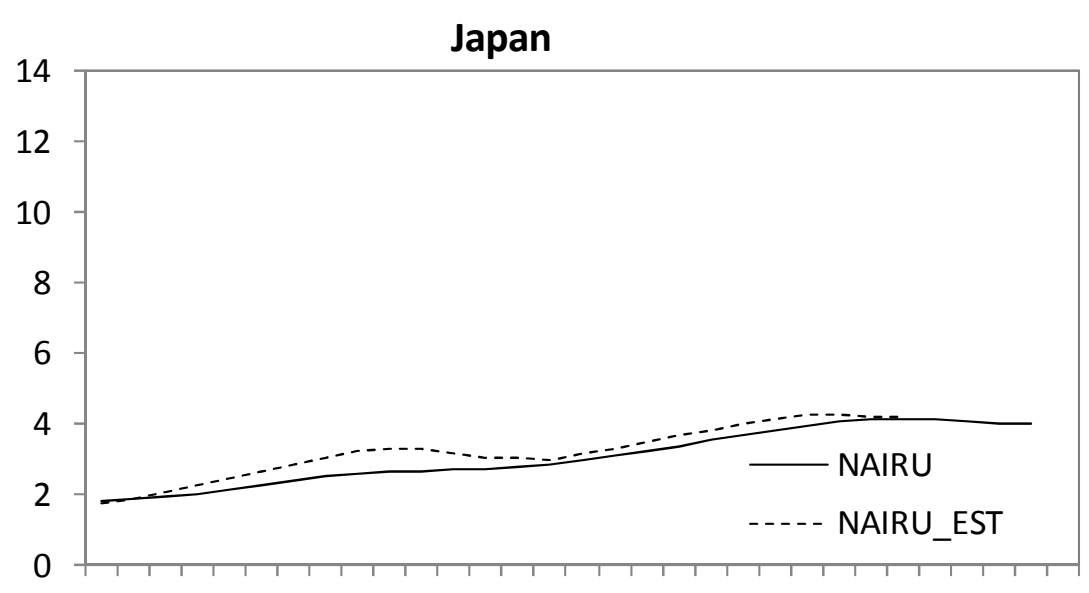

$\begin{array}{lllllllllllllll}78 & 80 & 82 & 84 & 86 & 88 & 90 & 92 & 94 & 96 & 98 & 00 & 02 & 04 & 06\end{array}$

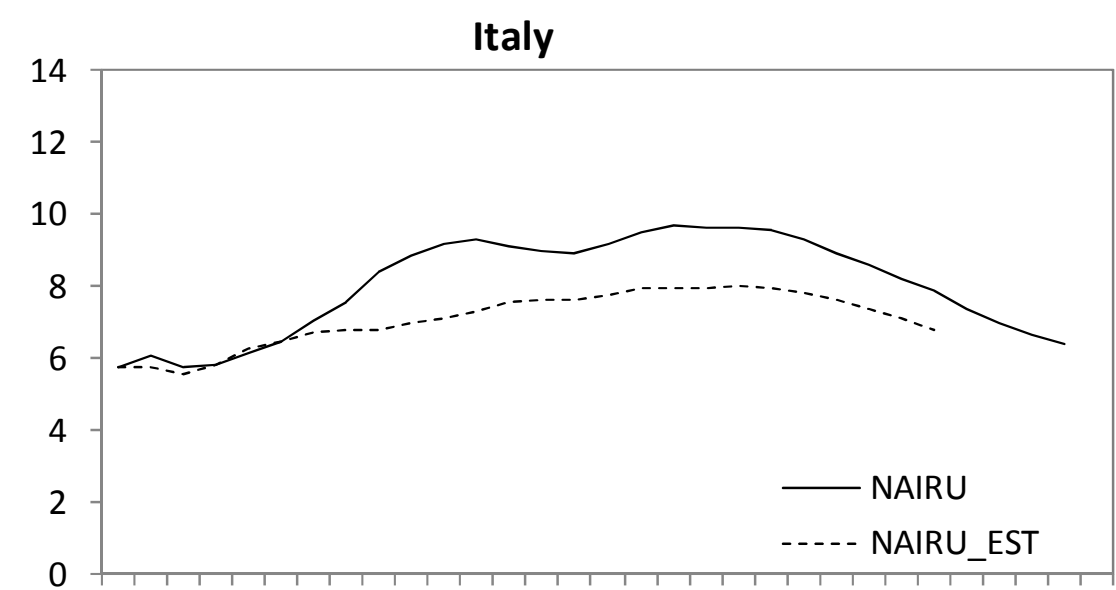

$\begin{array}{lllllllllllllll}78 & 80 & 82 & 84 & 86 & 88 & 90 & 92 & 94 & 96 & 98 & 00 & 02 & 04 & 06\end{array}$

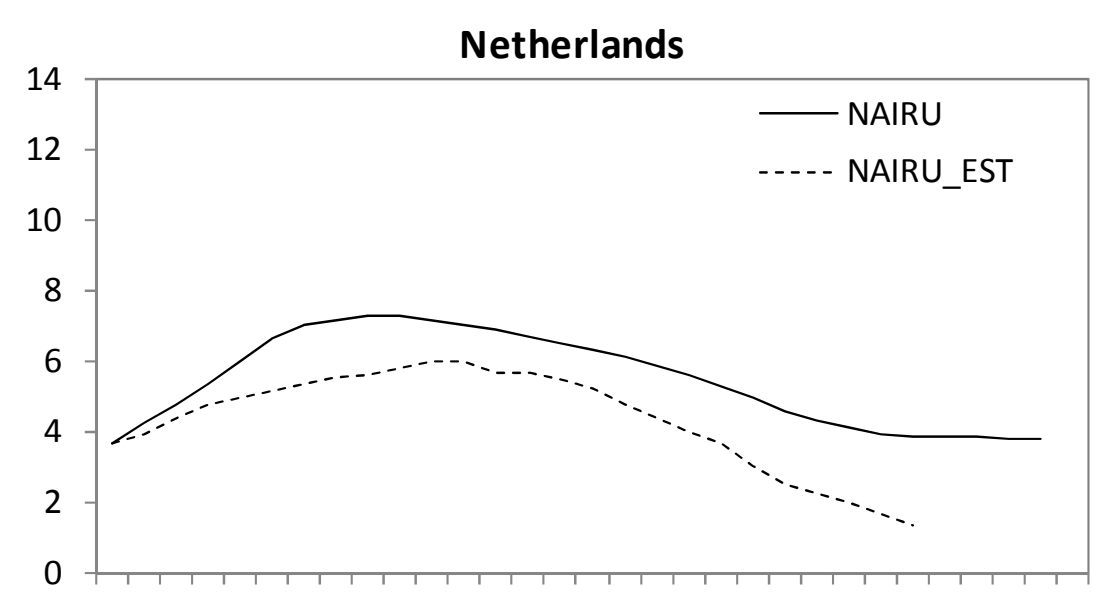

$\begin{array}{lllllllllllllll}78 & 80 & 82 & 84 & 86 & 88 & 90 & 92 & 94 & 96 & 98 & 00 & 02 & 04 & 06\end{array}$ 
Figure B1. NAIRUs and fitted NAIRUs (cont'd)

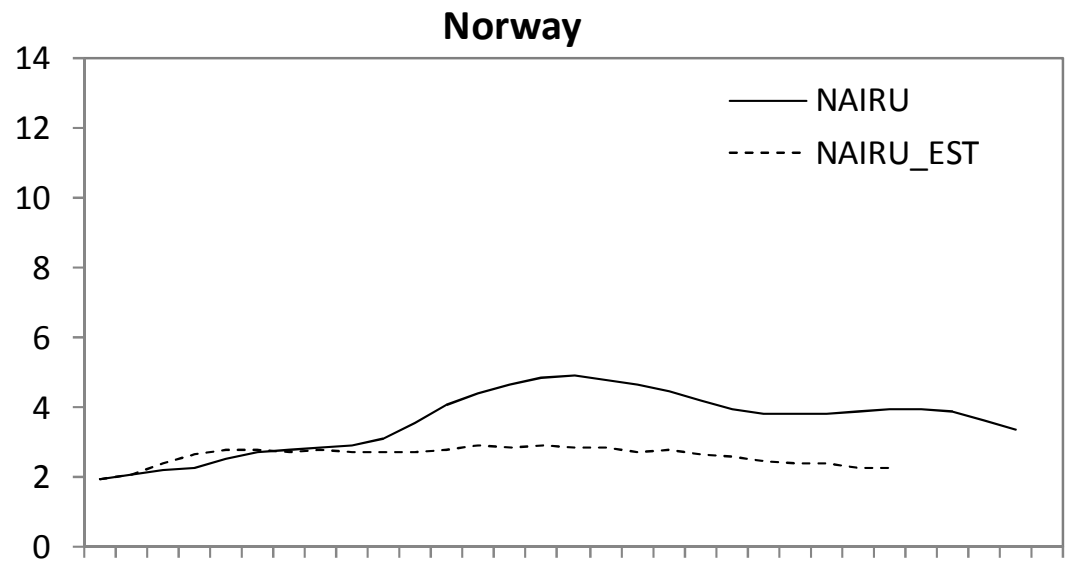

$\begin{array}{lllllllllllllll}78 & 80 & 82 & 84 & 86 & 88 & 90 & 92 & 94 & 96 & 98 & 00 & 02 & 04 & 06\end{array}$

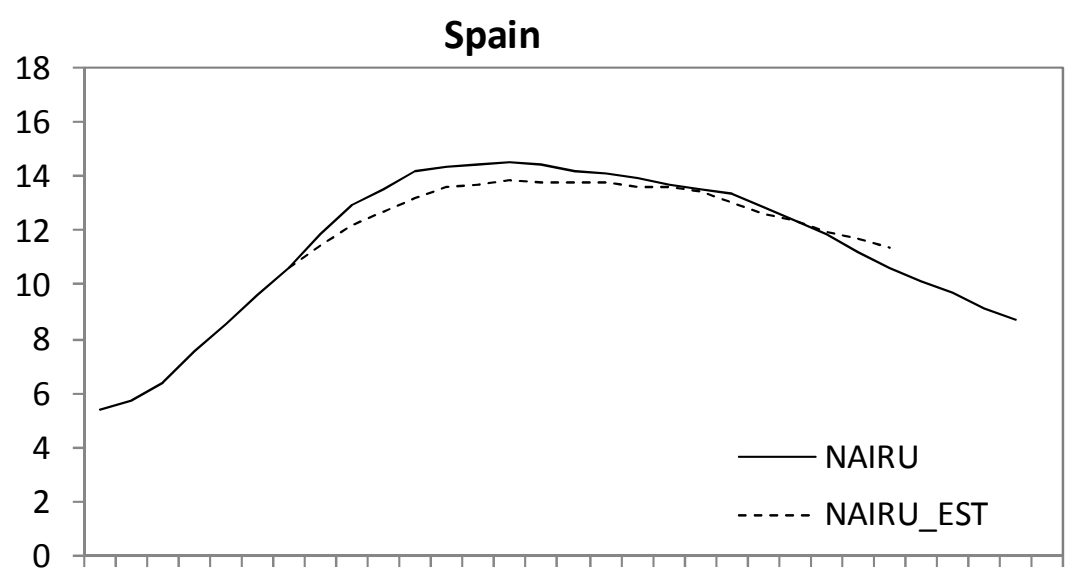

$\begin{array}{lllllllllllllll}78 & 80 & 82 & 84 & 86 & 88 & 90 & 92 & 94 & 96 & 98 & 00 & 02 & 04 & 06\end{array}$

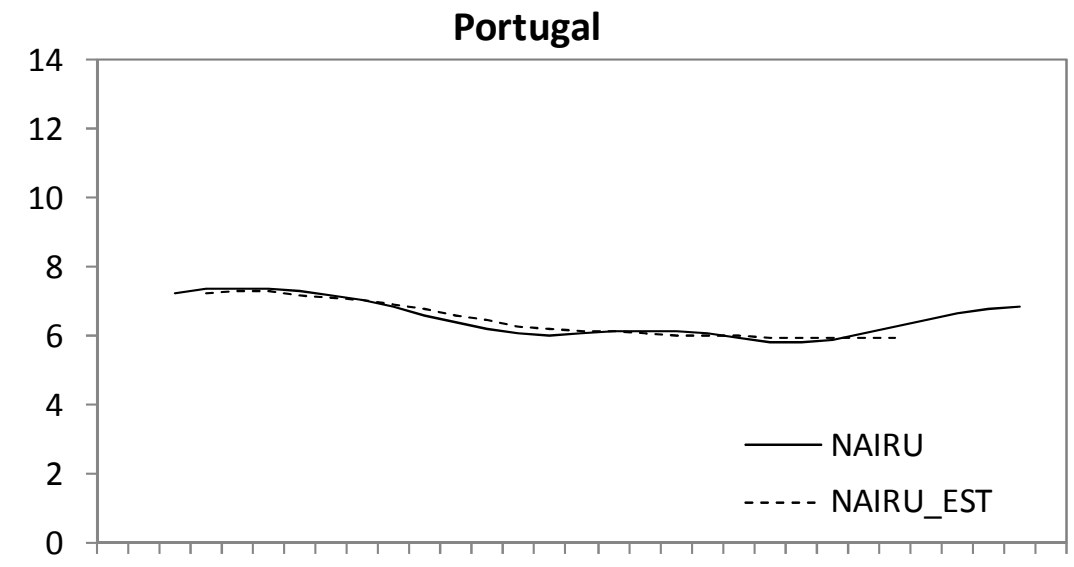

$\begin{array}{lllllllllllllll}78 & 80 & 82 & 84 & 86 & 88 & 90 & 92 & 94 & 96 & 98 & 00 & 02 & 04 & 06\end{array}$

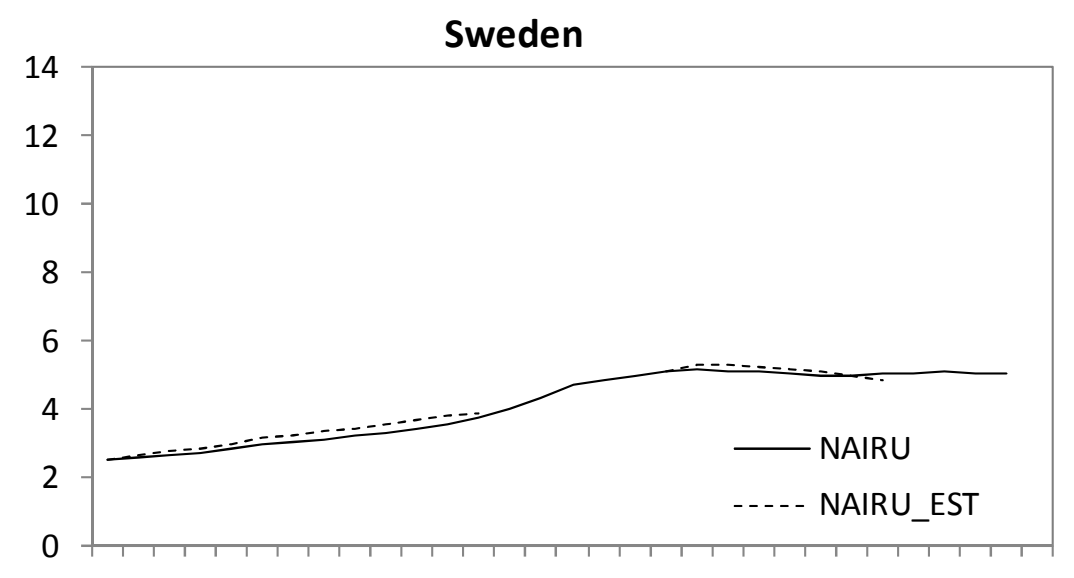

$\begin{array}{lllllllllllllll}78 & 80 & 82 & 84 & 86 & 88 & 90 & 92 & 94 & 96 & 98 & 00 & 02 & 04 & 06\end{array}$ 
ECO/WKP(2008)57

Figure B1. NAIRUs and fitted NAIRUs (cont'd)

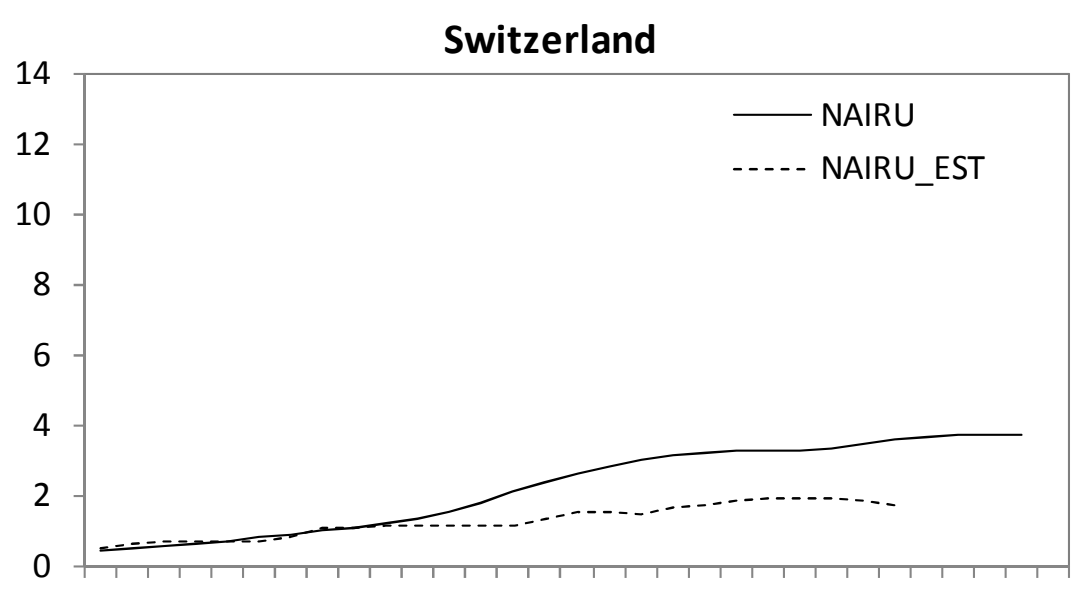

$\begin{array}{lllllllllllllll}78 & 80 & 82 & 84 & 86 & 88 & 90 & 92 & 94 & 96 & 98 & 00 & 02 & 04 & 06\end{array}$

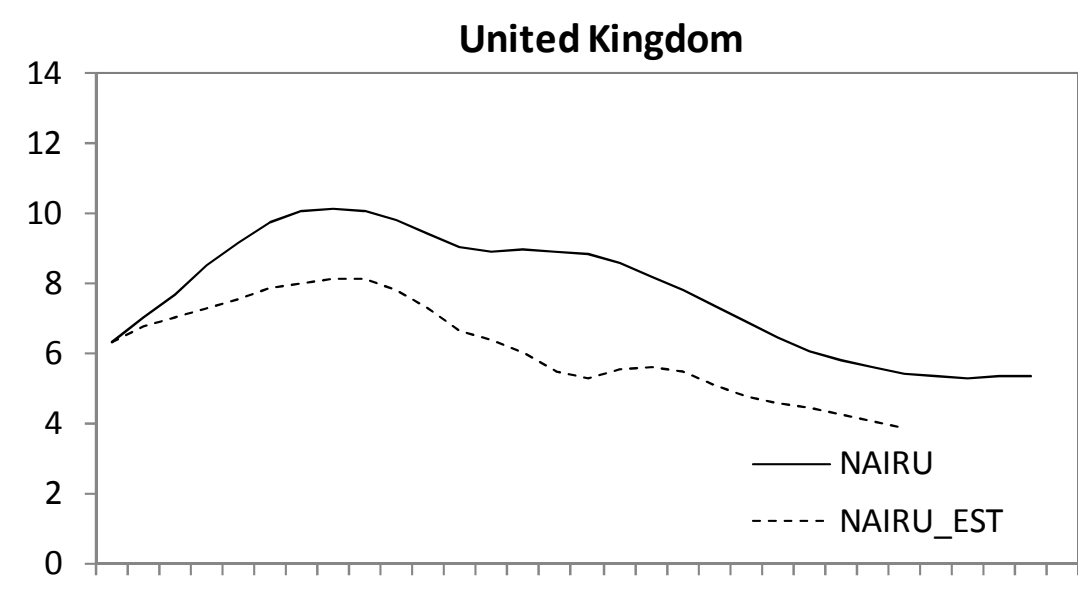

$\begin{array}{lllllllllllllll}78 & 80 & 82 & 84 & 86 & 88 & 90 & 92 & 94 & 96 & 98 & 00 & 02 & 04 & 06\end{array}$

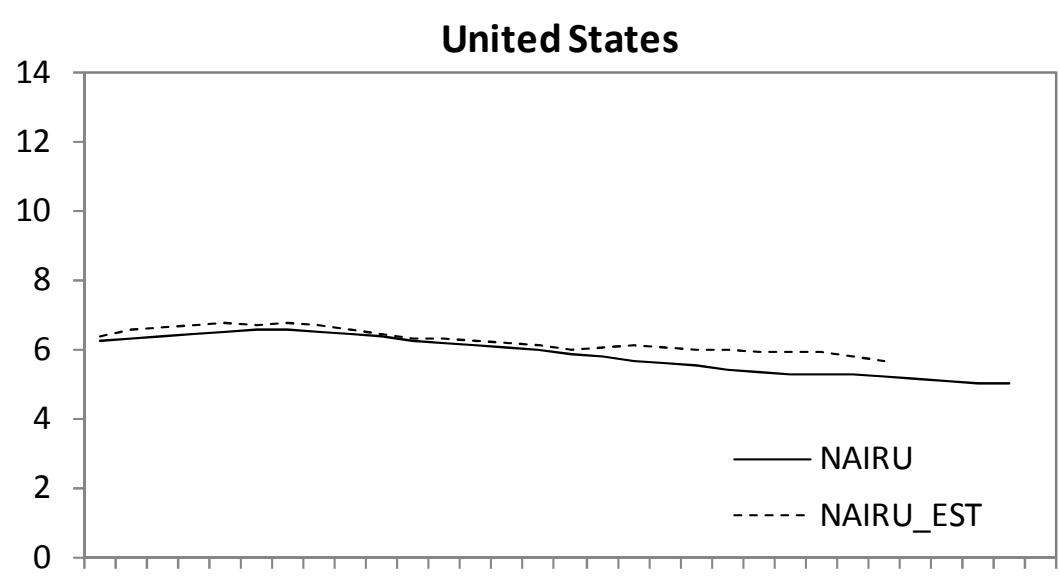

$\begin{array}{lllllllllllllll}78 & 80 & 82 & 84 & 86 & 88 & 90 & 92 & 94 & 96 & 98 & 00 & 02 & 04 & 06\end{array}$

Note: The fitted values are based on the system estimates reported in Table 3. 


\section{ANNEX C. DATA SOURCES AND DEFINITIONS}

\section{Average unemployment benefit replacement rate $(A R R)$}

The average unemployment benefit replacement rate is calculated across two income situations (100\% and $67 \%$ of APW earnings), three family situations (single, with dependent spouse, with spouse in work) and three unemployment durations $\left(1^{\text {st }}\right.$ year, $2^{\text {nd }}$ and $3^{\text {rd }}$ year, $4^{\text {th }}$ and $5^{\text {th }}$ year $)$. The data are taken from the OECD Benefits and Wages database.

\section{Tax wedge (WEDGE)}

The tax wedge is defined as the combined labour and consumption tax rate derived from the National Accounts. The data set is an updated version of the dataset constructed by Carey, D. and J. Rabesona (2002): "Tax ratios on labour and capital income and on consumption", OECD Economic Studies No. 35 using on data from the OECD Revenue Statistics and the OECD National Accounts databases.

\section{Product market regulations (PMR)}

The PMR indicator is the OECD summary indicator on regulatory impediments to product market competition in seven non-manufacturing industries (gas, electricity, post, telecoms, passenger air transport, railways and road freight). The data are taken from Conway, P., D. De Rosa, G. Nicoletti and F. Steiner (2006): "Regulation, competition, and productivity convergence", OECD Economics Department Working Paper No. 509.

\section{Union density $(U N D)$}

Union density is defined as the share of workers affiliated to a trade union (in percent). The data are taken from Bassanini, A. and R. Duval (2006): "Employment patterns in OECD countries: Reassessing the role of policies and institutions", OECD Economics Department Working Paper No. 486. The authors use data from the OECD Employment Outlook and national sources with data for missing years being interpolated/extrapolated.

\section{Long-term real interest rate (IRLR)}

Real long-term interest rates are calculating by deflating nominal long-term real interest rates on government bonds by the GDP deflator. All data are obtained from the OECD Economic Outlook database.

\section{Minimum wage $(M I N W)$}

The variable is defined as the ratio of the statutory minimum wage to the median wage (in per cent). Data on both variables are obtained from the OECD Minimum Wages database. 


\section{WORKING PAPERS}

The full series of Economics Department Working Papers can be consulted at www.oecd.org/eco/Working_Papers/

648. Short-term distributional effects of structural reforms: selected simulations in a DGSE framework (October 2008) Annabelle Mourougane and Lukas Vogel

647. Speed of adjustment to selected labour market and tax reforms (October 2008) Annabelle Mourougane, Lukas Vogel

646. The challenge of monetary policy in Turkey

(October 2008) Olcay Çulha, Ali Çulha and Rauf Gönenç

645. Improving cost-effectiveness in the health-care sector in Iceland (October 2008) Hannes Suppanz

644. Understanding Russian regions' economic performance during periods of decline and growth - an Extreme Bound Analysis approach

(October 2008) Rüdiger Ahrend

643. Do tax structures affect aggregate economic growth? Empirical evidence from a panel of OECD countries

(October 2008) Jens Arnold

642. Accounting for one-off operations when assessing underlying fiscal positions

(October 2008) Isabelle Joumard, Makoto Minegishi, Christophe André, Chantal Nicq and Robert Price

641. Do corporate taxes reduce productivity and investment at the firm level? Cross-country evidence from the Amadeus dataset

(October 2008) Cyrille Schwellnus and Jens Arnold

640. The challenge of rapidly improving transport infrastructure in Poland

(September 2008) Rafal Kierzenkowski

639. Bridging the housing gap in Poland

(September 2008), Rafal Kierzenkowski

638. Improving the business and investment climate in Indonesia

(September 2008), Diego Moccero

637. Growth performance and policy challenges

(September 2008), Luiz de Mello

636. A taxonomy of instruments to reduce greenhouse gas emissions and their interactions (September 2008), Romain Duval

635. Quantifying the effect of financial conditions on US activity (September 2008) Stéphanie Guichard and David Turner 
634. Have long-term financial trends changed the transmission of monetary policy (September 2008), Stéphanie Guichard and David Turner

633. Raising education achievement and breaking the cycle of inequality in the United Kingdom (August 2008) Anne-Marie Brook

632. The euro changeover in the Slovak Republic: implications for inflation and interest rates (August 2008) Felix Hüfner and Isabell Koske

631. Tax reform for efficiency and fairness in Canada (August 2008) Alexandra Bibbee

630. Reforming the Polish Tax System to Improve its Efficiency (August 2008) Alain de Serres

629. Modernising Canada's Agriculture Policies (August 2008) Peter Jarrett and Shuji Kobayakawa

628. Recent trends and structural breaks in US and EU15 labour productivity growth (August 2008) Laure Turner and Hervé Boulhol

627. Health Status Determinants: Lifestyle, Enviroment, Health Care Resources and Efficiency (August 2008) Isabelle Joumard, Christophe André, Chantal Nicq and Olivier Chatal

626. Market Mechanisms in Public Service Provision (August 2008) Hansjörg Blöchliger

625. Improving human capital formation in India (July 2008) Sean M. Dougherty and Richard Herd

624. Labour regulation and employment dynamics at the state level in India (July 2008) Sean M. Dougherty

623. India's growth pattern and obstacles to higher growth (July 2008) Sean M. Dougherty, Richard. Herd, Thomas. Chalaux and Abdul. Erumban

622. Reaping the benefits of stronger competition in network industries in Germany (July 2008) Nicola Brandt

621. The Usefulness of Output Gaps for Policy Analysis (July 2008) Isabell Koske and Nigel Pain

620. Taxation and Economic Growth (July 2008) Assa Johansson, Christopher Heady, Jens Arnold, Bert Brys and Laura Vartia

619. Coping with labour shortages: How to bring outsiders back to the labour market (July 2008) Ekkehard Ernst

618. Achieving sustainability of the energy sector in Canada (June 2008) Annabelle Mourougane 